\title{
Psychobiology of food intake in humans
}

Citation for published version (APA):

Westerterp-Plantenga, M. S. (1991). Psychobiology of food intake in humans. [Doctoral Thesis, Maastricht University]. Rijksuniversiteit Limburg. https://doi.org/10.26481/dis.19911121mw

Document status and date:

Published: 01/01/1991

DOI:

10.26481/dis.19911121mw

Document Version:

Publisher's PDF, also known as Version of record

\section{Please check the document version of this publication:}

- A submitted manuscript is the version of the article upon submission and before peer-review. There can be important differences between the submitted version and the official published version of record.

People interested in the research are advised to contact the author for the final version of the publication, or visit the DOI to the publisher's website.

- The final author version and the galley proof are versions of the publication after peer review.

- The final published version features the final layout of the paper including the volume, issue and page numbers.

Link to publication

\footnotetext{
General rights rights.

- You may freely distribute the URL identifying the publication in the public portal. please follow below link for the End User Agreement:

www.umlib.nl/taverne-license

Take down policy

If you believe that this document breaches copyright please contact us at:

repository@maastrichtuniversity.nl

providing details and we will investigate your claim.
}

Copyright and moral rights for the publications made accessible in the public portal are retained by the authors and/or other copyright owners and it is a condition of accessing publications that users recognise and abide by the legal requirements associated with these

- Users may download and print one copy of any publication from the public portal for the purpose of private study or research.

- You may not further distribute the material or use it for any profit-making activity or commercial gain

If the publication is distributed under the terms of Article $25 \mathrm{fa}$ of the Dutch Copyright Act, indicated by the "Taverne" license above, 


\section{PSYCHOBIOLOGY OF FOOD \\ INTAKE IN HUMANS}




\section{PSYCHOBIOLOGY OF FOOD \\ INTAKE IN HUMANS}

\section{PROEFSCHRIFT}

ter verkrijging van de graad van doctor

aan de Rijksuniversiteit Limburg, te Maastricht, op gezag van de Rector Magnificus, Prof. mr. M.J. Cohen, volgens het besluit van het College van Dekanen, in het openbaar te verdedigen op donderdag, 21 november 1991 om 14.00 uur

door

Margriet Sjoukje Westerterp-Plantenga

geboren te Groningen 
Promotor:

Co-promotor:

Beoordelingscommisie: Prof. dr. ir. W. H. M. Saris

Prof. dr. J. E. Blundell

Prof. dr. M. A. van den Hout

Dr. ir. J. A. Weststrate

Dr. M. von Meyenfeldt

CIP-Gegevens, Koninklijke Bibliotheek, Den Haag

Westerterp-Plantenga, Margriet Sjoukje

Psychobiology of Food Intake in Humans/

Margriet Sjoukje Westerterp-Plantenga

Maastricht: Datawyse

Proefschrift Maastricht. Met lit. opg.-Met samenvatting in het Nederlands

ISBN 9035809262

Trefw.: eetgedrag (geremd, ongeremd) / overgewicht /

dieetgeïnduceerde thermogenese

Vormgeving:

Mark Liedekerken

Evelin Karsten

Omslag:

Harry Vankan

Illustratie verantwoording:

Rijksmuseum, Amsterdam,

Floris van Dijck:

Stilleven met kazen

Figuren:

Audio Visuele Diensh,

RL Maastricht

Druk:

Datawyse Maastricht /

Krips Repro Meppel

Aan het onderzoek werd een financiële bijdrage verleend door de Nederlandse Hart Stichting, subsidie nr. 83055.

De uitgave van dit proefschrift werd mogelijk gemaakt door een subsidie van de Open universiteit.

Financial support by the Netherlands Heart Foundation and by the Dr.Jr.J.H.J, van der Laar Foundation for the publication of this thesis is gratefully acknowledged. 



\section{Contents}

Chapter 1 Theories on Eating Behaviour 9

1.1 Introduction 9

1.2 Eating behaviour in general 10

1.3 Theories for the explanation of eating behaviour 11

1.4 References.

Chapter 2 Eating Behaviour during a Meal Scope of the study 19

2.1 Subject characteristics and meal characteristics 19

2.2 Physiological aspects of eating behaviour 20

2.3 Psychological aspects of eating behaviour 22

2.4 Psychometric questionnaires 22

2.5 Scope of the study 24

2.6 References 26

$\begin{array}{lll}\text { Chapter } 3 & \text { Techniques } & 29\end{array}$

3.1 Subject characteristics 29

3.2 Actual meal parameters 29

3.3 Physiological effects of food intake 30

3.4 References 31

Chapter 4 The Shape of the Cumulative Food Intake Curve in Humans, during Basic and Manipulated Meals 33

4.1 Abstract 33

4.2 Introduction 34

4.3 Method 35

4.4 Description of the cumulative food intake curve in basic meals and data analysis $\quad 37$

4.5 Results 38

4.6 Manipulations 45

4.7 Variability of the cumulative intake curve 49

4.8 Discussion 49

4.9 References 51

Chapter 5 Restrained Eating, Obesity, and Cumulative

Food Intake Curves during Four-Course Meals 55

5.1 Abstract 55

5.2 Introduction 55

5.3 Method 57

5.4 Results $\quad 59$

5.5 Discussion 64

5.6 References 65

Chapter 6 Deceleration in Cumulative Food Intake Curves, Changes in Body-Temperature and Diet-Induced Thermogenesis

6.1 Abstract 69

6.2 Introduction 70

6.3 Method 71 


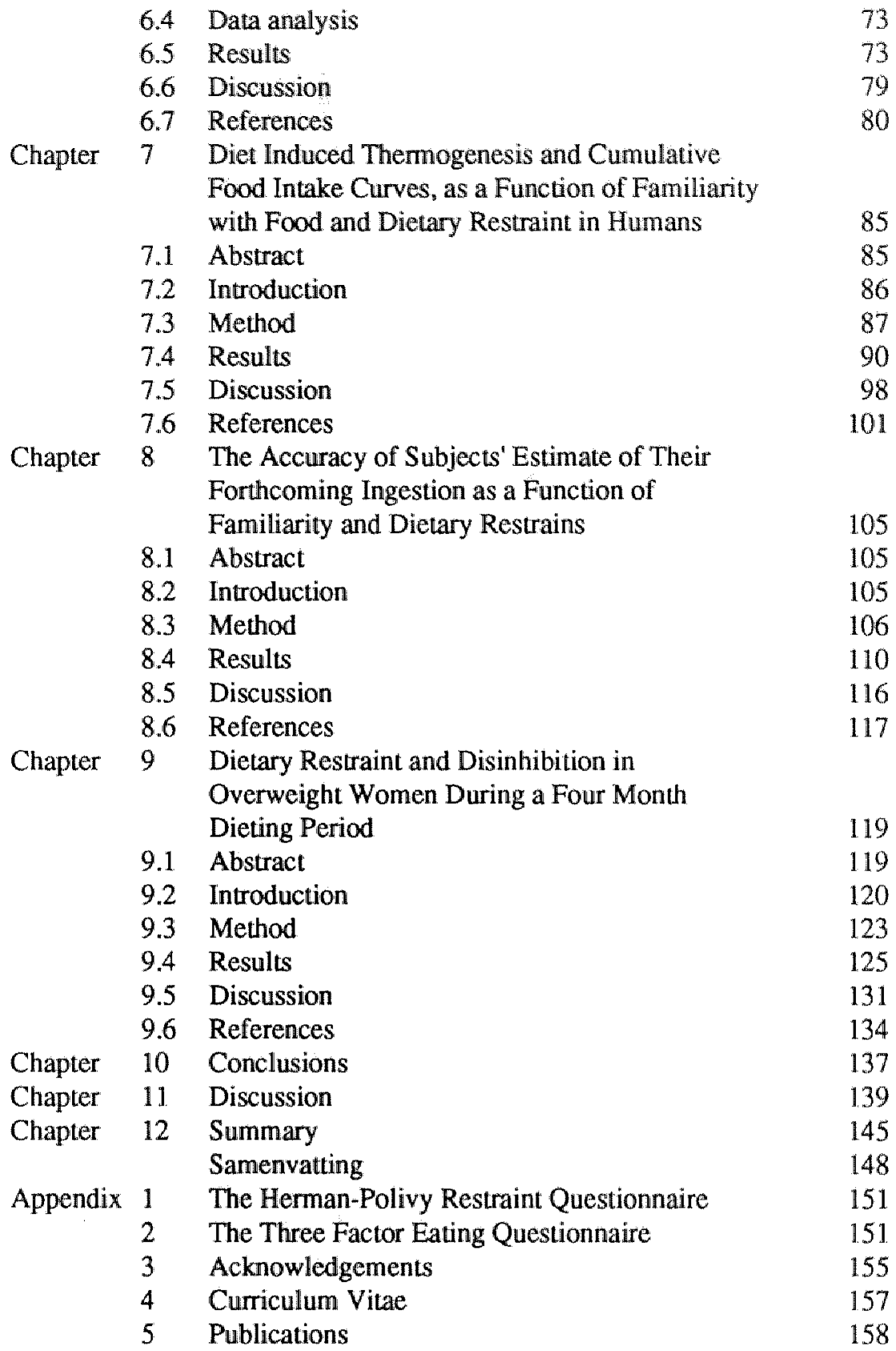




\section{Theories on Eating Behaviour}

\subsection{Introduction}

Everybody experiences the effects of feeding on physical and mental well-being and can think of explanations for these effects. For some time, this aspect of life has been studied scientifically in the field of the psychobiology of food intake. Psychobiology of food intake came into focus in the fifties of this century, when the research concerning the biology of the regulation of food intake expanded enormously. The main question was, and still is, what biological factors regulate food intake and food intake behaviour, and how these factors are affected by the food itself. When food intake behaviour is studied in humans, it is unavoidable that at the same time the influence of psychological factors on biological effects of food intake is studied.

Eating behaviour in animals is roughly based on the physiological signals hunger and satiety. Successive bouts of food intake contribute to the maintenance of body weight, an important homeostasis in life. The other contributor to the maintenance of body weight is the ecophysiologically determined factor energy expenditure; both factors ideally maintain the energy balance. Animals metabolize continuously and feed either continuously, or discontinuously. When feeding discontinuously, like for instance humans and rats do, adjustment of eating behaviour to metabolic needs, by anticipation or correction is required. This involves choices of amounts of food and choices of kinds of food at certain times. In humans many of these decisions depend on habits, often established by learning processes through which food intake can be tuned towards need. Eating behaviour in humans may be dominated by cultural, e.g. social, political, economic and ethnic factors, that overrule biological dispositions, for instance in political hunger strikers, but in certain stable subpopulations it may be possible to detect the effects of physiological factors. Examples like lactase deficiency, phenylthiocarbamide tasting and carbohydrate metabolism in Eskimos, which were mentioned by Rozin (1976), prove that biological variables can make a clear contribution to regional feeding habits. In general it is the interplay between biological variables and the mental processes that together determine human feeding practices (Blundell, 1983).

Eating behaviour, like most types of behaviour, is of course a phenotypical phenomenon, based on a genetic component, and developed 
under influences of different environmental factors. The genetic component concerns mainly the magnitude of body weight that is defended and maintained, through maintenance of an energy balance at a certain level. For instance, from twin- and adoption studies by Stunkard (1990) it was calculated that the heritability of body weight, corrected for length, could be as high as 0.7 , which leaves a small phenotypical margin. Sørensen et al. (1991) conclude from studies on the expression of genetic influence in childhood that the genetic influence on body mass index is already fully expressed by school age, and that the family environment in childhood has a weak influence. From the results of an adoption study of body mass index they conclude that the familial occurrence of obesity is incompatible with dominant, but possibly compatible with recessive transmission of a major gene with a frequency between 0.12 and 0.18 . James et al. (1990) observed that the more constant data of energy expenditure give a better idea of the energy balance than the data of fluctuating energy intake. So the maintenance of the energy balance at a certain level may be established mainly through energy output, notwithstanding fluctuating food intake due to for instance food preferences. With respect to the fluctuating energy intake, Rozin et al. (1987) argued that in omnivorous animals, such as humans, genetic predispositions with respect to food preferences are minimal. The modest sibling resemblances they find on a number of measurements are primarily attributable to a shared environment.

It is a fact that it is rather maintenance of energy balance and not food intake, that has a certain genetic predisposition.

Resuming, eating behaviour in humans seems to be controlled by genetic constitution, internal biological signals, the availability - with respect to sufficient amount and quality - and ingestion of certain kinds of food, and by socio-psychological factors, like the situation in which the meals are consumed, and the taste of the food.

\subsection{Eating behaviour in general}

Eating behaviour includes the total amount of food ingested during for instance a day, the periodicity of eating moments throughout the day, the qualitative and quantitative selection, composition and consumption per eating moment, the eating time, the eating rate, and the possible changes in eating rate.

When eating behaviour is studied in humans, some phenomena among others appear: eating behaviour is periodical and long lasting, with variations between days, but rather constant in the long term. Habits play an important role. In animals, eating behaviour is susceptible to changes in energy density of the food; some investigators have found similar, but not generally confirmed results for humans as well. Food intake appeared to increase to a certain extent, with increased palatability of the food, but also with increased physical activity of the subject. Variation in 
palatability enhances increase in food intake. Humans seem to find it extremely difficult to force themselves to eat consciously more or less than they would usually, over a longer time.

(Birch et al., 1986; Foltin et al., 1988; Jenkins et al., 1989; Lissner et al., 1987; Weststrate; 1991).

\subsection{Theories for the explanation of eating behaviour}

The mentioned phenomena concern eating behaviour throughout the day, as well as eating behaviour throughout meals. This particular study is focused on eating behaviour during a meal, therefore we concentrate on theories that try to explain the mentioned phenomena as far as they occur with respect to meals. This implies that we did not reflect on meal to meal intervals, or the number of meals throughout a day. When we focus on the start and finish of a meal, we come across 1) homeostatic as well as 2) non-homeostatic feed-back theories.

ad 1) Homeostatic theories assume that a certain variable is measured in the body, and that this proces results in generating signals that control eating behaviour. Research is focused on translating measurement of the variables and the control signals, into a biochemical and physiological context. Some homeostatic theories e.g. the lipostatic, glucostatic and aminostatic theories suggest that specific chemicals or nutrients in the body are regulated (Kennedy, 1953; Mayer, 1955; Mellinkoff, 1956); others suggest regulation of energy, or some function of it (Nicolaiidis, 1974), but most theories seem to present a too limited account of the control of food intake (Morley, 1983; Smith, 1983; Castonguay, 1983; van Itallie, 1983). Brobeck (1960) integrated the lipostatic, glucostatic and aminostatic theories into the thermostatic theory which considers metabolic heat production as the control of food intake. The energostatic theory (Booth, 1972) states that the energy produced by the metabolism of absorbed nutrients is monitored to regulate food intake, and can thus be considered as a further refinement of the thermostatic theory. Nicolardis postulated the ischymetric hypothesis which states that the critical message of depletion comes from the rate of utilization, at the cellulair level, of all of the energy - producing substrates (Nicolaildis, 1974; Nicolaidis and Even, 1990). The central problem in validating these theories is the location of detectors and effectors for the homeostatic response. It is now generally accepted that a diffuse complex of excitatory and inhibitory systems located in the hypothallamus contribute to the control of hunger and satiety (Steffens et al., 1990). However, it seems that various other factors are involved in the physiological control of food intake. The modern theories of food intake regulation imply a heterogeneous feed back system, in which various signals derived from the gastro-intestinal tract, liver, the circulating energy, i.e. nutrient pool, depot fat, or metabolizing cells, transmit information to a central system, 
ie. the brain, which is responding to and at the same time integrating information from the various peripheral components (Van ltallie 1983).

The question may arise, whether food intake in humans is still under physiological control, or whether it is largely determined by exogenous factors. These exogenous, mon-physiological factors may differ in origin,

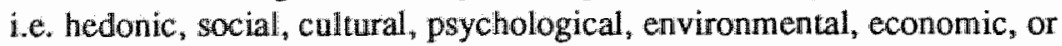
pharmacological. In man control of food intake is complex, and the primitive hypothalamic reflexes are buried under layers of conditioning, cognitive and social factors, that they are barely discernable (Garrow, 1978).

ad 2) Non-homeostatic theories explaining human eating behaviour emphasize mainly non-physiological factors. Castonguay et al. (1983) assume that eating behaviour does not necessarily compensate a deficiency in favour of a certain homeostasis, but originates from the motivation of the organism to find pleasure and satisfaction. Eating behaviour, regardless of how it started, is continued by certain sensory characteristics of the food that stimulate pleasure areas in the brain. These areas only can be stimulated when the organism is hungry. They communicate with other parts of the brain, including the nerve cells that are influenced by the hormonal and nutritional status of the organism, thus the non-homeostatic theories have homeostatic features as well. Nonhomeostatic theories give the possibility to include appetite as an explanation, as well as the hedonic value of food. The consumption of agreeable food stimulates the organism to further consumption by means of positive feed-back, until other inhibiting signals dominate, or pleasure areas are not stimulated anymore. Homeostatic and non-homeostatic theories can be summarized in the boundary model of Herman and Polivy, who postulate that hunger and satiety are controlled by homeostasis, whereas the area in between is controlled by nonhomeostasis. Biological pressures maintain consumption within a certain range between the boundaries of hunger and satiety, which they call the range of "biological indifference". Within this range psychological factors would have their greatest impact on the regulation of food intake.

It can be argued that a connection could be made between homeostatic and non-homeostatic theories with regard to control of food selection and mutrient intake. Major characteristics of omnivore feeding behaviour are its adaptabillity and selectivity, also with respect to homeostatic considerations. The flexibility of omnivore feeding behaviour, which enables the animal to meet the requirements of changing environmental circumstances, determines the biological success of omnivores. Food intake then, is seen as the outcome of an interaction between internal and external constraints (Blundell, 1983). Attention is focused to an investigation into the mechanisms that influence the choice of specific nutritional materials.

Also in the wild, many animals have the opportunity of consuming a variety of edible materials and the variability of the pattern of intake often suggests that a capacity for selection is demonstrated. This is shown for 
instance in birds, who develop prey-density dependent searching images for certain prey species, during certain periods (Tinbergen, 1960; Royama, 1970; Croze, 1970). Under natural conditions the problems of selecting appropriate food material are not equally difficult for all species. Herbivores spend a lot of time feeding on material of low caloric density and low nutritional quality and only by careful selection of plant species, herbivores can obtain a balanced intake. Moreover, with the universal factor of seasonal habitat shifts in grazing systems, the herbivore has to track the availability of forage of adequate quality. Geese, for instance, show a strong preference for young growing shoots whenever available and rely primarily on soluble carbohydrates and proteins contained in the cell sap to satisfy their demands (Drent et al., 1987).

Carnivores consume essential nutrients from single sources. They feed on high density material of good nutritional quality, but they are limited in variety of food that they are capable to consume. Thus, animals are either specialists or generalists (Krebs et al., 1981).

Omnivores face the most severe problems of nutrient selection. They eat a wide range of food among which most items do not contain all of the essential materials for optimal biological functioning. Selection of food must take place, related to internal physiological requirements. Physiological information in the internal milieu needs to be balanced with nutritional information in the external environment.

In this respect changes in release of the neurotransmitters are thought to be involved in the mechanisms controlling the selection of dietary protein and carbohydrate (Wurtman et all, 1981). Because this topic is subject to discussion nowadays, we will pay some attention to it.

With regard to food selection, nutrient selection is related to plasma and brain tryptophan and ultimately to the neurotransmitter serotonin. The important precursors are tryptophan and tyrosine. Brain serotonin is synthesized from tryptophan. A certain competition between plasma tryptophan and other large neutral amino acids exists in relation to the transport system of the blood-brain barrier, and in relation to the influence of insuline on brain serotonin synthesis. Entry of circulating free, i.e. not bound to albumin tryptophan into the brain can be facilitated by raising plasma tryptophan or by lowering plasma levels of other large neutral amino acids. Insulin has little effect on plasma tryptophan levels, but lowers plasma levels of other large neutral amino acids, thereby increasing the plasma tryptophan/LNAA ratio. The maintenance of plasma tryptophan is brought about by an increase in the amount of tryptophan bound to albumin, which makes up for the fall in plasma free tryptophan. Therefore, the effect of any meal on the plasma tryptophan/LNAA ratio will depend on the contribution of amino acids in the diet and the postprandial secretion of insulin. A high carbohydrate meal,- causing a substantial release of insulin,- will cause the plasma tryptophan/LNAA ratio to rise, whereas a high protein meal will cause it to fall. Since the plasma tryptophan/LNAA ratio is related to brain serotonin synthesis, it is argued that serotonin releasing brain neurons can 
function as variable ratio sensors that respond to the protein content of the diet. Consequently, nutrient selection is related to plasma and brain tryptophan and ullimately to the neurotransmitter serotonin.

One hypothesis states that the chronic selection of dietary protein content of animals is related to the effects of the diet on serotonin synthesis (Woodger, Sirek, and Anderson, 1979). From experiments by Ashley (1985), it was concluded that the animal defends its total caloric intake completely, its protein intake only to the amount required for adequate growth, and its carbohydrate intake not at all. From different experiments the major conclusions are that the serum tryptophan/large neutral amino acids (LNAA) ratio does not vary in any parametric way with the chronic level of protein ingested, implying that this ratio cannot serve as a signal to brain regarding chronic dietary protein consumption (Fernstrom, 1987). Rather, adequate protein intake could be ensured by a general behavioural mechanism for correcting any dietary imbalance (Leathwood and Ashley, 1983; Booth, 1985). These experiments and conclusions concern mainly long-term regulation of food intake.

With respect to short term regulation of food intake a second hypothesis states that the animal's acute selection of dietary carbohydrate depends on the diet's effects on brain serotonin synthesis (Wurtman and Wurtman, 1979). With respect to carbohydrate intake, Wurtman and Wurtman (1979) postulated a behavioural control loop wherein the selected composition of the diet modifies serotonin synthesis and release, and feeds back to influence the subsequent selection of nutrients. If carbohydrate is ingested, the serum tryptophan/LNAA ratio rises, brain tryptophan rises and serotonin synthesis is stimulated. This leads to enhanced release of serotonin from brain neurons which reduces appetite for carbohydrates. As subsequent carbohydrate intake falls, the serum tryptophan/LNAA ratio falls, and, thus, brain tryptophan levels and serotonin synthesis and release also decline. As a result, the inhibition of carbohydrate appetite is reduced, and the animal again begins to select for carbohydrates.

However, some studies showed in effect, that fenfluramine, a food intake suppressing drug, can suppress snacking in a selected group of obese subjects, but have not shown a truly selective effect on carbohydrate craving (Fernstrom, 1987). Nevertheless, Fernstrom has found a relation between dietary carbohydrate intake and brain serotonine levels under limited conditions, namely fasting rats given a single meal. This is also susceptible to discussion due to the fact that $24 \mathrm{hrs}$ of food deprivation produces a raise in brain tryptophan level, and increases serotonin synthesis, similar to that induced by a carbohydrate meal (Blundell, 1977). Moreover, due to the increased serotonin level, one should expect that after $24 \mathrm{hrs}$ food deprivation mainly protein would be consumed, and no carbohydrate. Curzon (1985) argued that the way a particular meal affects brain tryptophan concentration depends not only on the composition of the meal, but also on the extent to which tryptophan has been elevated by previous food deprivation. This might explain the 
apparent lack of systematic diet-brain tryptophan relations, observed by Fernstrom et al (1985). Should the natural food deprivation of inter-meal intervals varying from 30 minutes to 4 hours produce different changes in background brain tryptophan levels, then the killing of animals (for brain examination) after arbitrary time periods with no reference to the individual feeding pattern would recruit animals which are about to eat, have eaten, are eating, or are in the middle of the meal interval. In that case, the experimental set up produces its own effects and differences in deprivation and repletion may be sufficient to prevent a clear effect of diet on brain tryptophan levels. Another problem with respect to these experiments is that only levels of tryptophan and serotonin are measured, whereas turn-over measurements as well would have given more information.

The plasma tryptophan and brain serotonin levels and consequently turnover, should be measured continuously, by monitoring these contents of the cerebrospinal fluid during meal intervals, with synchronic observation of eating behaviour, in relatively free moving rats, leading a "normal' cage life .

In effect, food choice might be involved to a great deal in the processes of food intake regulation, whether short term or long term.

\section{$1.4 \quad$ References}

Ashley, D. V. M. Factors affecting the selection of protein and carbohydrate from a dietary choice. Nutr. Res. 1985; 5: 555-571.

Birch, L. L. Deysher, M. Caloric compensation and sensory specific satiety: evidence for the self regulation of food intake by young children. Appetite, 1986; 7: 323-331.

Blundell, J. E. Problems and processes underlying the control of food selection and nutrient intake. In: Wurtman, R. J. and Wurtman, J. J. Nutrition and the brain. 1983; 6: 163-221. Raven Press, New York.

Blundell, J. E. Is there a role for serotonin in feeding? Int. J. Obes. 1977; 1: $15-42$.

Booth, D. A. Food conditioned eating preferences and aversions with interoceptive elements: learned appetites and satieties. Ann. NY. Acad. Sc. 1985; 443: 22-37.

Booth, D. A. Post absorptively induced suppression of appetite and the energostatic control of feeding. Physiol. Behav. 1972; 9: 199-202.

Brobeck, J. R. Hormone and metabolism: food and temperature. Rec. Adv. Horm. Res. 1960; 16: 439-459.

Castonguay, T. W., Applegate, E. A., Upton, D. E., Stern, J. S. Hunger and appetite: old concepts/ new distinctions. Nutr. Rev. 1983; 41 : 101-110.

Croze, H. Searching images in carrion crows. Z. Tierpsych. 1970; Beiheft 5. 
Curzon, G. Effect of food intake on brain transmitter amine precursors and amine synthesis. In: M. Sandler and T. Silverstone (eds). Psychopharmacology and food intake. Oxford, Oxford university press, $1985 ; 59-70$

Drent, R. H., Prins, H. H. T. The herbivore as prisoner of its food supply. In: Disturbance in grasslands. van Andel, J. et al eds. 1987; 9: 131147. Dr. W. Junk Publishers, Dordrecht, The Netherlands.

Fernstrom, J. D., Fenstrom, M. H., Grubb, P. E., Volk, E. A. Absence of chronic effects of dietary protein content on brain tryptophan concentrations in rat. Journ. Nutr. 1985; 115: 1337-1344.

Fernstrom, J. D. Food-induced changes in brain serotonin synthesis: is there a relationship to appetite for specific macronutrients? Appetite, 1987; 8: 163-182.

Foltin, R. W., Fischmann, M. W., Emurian, C. S., Raclinski, J. J. Compensation for caloric dilution in humans given unrestricted access to food in a residential laboratory. Appetite, 1988; 10: 13-24.

Garrow, J. S. Energy balance and obesity in man. 2nd ed. Amsterdam: Elsevier, 1978.

Herman, C. P., Polivy, J. A boundary model for the regulation of eating. In: Stunkard AJ, \& Stellar E, eds. Eating and its disorders . New York: Raven Press, 1984; 141-156.

James, W. P. T., Mc Neill, G. \& Ralph, A. Metabolism and nutritional adaptation to altered intakes of energy substrates. Am. J. Clin. Nutr. 1990; 51: 264-269.

Jenkins, D. J. A., Wolever, T. M. S., Vuksan, V., Nibbling versus gorging: metabolic advantages of increased meal frequency. N. Engl. J. Med., 1989; 321: 929-934.

Kennedy, G. C. The role of depot fat in the hypothalamic control of food intake in the rat. Proc. R. Soc. Lond. Ser. B 1953; 140: 578-592.

Krebs, J. R. and Davis, N. B. An introduction to behavioural ecology. 1981. Blackwell, Oxford.

Leathwood, P. D., Ashley, D. V. M. Strategies of protein selection by weanling and adult rats. Appetite, 1983; 4:97-112.

Leathwood, P. D. Ashley, D. V. M. Behavioural strategies in the regulation of food choice. Experientia, 1983; 44: 171-196.

Lissner, L., Levitsky, D. A., Strupp, B. J., Kalkwarff, M. J., Roe, D. A. Dietary fat and the regulation of energy intake in human subjects. Am. J. Clin. Nutr. 1987; 46: 886-892.

Mayer, J. Regulation of energy intake and the body weight: The glucostatic theory and the lipostatic hypothesis. Ann. NY. Acad. Sci. 1955; 63: $15-43$.

Mellinkoff, S. M., Frankland, M., Boyle, D., Greipel, M. Relationship between serum amino acid concentration and fluctuation in appetite. $\mathrm{J}$. Appl. Physiol. 1956; 8: 535-538.

Morley, J. E., Levine, A. S. The central control of appetite. Lancet 1983; 2: 398-401. 
Nicolaindis, $S$. Short term and long term regulation of energy balance. Proc. 26th Int. U. Physiol. Sc. 1974; 122-123.

Nicolaĩdis, S. Even, P. C. The ischymetric control of feeding. Int. J. Obes. $1990 ; 14: 35-52$.

Royama, T. Factors governing the hunting behaviour and selection of food by the Great Tit (Parus major L.). J. Anim. Ecol. 1970; 39: 619668.

Rozin, P. The selection of foods by rats, humans and other animals. In: Advances in the study of behaviour VI, Rosenblatt, J., Hinde, R., Beer, C., Shaw, E. ed. 1976: 21-76. Acad. press, New York.

Rozin, P., Millman, L. Family environment, not heredity, accounts for family resemblances in food preferences and attitudes: a twin study. Appetite, 1987; 8: 125-134.

Smith, G. P. The peripheral control of appetite. Lancet 1983; 2: 88-90.

Sørensen, T. I. A., Holst, C., Stunkard, A. J. Genetic and environmental influencies on body mass index in childhood-The Danish Adoption Study. Int. J. Obesity, 1991; $15(1), 12$.

Sørensen, T. I. A. , Stunkard, A. J. , Holst, C. Recessive inheritance of a major gene for human obesity-Analysis of the Danish Adoption Study. Int. J. Obesity, 1991; 15 (1), 13.

Steffens, A.B., Strubbe, J.H., Balkan, B., Scheurink, A.J.W., Neuroendocrine mechanisms involved in regulation of body weight, food intake, and metabolism. Neurosci. Biobehav. Rev. 1990; 14: 305-313.

Stunkard, A. J., Harris, J. R., Pedersen, N. L., McClearn, G. E. The body mass index of twins who have been reared apart. N. Engl. J. Med. 1990; 322: 1483-1487.

Tinbergen, L. The natural control of insects in pine woods. I. Factors influencing the intensity of predation by songbirds. Arch. neerl. Zool. 1960; 13: 265-336.

Vanltallie, T. B. Kissileff, H. R. The physiological control of energy intake: an econometric perspective. Am. J. Clin. Nutr. 1983; 38: 978988.

Weststrate, J. A. Psychobiologie ten aanzien van de voeding. In: Westerterp-Plantenga et al., 1991; Portretten van Voeding. Open universiteit, Heerlen, The Netherlands.

Woodger, T. L., Sirek, A., Anderson, G. H. Diabetes, dietary tryptophan, and protein intake regulation in weanling rats. Am. J. Physiol. 1979; 236: 307-311.

Wurtman, J. J., Wurtman, R. J. Drugs that enhance central serotonergic transmission diminish elective carbohydrate consumption by rates. Life sciences, 1979; 24: 895-904.

Wurtman, R. J., Heftl, F., Melamed, E. Precursor control of neurotransmitter synthesis. Pharmacol. Rev. 1981; 32: 315-335. 


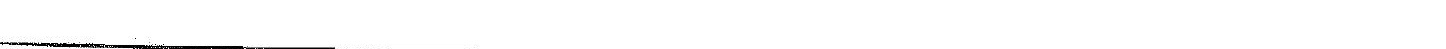




\title{
Eating Behaviour during a Meal
}

\author{
Scope of the study
}

\section{$2.1 \quad$ Subject characteristics and meal characteristics}

Observation and analysis of eating behaviour is regarded as relevant for subjects who suffer from subjective and, or objective problems with their body weight. These problems can result in overweight, restrained eating behaviour, binge eating, or lack of appetite. Therefore, this study has a medical relevance, namely susceptibility to obesity, anorexia nervosa, or bulimia nervosa, diseases of civilization, nowadays. As participating subjects, only subjects from one sexe were chosen, as large differences between sexes with respect to eating behaviour were to be expected, regarding some reports in the literature (Kissileff et al., 1984; 1986). The approach to the topic has been rather naturalistic, with respect to daily life in humans, than exact, like an animal model would be. Only women were chosen to participate, for several reasons. One reason was that at the same time at the same University, a project on smoking started, where only men participated. For the women our project was a nice opportunity to participate. Another reason was that women seem to have more subjective weight problems than men seem to have, so more subjects with restrained eating were to be expected.

Regulation of food intake occurs through the long-term operation of subtle but persistent factors in an environment with short term influences. These factors operate through either postprandial or preprandial regulation or both, whereas short term influences on regulation of food intake are effective during a single meal (de Castro et al., 1985). Short term influences on regulation can be either physiological or cognitive in nature. Physiological influences are related to hunger and satiation, while cognitive influences are for example related to habits (Castonguay et al., 1983). In humans, food intake regulation rests largely on the control of meal size, since meal to meal intervals are fixed by social rather than physiological demands (Bellisle et al., 1980). This short term regulation or control of meal size might be reflected in eating style, which can be characterized by behaviour and by rate of food intake. The rate of food intake during a single meal is described by the cumulative food intake curve, which is either non-decelerating (linear), or decelerating (Kissileff 
et al., 1982; MacCleery et al., 1977; Meyer et al., 1972; Pudel et all., 1975).

The parameters of cumulative food intake curves during a meal, could reflect underlying physiological or cognitive processes. If cumulative food intake reflects physiological processes involved in short term control of food intake, the paramelers should relate to the amount eaten during the meal.

Several studies have shown correlations between the shape of the cumulative intake curve and obesity or latent obesity. Normal weight subjects, for instance, displayed a deceleration in the rate of intake during a meal whereas the obese and latent obese tended to show a linear rate of intake over time (Meyer et al., 1972). The conclusion was that deceleration in intake reflects biological satiation which is deficient in the obese. On the contrary in one report decelerated cumulative intake curves for obese men and linear curves for non-obese men were described (Kaplan, 1980). Others have found that obese and non-obese subjects did not differ in eating styles (Adams et al., 1978; Pudel et al., 1975) and moreover that the percentage of non-decelerating (or linear) and decelerating curves in obese and non-obese subjects was the same (Kissileff et al., 1986). Some studies show no relation between obesity and the linear or decelerated aspect of the cumulative food intake curve (Kissileff \& Kral, 1986; Westerterp et al., 1988) but rather a relation between 'restrained eating' (Herman and Polivy, 1980; Stunkard and Messick, 1985) and the linearity or deceleration of the curve.

Considering certain aspects of the cumulative food intake curve, its slope and deceleration have been shown sensitive to palatability (Bobroff \& Kissileff, 1986), type of food eaten (Kissileff et al ., 1984) and preloads (Kissileff, 1984). Sensitivity to these meal parameters has been taken to indicate that the cumulative food intake curve is the expression of internal regulatory mechanisms (Meyer \& Pudel, 1972; Kissileff \& Thornton, 1982) that slow down eating and eventually terminate the meal. The parameters describing the cumulative food intake curve may thus be explained from changes in the internal state.

On the other hand appetite could be the result of learning experiences based on relations between food and the body during eating and drinking. Learning appears to be the main process by which food intake can be tuned towards need (Booth et al., 1981). The process can be regarded as the conditioning of ingestatory reflexes. If hunger and satiety can be considered as conditioned reflexes, the shape of the cumulative food intake curve is likely to reflect a stable pattern.

\subsection{Physiological aspects of eating behaviour}

Food intake in humans is affected by physiological and non-physiological factors, and has certain physiological effects, like diet induced thermogenesis. Food intake behaviour during a meal is reflected in 
cumulative food intake curves, which parameters may reflect short term regulation mechanisms. The shape of a decelerated cumulative food intake curve seems to depend on internal processes; the shape of a linear cumulative food intake curve seems to reflect primarily a cognitive eating style (Westerterp et al., 1988; Westerterp-Plantenga et al., 1990 a and b). Thus cumulative food intake curves may be used as an instrument to study eating behaviour in relation to the relative contribution of physiological factors that control food intake during a meal. Two of these physiological factors, which, according to the thermostatic theory, are important feedback signals, namely diet-induced-thermogenesis and body-temperature, can be measured in humans during and after a meal, without disturbing them. The measurement of other physiological factors in blood and in the gastro-intestinal tract might be very interesting but may influence eating behaviour to a large extent.

Diet-induced thermogenesis is the acute effect of food ingestion on resting metabolic rate, which in the average individual accounts for about 10-15 percent of total daily energy expenditure (Sims et al., 1987; Woo et al., 1985). The primary determinants of diet-induced-thermogenesis are the level of energy intake and the nutrient composition of food. Dietinduced thermogenesis is linearly related to energy intake, but consists of two distinct components: the obligatory component, involved in the postprandial metabolism of the nutrients (Jéquier, 1984; Sims et al., 1987; Woo et al., 1985) and the facultative component, i.e. increased sympathetic nervous system activity. Several factors may determine this facultative component, for instance subject characteristics like degree of obesity (Jéquier, 1984), responses to food like overfeeding (Sims et al., 1987) and sensory characteristics of food (Bessard et al., 1983; Glick et al., 1977; Henry et al., 1986; James et al., 1981; Jung et al., 1978; LeBlanc et al., 1985; Pittet et al., 1976; Schutz et al., 1984).

For instance, Le Blanc et al. (1985) found that reduction of food palatability caused a significant diminution in meal thermogenesis and suggested that palatability increases the activity of the sympathetic nervous system, and consequently enhances thermogenesis. On the other hand, Weststrate et al. conclude from experiments where the impact of variation in palatability on diet-induced thermogenesis was studied with liquid test meals being palatable or unpalatable in a random order, that the difference in palatability did not have a significant impact on postprandial metabolism (Weststrate et al., 1990).

Possible activation of the sympathetic nervous system does not necessarily contribute at a constant level to diet-induced thermogenesis. This activation may vary with different sensory characteristics of food (Henry et al., 1986) and may be conditioned by familiar menus. Moreover, considering the different subject characteristics, it has been reported that diet induced thermogenesis is relatively low or delayed in obese women (Bessard et al., 1983; Jéquier et al., 1985; Jung et al., 1978; Pittet et al., 1974; Schutz et al., 1984; Steiniger et al., 1987). 
Physiological, psychological and sociological parameters determine the start, size and end of a meal (Bernstein, 1981, Kissileff et al., 1982). One of the psychological parameters, namely the cognitive aspect in judging quality and quantity of food will certainly interfere with physiological factors. People seem to have the ability to estimate their forthcoming ingestion while shopping, cooking and eating, although the more constant data of energy expenditure give a better idea of their energy balance than their fluctuating energy intake data (James et al., 1990).

The capacity to estimate food intake in general is tested in Stunkards three factor eating questionnaire, (1985), in questions like: "I have a pretty good idea of the number of calories in common foods', true $=F_{1}$; or: 'I often stop eating when I am not full as a conscious means of limiting the amount that I eat", true $=\mathrm{FI}$; or "I do not eat some foods because they make me fat", true $=F_{1}$; or "How likely are you to shop for low calory foods?', very $=F_{1}$. High scores on this type of questions label subjects as cognitive restraint: subjects who also might have a high degree of accuracy in estimating their forthcoming food intake during a meal.

The accuracy of estimating might be stabilized with familiar menus but might yet have to be developed with an unfamiliar menu.

\subsection{Psychometric questionnaires}

When one of the subject characteristics related to food intake, namely dietary restaint, appears to play a major role as a psychological factor that influences biological effects of eating behaviour, the question arises of how consistent the phenomenon of dietary restraint is in the long term. and under changing conditions. Most dieters do not succeed in maintaining uninterrupted restriction of intake. The average dieter exhibits periods of restraint punctuated by episodes of disinhibited overeating and does not achieve significant weight loss in relation to physiologically defended levels (Hibscher et al., 1977). A "restrained eater" is no doubt restrained, but such a restraint is likely to be accompanied by these lapses, or such a restraint may even be a major contributor to such lapses.

Differences between the methods to measure restraint are as much conceptual as psychometric. The Herman-Polivy restraint scale (1980) is designed to identify dieters, whereas the three factor eating questionnaire (Stunkard et al., 1985) is designed to measure successful dieting.

Overweight restrained eaters appear to be less successful dieters with lapses of restraint, as well as restraint per se (Herman et al., 1975 a and b). Normal weight restrained eaters appear to be very successful in keeping their weight at a certain level for a relatively long time, by maintaining their low energy intake, often in relation to a relatively low 
energy expenditure (Tuschl et al., 1990). They do not necessarily have to score high on the Herman-Polivy restraint scale, as they appear to be mainly food-concerned and less weight concerned (Westerterp-Plantenga et al., 1991).

Notwithstanding small distinctions both the Herman-Polivy restraint and the cognitive restraint scores (TFEQ), showed relations with actual eating behaviour (Westerterp-Plantenga et al., 1990, a and b). However, incidentically, but not generally, a relation has been found between degree of restraint and amount eaten, although restrained eaters restrict their food intake.

In some situations the amount eaten is an exponent of restraint or vice versa. If the amount to eat is very limited (for instance during a strict diet) the subject may show exceptional restraint as a consequence. Reversily, in case of disinhibition of restraint, a raise in the amount eaten may be the consequence.

A phenomenon like counterregulation elucidates eating behaviour during the meal with regard to the amount eaten. Counterregulation has been shown in restrained eaters who were given a preload. Eating this preload was perceived as overeating and led to a successive deliberate increased intake. Consequently, disinhibition led to increased food intake, which was positively correlated with preload size. (Herman et al., 1975).

As mentioned before (chapter 1), Herman and Polivy (1984) proposed that biological pressures maintain consumption within a certain range between the boundaries of hunger and satiety, which they call the range of "biological indifference". Within this range psychological factors would have their greatest impact on the regulation of food intake. The boundary model postulates that the zone of biological indifference is wider in dieters than in non-dieters. Dieters are said to have lower hunger boundaries and higher satiety boundaries than non-dieters. Also, dieters have a third, self-imposed 'diet' boundary, located between hunger and satiety boundaries, marking their maximum desired consumption. Herman and Polivy (1984) suggest that once restrained eaters transgress this diet boundary, they eat until they reach the satiety boundary. This has been called the disinhibition which explains the phenomenon of counterregulation in restrained eaters: when the self control of restrained eaters is disrupted, overeating ensues. The perception of having overeaten disinhibits restrained eaters (Hibscher et al., 1977; Ruderman et al., 1986). Consequently, if a preload is given within the diet boundary, counterregulation does not have to occur.

Another model has been presented alternatively in the context of counterregulation and binge eating: an anticipative physiological response, e.g. the release of insulin before a meal leads to a decline in blood glucose level, which in this theory is viewed as a compensatory response. As during and after the meal the glucose level increases, it is thought to be convenient to lower glucose level in advance when cues serving as disinhibitors predict large intake. In this context hypoglycemia is regarded as a conditioned compensatory response and as particularly 
strong in the case of intermittent dieting. Hypoglycemia would subjectively be experienced as hunger and would stimulate overeating like binging or counterregulation in order to restore blood glucose level (Jansen, 1990). This model might particularly apply to bulimics as frequent binging will induce rather fluctuating insulin levels.

\subsection{Scope of the study}

The above mentioned leads to the following hypotheses:

- normal weight unrestrained eating subjects display eating behaviour, mainly controlled by underlying physiological mechanisms

- overweight subjects display aberrant eating behaviour, with defects in their physiological mechanisms

- restrained eating subjects display a type of eating behaviour which is mainly controlled by psychological, i.e. cognitive factors.

- weight concened restraint is chronic, and is not affected by a strict diet

- food-concerned restraint demands a cognitively directed attitude with respect to food, which is affected by a strict diet

- disinhibition of restraint is unlikely, if only a modest preload is given

In order to elucidate the relevant underlying mechanisms, a possible relation between the subject characteristics relevant to food intake and parameters that characterize eating behaviour needs to be established. Moreover, the nature of a possible relation between subject characteristics and eating behaviour parameters may be understood better, when this relation is assessed under different food conditions as well.

Chapter 3 deals with the description of the techniques which were used to obtain the relevant parameters.

Chapter 4 deals with the description of the eating behaviour of normal weight and overweight subjects, either unrestrained or restrained with respect to eating behaviour. In effect, cumulative food intake curves during single course solid food lunches, artificially prolonged meals, and energy enriched meals were recorded and analysed.

With respect to the experimental set-up of the following studies, this study revealed that in overweight eaters the distinction between restrained and unrestrained was not reliable. Therefore, in the following studies only overweight restrained eating subjects, of whom we were certain that they were restrained based on previous dieting and the then following trial to keep their body weight at the achieved level, were chosen to participate, as well as normal weight conspecifics, who were either restrained or unrestrained. Moreover, in the following studies more homogeneous groups of subjects, with respect to age and body mass index were chosen, and a second, different psychometric questionnaire was added to the first one.

A single course meal might not be representative, as we noticed with the subjects in the first study, -who wanted a dessert anyway,- and a single 
course meal might imply too short a meal duration, to be able to establish a meal size. Therefore, in the following studies we offered four course meals, thus lengthening meal duration.

Chapter 5 deals with the relation between subject characteristics, especially body weight and dietary restraint, and eating behaviour, described by various meal parameters, especially cumulative food intake curves, in the situation where four course meals were offered. The consequences of the four course meal situation with respect to the effects of succession and relative palatability were assessed as well.

Chapter 6 deals with the assessment of a possible relation between eating behaviour on the one hand and a reflection of internal processes and subject characteristics on the other hand. In effect, cumulative food intake curves, diet-induced thermogenesis and skin and core temperature of normal weight restrained and unrestrained eating women and of obese restrained eating women were recorded during four course solid lood lunches, eaten in a laboratory setting (respiration chamber), at a constant ambient temperature.

Chapter 7 deals with the question, of how different thermogenic responses may be related to familiarity with the sensory characteristics of the presented food.

In effect, the relation between eating behaviour, subject characteristics and diet-induced thermogenesis was established with subjects eating menus differing in familiarity.

Chapter 8 deals with the assessment of the role of the cognitive factor 'estimation accuracy' in determining meal size. In effect we offered different meal types to different types of subjects. Normal- and overweight restrained eating women and normal weight unrestrained eating women were served a familiar meal, and the same unfamiliar meal twice, respectively. We analysed accuracy of estimate as a function of meal type and dietary restraint.

Chapter 9 deals with the question of how a strict diet affects 'restraint' in the course of some months, and, if restraint takes place consistently during a period of strict dieting, how likely is disinhibition as a consequence of a modest preload, and how does this affect the amount eaten? In order to be able to support the consistency of the subject characteristics we have been using throughout the study, we studied dietary restraint during a counselled four month weight reduction programme in overweight restrained eating subjects, and compared this to their conspecifics without this programme.

In effect, in connection with assessing the consequences of dietary restraint during a four month weight reduction programme in overweight restrained eating women, low and high caloric preload effects on food intake were measured. During this period of four months body mass index and fat mass were measured regularly, and repeated scores on both restraint questionnaires of this group were compared with those of normal weight and overweight conspecifics without the weight reduction programme. In order to obtain meal parameters as part of eating 
behaviour, the subjects were invited for lunch to the laboratory about once a fortnight. In two of the seven lunches the preload experiments were conducted.

\subsection{References}

Adams, N., Ferguson, J., Stunkard, A. and Agras, S. The eating behaviour of obese and non obese women. Behavioural Research and Therapy, $1978,16,225-232$.

Bellisle, F. \& Le Magnen, J. The structure of meals in humans: eating and drinking patterns in lean and obese subjects. Physiology \& Behaviour, $1981,4,27,649-658$.

Bessard, T., Schutz, Y., and Jéquier, E. Energy expenditure and postprandial thermogenesis in obese women before and after weight loss. Am. J. Clin. Nutr. 1983, 38: 680-693.

Bobroff, E.M. \& Kissileff, H.R. (1986).. Effects of changes in palatability on food intake and the cumulative food intake curve in man. Appetite, 7,85-96.

Booth, D.A. Hunger and satiety as conditioned reflexes. In:, eds. H. Weiner, M.A. Hofer, and A.J. Stunkard (eds) Brain, Behaviour, and Bodily Disease. Raven Press, New York, 1981.

Castonguay, T.W., Applegate E.A., Upton D.E., Stern J.S. Hunger and appetite: old concepts/new distinctions. Nutrition reviews 1983,41, 4 .

Castro, de J.M. and Kreitzman, S.M. A micro regulatory analysis of spontaneous human feeding patterns. Physiology \& Behaviour, 1985, $35,329-335$.

Glick, Z., Svartz, E., Magazanik, A., Modan, M. Absence of increased thermogenesis during short-term overfeeding in normal and overweight women. Am. J. Clin. Nutr. 1977.30:1026-1035

Henry, C.J.K. and Emery, B. Effect of spiced food on metabolic rate. Human Nutrition: Clinical Nutrition 1986, 40C, 165-168.

Herman C.P., Mack D. Restrained and unrestrained eating. Journal of personality $1975 ; 43: 647-660$.

Herman, C.P., Polivy, J. A boundary model for the regulation of eating. In: Stunkard, A.J., \& Stellar, E., eds. Eating and its disorders. New York: Raven Press, 1984: 141-156.

Herman, C.P., Polivy, J. Anxiety, restraint and eating behaviour. Journ. of Abn. Psychol. 1975; 84: 666-672.

Herman, C.P., Polivy, J. Restrained eating. In: Stunkard AJ ed. Obesity. Philadelphia: Saunders, 1980: 208-225.

Hibscher, J.A., Herman, C.P. Obesity, dieting and the expression of 'obese' characteristics. Journ of comparative and physiological psychology 1977; 91: 374-380.

James, W.P.T., and Trayhurn, P. Thermogenesis and obesity. Brit. Med. Bull. 1981, 37, 1. 43-48. 
James, W.P.T., Mc Neill,G. \& Ralph; A . (1990). Metabolism and nutritional adaptation to altered intakes of energy substrates. American Journal of Clinical Nutrition, 51, 264-269.

Jansen, A.T.M. Binge eating: notes and data. Thesis Maastricht, 1990.

Jéquier, E., Schutz, Y. New evidence for a thermogenic defect in human obesity. Intern. Journ. of Obesity $9,2,: 1-7 ; 1985$.

Jéquier, E. Energy expenditure in obesity. Clin. Endocrinol. Metab. 1984. 13:563-580.

Jéquier, E. Thermogenesis induced by nutrient administration in man. Infusionstherapie 1984.11:184-188.

Jéquier, E., Pittet, P.H. and Gygax, P.H. Thermic effect of glucose and thermal body insulation in lean and obese subjects: a calorimetric approach. Proc. Nutr. Soc. 1987, 37, 45-53.

Jung, R.T.; Shetty, P.S. ; James W.P.T. Reduced thermogenesis in obesity. Nature 279: 322-323; 1978.

Kaplan, D.L. Eating styles of obese and non-obese males. Psychosomatic Medicine, $1980,42,529-538$.

Kissileff, H.R, Gruss, L.P., Thornton, J.L., \& Jordan, H.A. (1984), The satiating efficiency of foods. Physiology and Behaviour. 32, 319-332.

Kissileff, H.R. \& Thomton J. (1982) . Facilitation and inhibiton in the cumulative food intake curve in man. In A.J. Morrison \& P. Strick (eds.). Changing concepts of the nervous system. Pp. 585-607, New York: Academic Press.

Kissileff, H.R. \& van Itallie.,T.B. (1982). Physiology of the control of food intake. Annual Reviews in Nutrition. 2, 371-418.

Kissileff, H.R. and Kral, J.S. Abnormal eating behaviour in morbidly obese men and women. In Abstracts 5th International Congress on Obesity. Pp 11, Jerusalem, Israel, 1986.

Kissileff, H.R., Thornton J. \& Becker E.. A quadratic equation adequately describes the cumulative food intake curve in man. Appetite, 1982, 3, 255-272.

LeBlanc, J., Brondel, L. Role of palatability on meal-induced thermogenesis in human subjects.Am.J.Physiol. 1985, 248: E333E336.

MacCleery, R.H. On satiation curves. Animal Behaviour, 1977, 25, 10051015.

Meyer, J.E. \& Pudel V. Experimental studies on food intake in obese and normal weight subjects. Journal of Psychosomatic Research, 1972, 16, 305-308.

Pittet, P.H. : Gygax, P.H. ; Jéquier, E. Thermic effect of glucose and amino acids in man studied by direct and indirect calorimetry. $\mathrm{Br}$. J. Nutr. 31: 343; 1974.

Pittet, P.H., Chappuis, P.H., Acheson, K., Techterman, F. de and E. Jéquier. Thermic effect of glucose in obese subjects studied by direct and indirect callorimetry. Br. J. Nutr. 1976, 35, 281-292. 
Pudel, V., Metzdorf, M. und Oetting, M. Zur Personlichkeit Adiposer in psychologiscthen Tests unter Berucksichtigung latent Fettsuchtiger. Zeitschrift fur Psychosomatische medizin, 1975, 21, 345-361.

Ruderman, A.J., Dietary restraint: a theoretical and emperical review. Psychol Bull 1986; 99, 2: 247-262.

Schulz, Y., Bessard, T. and Jêquier, E. Diet-induced thermogenesis measured over a whole day in obese and non-obese women.Am.J. Clin.Nutr.1984,40:542-552.

Sims, E.A.H., Danforth, E. Expenditure and storage of energy in man.J. Clin. Invest. 1987 79:1019-1025.

Steiniger, J., Karst, H.; Noack, R.; Steglich, H.D. Diet-induced thermogenesis in man: thermic effects of single protein and carbohydrate test meals in lean and obese subjects. Ann.Nutr.Metab. 31:117-125; 1987.

Stunkard, A.J., Messick, S. The three-factor eating questionnaire to measure dietary restraint and hunger. Journ of Psychosomatic research 1985; 29: 71-83.

Tusch1, R.J., Laessle, R.G., Platte, P., Dirke, K.M. Differences in foodchoice frequencies between restrained and unrestrained eaters. Appetite 1990; 14: 9-13.

Westerterp, K.R., Nicolson, N.A., Boots, J.M.J., Mordant, A.,\& Westerterp-Plantenga, M.S. (1988) Obesity,restrained eating and the cumulative intake curve. Appetite, 11: 119-128.

Westerterp-Plantenga, M.S., van den Heuvel, E., Wouters, L., ten Hoor, F. Restrained eating, obesity and cumulative food intake curves during four -course meals. Appetite 1991, 16: 149-158

Westerterp-Plantenga, M.S., van den Heuvel, E., Wouters, L., ten Hoor, F. Subjects' estimation of their forthcoming ingestion of familiar and unfamiliar foods as a function of dietary restraint. Int. J. Obesity 1990; 14, 2: 169 (c).

Westerterp-Plantenga, M.S., Westerterp, K.R., Nicolson, N.A., Mordant, A., Schoffelen, P.F.M., ten Hoor, F. The shape of the cumulative food intake curve in humans, during basic and manipulated meals. Physiol. and Behav. 1990; 47: 569-576 (a).

Westerterp- Plantenga, M.S., van den Heuvel, E., Wouters, L., ten Hoor, F. Deceleration in cumulative food intake curves, changes in body temperature, and post prandial thermogenesis. Physiol and Behav 1990; 48: (6) 831-836 (b).

Weststrate, J. A., Dopheide, T., Robroch, L., Deurenberg, P., Hautvast, J. G. A. J. Does variation in palatability affect the postprandial response in energy expenditure? Appetite, 15, 209-219, 1990.

Woo, R., Daniels-Kush, R., Horton,E.S. Regulation of energy balance.Ann. Rev. Nutr. 1985-5:411-433. 


\section{Techniques}

In order to obtain evidence for possible relations between psychological factors and physiological effects, relevant to food intake behaviour, the following three categories of parameters are necessary:

subject characteristics

actual meal parameters

physiological parameters

\subsection{Subject characteristics}

In this study women with subjective and, or objective weight problems participated. Both categories could include women with restrained and unrestrained eating behaviour. Next to these women, normal weight, unrestrained eating conspecifics without weight problems participated.

In humans overweight can be classified in several ways. To establish the body mass index that correlates weight and height, we used the Quetelet Index (weight/height ${ }^{2}$ ) (Quetelet, 1869), the index that is most widely used (Revicki and Israel, 1986). According to Garrow。(1981), we classified women with a Quetelet Index $>25$ as overweight.

By means of the scores on the psychometric questionnaires distinction was made between unrestrained and restrained ealing behaviour. Two following types of psychometric questionnaires were used: the Three Factor Eating Questionnaire (TFEQ) by Stunkard and Messick (1985) and the Herman-Polivy (1980) restraint scale (see appendix).

The Herman-Polivy restraint scale is designed to identify dieters and is mainly weight concerned, whereas the TFEQ is designed to measure successful dieting and is mainly food concerned. In the Three Factor Eating Questionnaire the three factors that are distinguished are, F1: 'Cognitive restraint', F2: 'Disinhibition', and F3: 'Hunger'.

\subsection{Actual meal parameters}

The meal parameters that are obtained from the experiments concerning solid-food lunches, are amount eaten, eating time, eating rate and change in eating rate. 
Eating behaviour was obserwed directly by the experimenter, through a door-window of the chamber where the subjects stayed before, during and after the meal (from 11 a.m. till 15.00 p.m.), which did not disturb the subject because of a difference in light intensity. The experimenter scored the time at which each bite occurred directly into a digital computer. Intake was monitored via an electronic weighing scale built into the table under the plate and connected to the same computer. This set-up is similar to "the universal eating monitor" developed by Kissileff et al ., (1980). The technique provides a detailed record of food intake during a meal. Apart from the amount eaten, eating time, eating rate and change in eating rate, it also provides bite frequency and bite size. The result can be presented as a cumulative food intake curve over time.

\subsection{Physiological effects of food intake}

The main physiological effect of food intake that is measured, is thermogenesis during and after the meal. Energy expenditure was measured in the so-called respiration chamber. The respiration chamber is an open-circuit chamber, with a volume of $14 \mathrm{~m}^{3}$ equipped with bed, toilet, tv, telephone, chair and table. The volume of air drawn from the chamber is measured by a dry gasmeter. Samples of in- and out going air are continuously analysed by a paramagnetic $\mathrm{O}_{2}$-analyser (Serwomex Taylor, England) and an infrared $\mathrm{CO}_{2}$-analyser (Hartman and Braun, West Germany). From the air flow rate, and the $\mathrm{O}_{2}$ and $\mathrm{CO}_{2}$ concentration of the in- and outflowing air, $\mathrm{VO}_{2}, \mathrm{VCO}_{2}, \mathrm{RQ}$ and consequently energy expenditure were calculated on line, using an Apple $2 \mathrm{E}$ computer (Schoffelen et al., 1985). Energy expenditure was calculated using the equation of Brouwer (1965).

Metabolic rate (MR) was calculated from values taken during the period when subjects sat down quietly one hour before the start of a meal. Dietinduced thermogenesis (DIT) was calculated from values taken during two and a half hours from the start of the meal, and was expressed as a percentage of energy ingested during the meal.

Skin and core temperatures were measured by small sensors, connected to the same digital computer as the weighing scale was, as well as the experimenters' scores of the times at which each bite occurred.

Skin temperature was measured at the upper arm, upper leg, and in the proximity of the liver. Core temperature was measured at the tympanic membrane. These sites for measuring core and skin temperature were chosen in a uniform way according to the literature (Benzinger 1969, Cabanac et al., 1977, Ramanathan et al., 1964). The proximity of the liver was chosen according to Berry et al., (1985) and Ma et al. (1987). 
Benzinger, $T$. H. Heat regulation: Homeostasis of central temperature in man. Physiol. Rev. 1969; 49: 4: 671-759.

Berry, M. N., Clark, D. G., Grivell, A. R., Wallace, P. C. The contribution of hepatic metabolism to diet-induced thermogenesis. Metabolism 1985; 34: 141-147.

Brouwer, E. Report of subcommittee on constants and factors. In: Energy Metabolism, ed. Blaxter, K. I. Proceedings of 3rd symposium on energy metabolism. EAAP. Publ. 11. Acad. Press, London, 1965: 440-443.

Cabanac, M. Massonnet, B. Thermoregulatory responses as a function of core temperature in humans. J. Physiol. 1977; 265: 587-596.

Garrow, J. S. Treat obesity seriously: a clinical manual. Edinburgh Churchill Livingstone, 1981.

Herman, C.P. Polivy, J. Restrained Eating. In: Stunkard, A. J. ed. Obesity. Saunders, Philadelphia.

Kissileff, H. R., Klingsberg, G., VanItallie, T. B. Universal eating monitor for continuous recording of solid or liquid consumption in man. Am. J. Physiol., 1980; 238: 14-22.

Ma, S. W. Y., Nadeau, B. E., Foster, D. O. Evidence for liver as the major site of the diet-induced thermogenesis of rats fed a 'cafetaria' diet. Can. J. Physiol. Pharmacol. 1987; 65: 1802-1804.

Quetelet, L. A. J. Physique sociale, Vol. 2. 1869 C. Muquardt, Brussels, Belgium.

Ramanathan, N. L. A new weighting system for mean surface temperature of the human body. J. Appl. Physiol. 1964; 19 (3): 531-533.

Revicki, D. A., Israel, R. G. Relationship between body mass indices and measurement of body adiposity. Am. J. Public Health, 76: 992-994.

Schoffelen, P., Saris, W. H. M., Westerterp, K. R., ten Hoor, F. Evaluation of an automatic indirect calorimeter for measurement of energy balance in man. In: Human energy metabolism: Physical activity and energy expenditure measurement in epidemiological research based upon direct and indirect calorimetry. ed. A. J. H. van Es. Euro Nut report 1985; 5: 51-54.

Stunkard, A. J. and Messick, S. The three factor eating questionnaire to measure dietary restraint, disinhibition and hunger. Journ. Psych. Res. 1985; $29: 71-83$. 



\title{
The Shape of the Cumulative Food Intake Curve in Humans, during Basic and Manipulated Meals
}

\author{
M.S. Westerterp-Plantenga, K.R. Westerterp, \\ N.A. Nicolson, A. Mordant, P.F.M. Schoffelen, \\ F. ten Hoor
}

Open University, Heerlen

State University of Limburg, Maastricht

The Netherlands

Physiology and Behavior, 1990; 47 (3); 569-576.

\subsection{Abstract}

WESTERTERP-PLANTENGA, M.S., K.R. WESTERTERP, N.A. NICOLSON, A. MORDANT, P.F.M. SCHOFFELEN AND F. TEN HOOR. The shape of the cumulative food intake curve, in humans, during basic and manipulated meals. PHYSIOL BEHAV 47(3) 569-576, 1990.The shape of the cumulative food intake curve of normal weight and obese women was studied during solid food lunches, artificially prolonged meals, and energetically enriched meals eaten in a laboratory setting. Subjects ( 86 normal weight, 50 obese) displayed consistent eating behaviour over 3-6 repeated meals, with marked differences between individuals. Aspects of eating behaviour were reflected in decelerated and. non-decelerated (or linear) cumulative intake curves depending on changes or no changes in eating rate during the course of a meal respectively. A change in eating rate was generally related to a decrease in bite size, with bite rate remaining constant, from the third temporal quarter of the meal onwards, resulting in a decelerated cumulative intake curve. The non-decelerated (linear) cumulative intake curve does not show this change in eating rate: in the first three temporal quarters bite size and bite rate were constant, whereas in the fourth temporal quarter bite size decreased slightly, compensated by a small increase in bite rate. Intraindividual ranges for meal pararneters such as chewing time per bite, bite interval and initial eating rate indicated consistency of individual eating behaviour. 
In manipulation experiments with a subset of 21 subjects in which meals were artificially prolonged by an interval of $8 \mathrm{~min}$, the cumulative intake curves dit not differ significantly from the original cumulative intake curves in 10 non-decelerated (linear) eaters but showed a change towards non-decelerated curves in 8 out of 11 decelerated eaters. In manipulation experiments with a subset of 34 subjects, who consumed similar meals, but energetically enriched by addition of either fat, protein, or carbohydrates, 25 of these subjects showed no change in the shape of their cumulative intake curves.

\subsection{Introduction}

Regulation of food intake occurs through the long-term operation of subtle but persistent factors in an environment with short term influences. These factors operate through either postprandial or preprandial regulation or both, whereas short term influences on regulation of food intake are effective during a single meal [8]. Short term influences on regulation can be either physiological or cognitive in nature. Physiological influences are related to hunger and satiation, while cognitive influences are for example related to habits [7]. In humans, food intake regulation rests largely on the control of meal size, since meal to meal intervals are fixed by social rather than physiological demands [4]. This short term regulation or control of meal size might be reflected in eating style, which can be characterized by behaviour and by rate of food intake. The rate of food intake during a single meal is described by the cumulative food intake curve, which is either non-decelerating (linear), or decelerating $[18,20,22,25]$.

Several studies have shown correlations between the shape of the cumulative intake curve and obesity or latent obesity. Normal weight subjects, for instance, displayed a deceleration in the rate of intake during a meal whereas obese and latent obese tended to show a linear rate of intake over time [22]. The conclusion was that deceleration in intake reflects biological satiation which is deficient in the obese. On the contrary, decelerated cumulative intake curves for obese men and linear curves for non-obese men were found [14]. Others, however, have found that obese and non-obese subjects did not differ in eating styles $[1,25]$ and, moreover, that the percentage of non-decelerating (or linear) and decelerating curves in obese and non-obese subjects was the same [16]. The results of some experiments lend support to the hypothesis that the rate of eating a single relatively homogeneous food is related to an internal state, which changes and leads to inhibitory processes that slow down and eventually terminate the meal [18]. The significance of the shape of the cumulative food intake curve may thus be attributed to changes in internal state.

On the other hand, appetite could be the result of learning experiences based on relationships between food and the body during eating and 
drinking. Learning appears to be the main process by which food intake can be tuned towards need [6]. The process can be regarded as the conditioning of ingestatory reflexes. If hunger and satiety can be considered as conditioned reflexes, the shape of the cumulative food intake curve is likely to reflect a certain pattern. In the present study we recorded, described and analysed cumulative food intake curves and eating behaviour of normal weight and overweight subjects during solid food lunches, artificially prolonged meals, and energetically enriched. meals. Variability of the cumulative food intake curve was studied by analysing intra-individual and inter-individual ranges for some meal parameters. In order to find out whether the shape of the cumulative food intake curve is a reflection of a changing internal state or of a certain pattern, manipulation experiments with interval-meals and energyenriched meals were performed.

\subsection{Method}

\subsubsection{Subjects}

Female subjects from several groups, including university and hospital employees, university students and women with or without self-defined weight problems were recruited via a local newspaper. Out of the 158 females who responded, 136 healthy non-pregnant women were selected as subjects. We defined a prospective subject as healthy if she did not suffer from diabetus mellitus or hypertension and was not receiving any type of medication. For each subject, weight and height in indoor clothes, without shoes, were used to calculate body mass index $\left(B M I=\mathrm{kg} / \mathrm{m}^{2}\right)$. According to the criterion of $\mathrm{BMI}>25[11], 50$ subjects ( $36.8 \%$ ) were classified as overweight. The remaining 86 subjects were classified as normal weight.

\subsubsection{Procedure}

Data presented are based on series of either three or six lunches, which took place at the same time and same day of the week in consecutive weeks. Subjects ate lunch alone in a closed, windowless room, in which table arrangement, lighting, and taped music gave the atmosphere of a restaurant. Eating behaviour was monitored with a concealed camera. Rate of intake was measured and recorded via an electronic balance built into the table under the plate which was connected to a digital computer [15]. All subjects were assured that data would be kept in strict confidence. An initial series of subjects $(n=60)$ was told that they were participating in an experiment concerning the effects of hunger and satiety on saliva production. The subsequent series of subjects $(n=76)$ was 
informed that video recordings might be made of some meals and that total amount eaten would be measured. The basic meals included in this analysis consisted of a single course of a homogeneous food, rated as moderately to highly palatable by all participants. Pasta $(2 \mathrm{~cm}$ segments) was mixed uniformly with a sauce of ground meat, tomato puree, mild red bell peppers; ontons and mushrooms. The energy density of the food was $4,8 \mathrm{~kJ} / \mathrm{g}$. An ample portion $(700 \mathrm{~g})$ was served on a large plate at a temperature between 60 and $62^{\circ} \mathrm{C}$.

Manipulation experiments were performed with a selected subset of 55 subjects who had either consistent deceleration or a consistent linearity over three basic meals. The manipulation experiments consisted of either two articificially prolonged meals (for 21 subjects) or two energetically enriched meals (for 34 subjects). These subjects again were told that they were participating in subsequent experiments concerning effects of hunger and satiety on saliva production.

During the manipulation experiments with prolonged meals, meal length was artificially increased by interrupting the meal for $8 \mathrm{~min}$ after subjects had eaten a first portion (150 g). During this interval according to the cover story saliva production was measured with a cotton dental roll held under the tongue for $1 \mathrm{~min}$. After this interval the subjects received a second plate with a full $(700 \mathrm{~g})$ portion of the same food.

During the manipulation experiments with energetically enriched food, energy density was increased by addition of either fat, protein, or carbohydrates raising the energy density from the original 4.8 to $6.1 \mathrm{~kJ} / \mathrm{g}$. The increase in energy density through additional fat was done by replacing $50 \mathrm{~g}$ of the food by a "burmanier" consisting of $30 \mathrm{~g}$ sunflower oil and $20 \mathrm{~g}$ flour. Increase in energy density through additional carbohydrates was done by exchanging $80 \mathrm{~g}$ of the food by a 'fantomalt' grain, and increase in energy density through protein was done by exchanging $60 \mathrm{~g}$ of the food by a 'protifar' grain. (Fantomalt consists of $94,5 \%$ carbohydrates, ( $3 \%$ glucose, $7 \%$ maltose, $84,5 \%$ polysaccharides), $5 \%$ water, and $0,5 \%$ minerals. Protifar consists of $60 \%$ protein, $<1 \%$ fat, $29,1 \%$ carbohydrate, $<4 \%$ water, $6,9 \%$ minerals. Both are tasteless powders). Care was taken to avoid influencing taste, consistency, and appearance of the meal with these additions. The increase of $25-30 \%$ in energy density was the largest technically possible increase without influencing taste, consistency, or appearance of the meal.

Subjects were instructed to eat no solid food in the three hours preceding a test meal.

Upon arrival, they were asked to record the time they had arisen that morning, time of breakfast, kind and amount of food and beverages consumed at breakfast and before coming to the laboratory. Subjects then rated their degree of hunger on a $100 \mathrm{~mm}$ visual analogue scale (VAS). Under the first protocol, salivation was measured as described above. After receiving the meal subjects were left alone, having been instructed to eat as much as they wanted and that it was not necessary to finish everything on the plate. Subjects signalled when they were finished by 
ringing a buzzer on the table. Hunger ratings and saliwation measurements (when applicable) were then repeated; in addition, subjects filled in VAS ratings conceming the palatability of the meal, how comfortable they felt during the meal, and how much they had eaten in comparison to their normal lunch. Each subject was weighed, measured for height and asked to fill out a Dutch translation of the Three-Factor Eating Questionnaire (TFEQ) [28]. The three dimensions of response are labelled "cognitive restraint' $\left(F_{1}\right)$ 'disinhibition' $\left(F_{2}\right)$ and "hunger" $\left(F_{3}\right)$.

\subsection{Description of the cumulative food intake curve in basic meals and data analysis}

In this paper we present the results of the analysis of food intake data. Results concerning subject characteristics and characteristics of basic meals, published elsewhere [29], are given as far as relevant for this data analysis.

Video recordings of eating behaviour during the test meals were scored by one rater with the help of a portable event recorder, from which data were transferred directly to a computer. Based on these observations, the beginning and end of each meal were defined as the first bite and the last swallow, respectively. The behavioural record and independant weighings of food and plate before and after the meal provided a check on intake data from the electronic balance built into the table. When intake and observational data did not correspond (because, for example, a subject moved her plate off the balance during the meal), the meal was excluded from further analysis. Data from each subject were collected of at least three undisturbed basic meals. Bite rate, bite size and rate of intake were calculated from number of bites, meal duration, and total intake. Because the number of meals per subject varied, two separate analyses of variance with repeated measures were performed, the first of subjects with data for at least three meals $(n=103)$ and the second for those with at least five meals $(n=34)$. Both analyses indicated greater between than within subject variability on all of the measures.

A small microcomputer (APPLE $/ /+$ ) recorded the weight data from electronic scales (METTLER PE4) through a four input RS232 datalink. The experiment was recorded on videotape; after the experiment behavioural observations were recorded (digital observation unit) and transferred to the microcomputer. Since the observed bites per unit time are better defined than the weight changes from the scales due to unrelated activity (stirring, several bites taken from one full spoon etc.) the weight versus time data were autocorrelated with the behavioural versus time data. From this autocorrelation, the time shift between weight changes could then be distributed over the observed bites resulting in one file containing bite moment and bite size.

From this pattern of bite moments (placed on the $x$-axis) and bite sizes (cumulativelly placed on the $y$-axis) the cumulative intake curve was 
derived. The bite moment - bite size pattem makes it possible to calculate the average rate of intake, bite rate and bite size over any part of the meal. The two different types of cumulative food intake curves which thus appear, are characterized as decelerated and linear or non-decelerated $[14,16,18,19,22,23,25]$ by a change in eating rate or not, over the course of a meal.

An analysis to discriminate between decelerated and non-decelerated cumulative food intake curves was performed by curve-fiting. Kissileff describes the quadratic equation as a good fit for the decelerated cumulative intake curve [18]. From the fitted curves the slope as well as the change in slope was calculated.

In order to find out when eating rate decelerates, if it does, and how the components of eating rate i.e. bite size and bite rate contribute to this change, a ternporal quarter analysis as well as a fixed time analysis on eating rate, including bite rate and bite size, were performed. Curve filting was performed for 55 randomly selected subjects. The temporal quarter analysis included 92 subjects with 302 meals out of the entire sample of valid observations. In order to study variability of the cumulative food intake curve, inter-individual and intra-individual ranges for the meal parameters chewing time per bite, bite interval and initial eating rate were calculated.

\subsection{Results}

\subsubsection{Subject characteristics}

Characteristics for the normal and for the overweight group are summarized in Table 1, which includes scores of the three dimensions of the TFEQ, meal size and meal length. Subjects were not selected on the basis of age and therefore, as in the general population, age was correlated with being overweight in this sample $(r=0.58, \mathrm{p}<0.001)$. Overweight subjects scored significantly higher than normal-weight subjects on all dimensions of the TFEQ (two-tailed Mann-Whitney $U$ test: $\mathrm{F} 1, \mathrm{p}<0.05 ; \mathrm{F} 2, \mathrm{p}<0.001 ; \mathrm{F} 3, \mathrm{p}<0.01)$. In addition, there was a different pattern of intercorrelation between the factors in the two weight groups. In the normal-weight group $F 1$ and $F 2$ were positively correlated (Spearman $\rho=0.32, p<0.01$ ), while in the overweight group the correlation between these two scores was negative $(p=-0.35, p<0.01)$. Meal size, meal length and percentage change in slope of the cumulative food intake curves did not differ significantly between normal and overweight groups. 


\begin{tabular}{|c|c|c|c|c|}
\hline & \multicolumn{2}{|c|}{$\begin{array}{l}\text { Normal Weight } \\
(n=35)\end{array}$} & \multicolumn{2}{|c|}{$\begin{array}{c}\text { Obese } \\
(n=20)\end{array}$} \\
\hline & Mean & SD: & Mean & S.D. \\
\hline Weight (kg) & 59.0 & 6.0 & 79.5 & 12.8 \\
\hline Body mass index & 21.0 & 1.7 & 29.9 & 4.4 \\
\hline$F_{1}$ ("cognitive restraint") & 7.5 & 4.7 & 9.3 & 4.2 \\
\hline$F_{2}(" d i s i n h i b i t i o n ")$ & 5.2 & 3.1 & 7.7 & 3.6 \\
\hline $\mathrm{F}_{3}($ ("hunger" $)$ & 4.3 & 2.8 & 5.9 & 3.7 \\
\hline Age (years) & 27.3 & 9.8 & 43.2 & 11.9 \\
\hline Percentage change in slope & $-12 \%$ & 22.4 & $-13 \%$ & 20.1 \\
\hline Meal size $(\mathrm{g})$ & 480 & 126 & 472 & 130 \\
\hline Meal length (sec) & 582 & 139 & 474 & 121 \\
\hline
\end{tabular}

The relationship of subject characteristics to intake rate changes is given in table 2. The 'disinhibition' factor $\left(\mathrm{F}_{2}\right)$ showed a negative relationship with the percentage change in slope in the normal-weight subjects but a positive rellationship with percentage change in slope in the overweight group. Age was an important contributor to percentage change in slope in both weight classes. Some negative association between the "cognitive restraint' factor $\left(F_{1}\right)$ and percentage change in slope was evident in the normal-weight group, but among the overweight subjects $F_{1}$ showed a positive relationship with percentage change in slope.

'Hunger' $\left(\mathrm{F}_{3}\right)$ made no significant contribution to percentage change in slope in either group.

Table 4.2 Pearson correlation coefficients $(\mathrm{r})$ and partial beta values $(\beta)$ from multiple regression of TFEQ factor scores and age onto percentage change in slope of the curve

\begin{tabular}{|c|c|c|c|c|}
\hline & \multicolumn{2}{|c|}{$\begin{array}{l}\text { Normal Weight } \\
\qquad(\mathrm{n}=35)\end{array}$} & \multicolumn{2}{|c|}{$\begin{array}{c}\text { Obese } \\
(\mathbf{n}=20)\end{array}$} \\
\hline & I & $\beta$ & $\mathrm{r}$ & $\beta$ \\
\hline $\mathrm{F}_{1}$ & $-.23 t$ & -0.14 & .17 & $0.29 *$ \\
\hline$F_{2}$ & -.24 & -0.22 & $.25^{*}$ & $0.52^{*}$ \\
\hline $\mathrm{F}_{3}$ & -.05 & 0.10 & .12 & 0.00 \\
\hline \multirow[t]{2}{*}{ Age } & $.29+$ & $0.32 *$ & .13 & $0.31 *$ \\
\hline & $\mathrm{T}^{2}=20.2 \%$ & $r^{2}=22.0 \%$ & & \\
\hline
\end{tabular}


Based on the mean values for each of the 136 subjects, average meal duration for the entire group was $9.1 \mathrm{~min}(\mathrm{SD}=2.4$ ) and average total intake was $479 \mathrm{~g}(\mathrm{SD}=118)$. Changes in eating rate over the course of a meal were characterized by curve fitting and by a temporal quarter analysis.

\subsubsection{Temporal quarter analysis}

A temporal quarter is defined as meal duration divided by 4 . The analysis gives mean data for the successive temporal quarters of the meals for 92 subjects with 302 meals. These subjects had either a significant drop in eating rate during the fourth temporal quarter -compared to eating rate during the first temporal quarter-, or not, and therefore were classified as decelerated or non-decelerated eaters.

Eating rates, bite sizes and bite rates for every temporal quarter are shown in figure 4.1. 

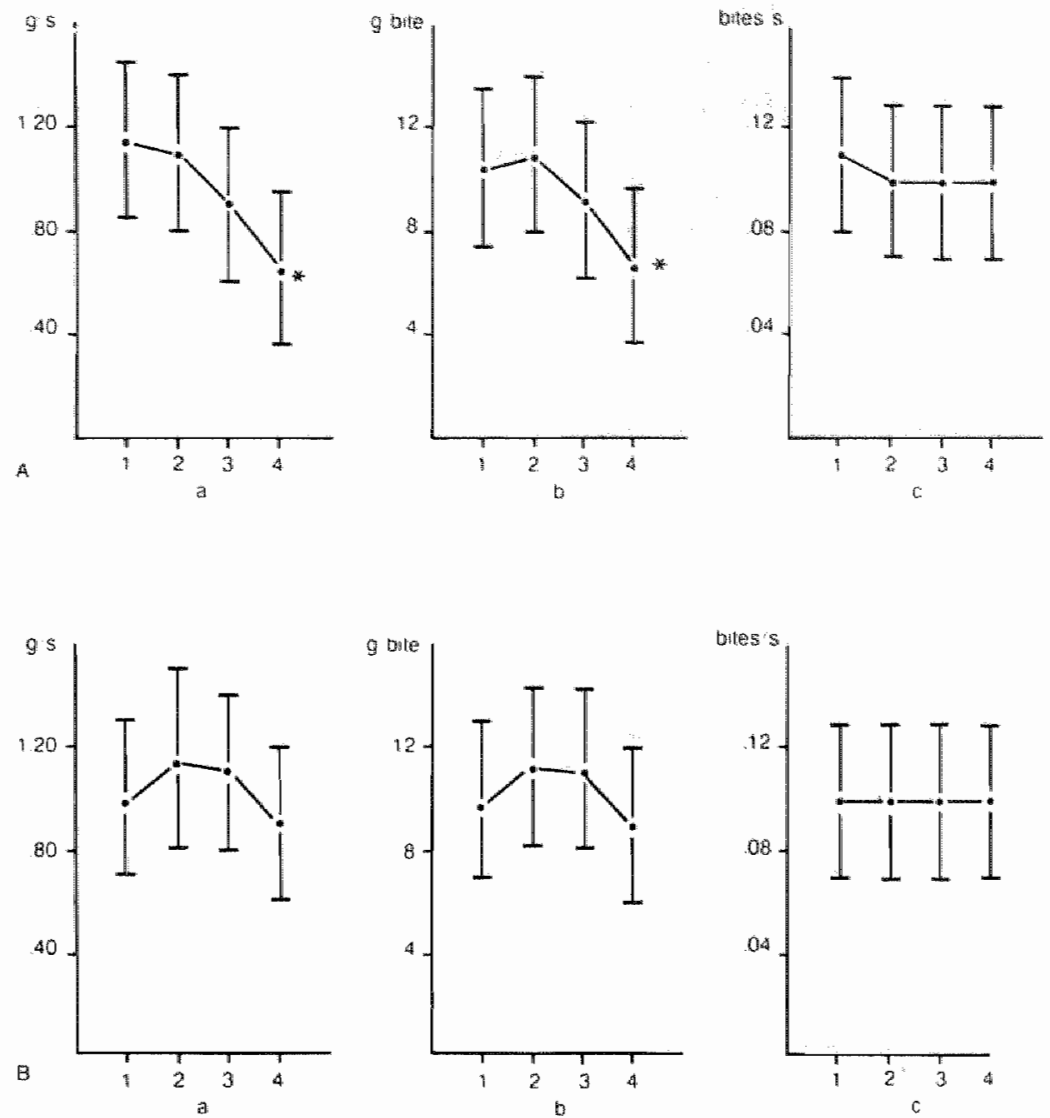

Figure 4.1 Temporal quarter analysis of basic mealls. Eating rate (g/sec), bite size (g/bite), bite rate (bites/sec) for each temporal quarter in decelerated $(A)(n=39)$ and nondecelerated $(B)(n=53)$ eaters. $(A) a, b$, $c$ : decelerated eaters; eating rate, bite size, bite rate, respectively, for each temporal quarter. (B) $a, b, c$ : nondecelcrated eaters; eating rate, bite size, bite rate, respectively, for each temporal quarter. * Significant differences from the data of the first temporal quarter $(p<0.05)$.

The significant drop in eating rate, which is shown by the therefore socalled decelerated eaters, is caused by a significant drop in bite size at a constant bite rate in the fourth temporal quarter of the meal (chisquare $=64.4, \mathrm{p}<0.05$ ). This drop in eating rate had already started in the third temporal quarter but was not statistically significant. Nondecelerated eaters do not display a drop in eating rate. An analysis of variance on eating rate and bite size shows no differences between decelerated and non-decelerated eaters in eating rate and bite size during the first three temporal quarters, but it does show statistically significant differences in eating rate and bite size between decelerated and non- 
decelerated eaters during the fourth temporal quarter (eating rate: $F 1,90=4.60 ; p<0.05$, bite size $F 1,90=5.52 ; p<0.025$ ). In order to determine whether a change in eating rate (bite size, bite rate) occurs after a temporal part of a meal or after a fixed time period of a meal, a fixed time analysis was performed for 55 out of 92 randomly selected subjects who ate three meals each. The fixed time analysis does not give a clear indication of the moment at which eating rate if it does change, changes.

\subsubsection{Curve fitting}

An analysis to discriminate between decelerated and non-decelerated cumulative intake curves was performed by curve fitting. Kissileff [18] describes the quadratic equation as a good fit for the decelerated cumulative intake curve. Our temporal quarter analysis shows that the first part of any meal is linear up to about $50 \%$ of the meal duration. For this reason our equation for curve fitting starts with a linear part of, empirically chosen, $30 \%$, and is followed by a second quadratic part. This means that in the equation

$y=a x+b x^{2}, b$ is zero for the first $30 \%$. Also, these cumulative intake curves do not have an intercept. Curve fitting was performed for 165 meals eaten by 55 subjects (figs 4.2 and 4.3 )

The following variables were calculated:

$a$, the slope of the first $30 \%$

$a+2 b x$, the slope of the next $70 \%$

$\frac{(a+2 b x)-a}{a}$, the change in slope as a percentage of the first slope

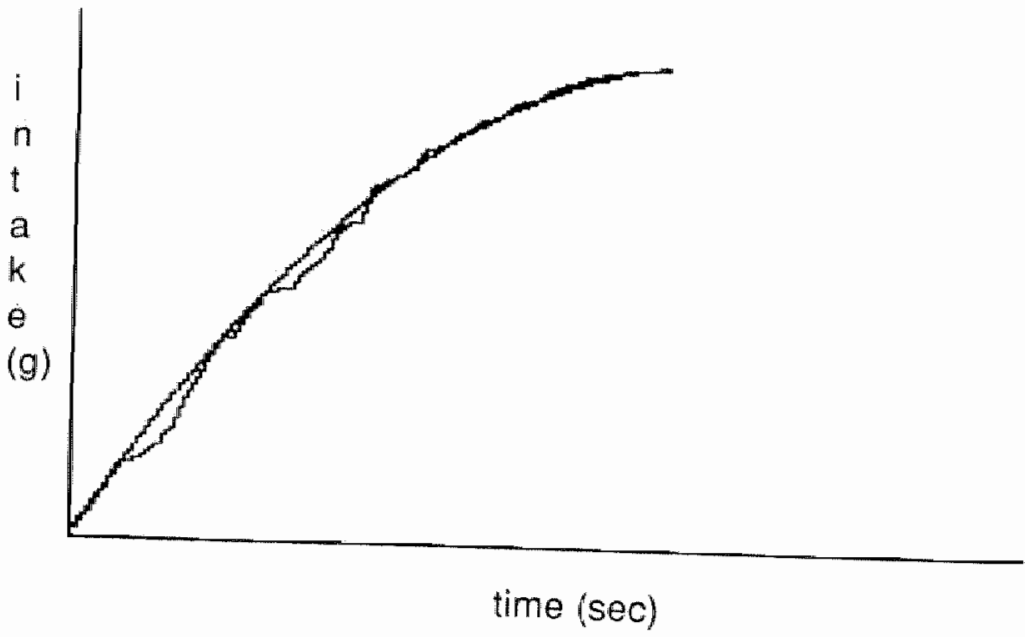

Figure 4.2 Fitting of a decelerated curve, at the slope of the first $30 \%$ of the curve $=1.80$; $\mathrm{a}+2 \mathrm{bx}$, the slope of the next $70 \%$ of the curve $=0.20$. Change in slope as percentage of a, the slope of the first $30 \%:-89 \%$. 


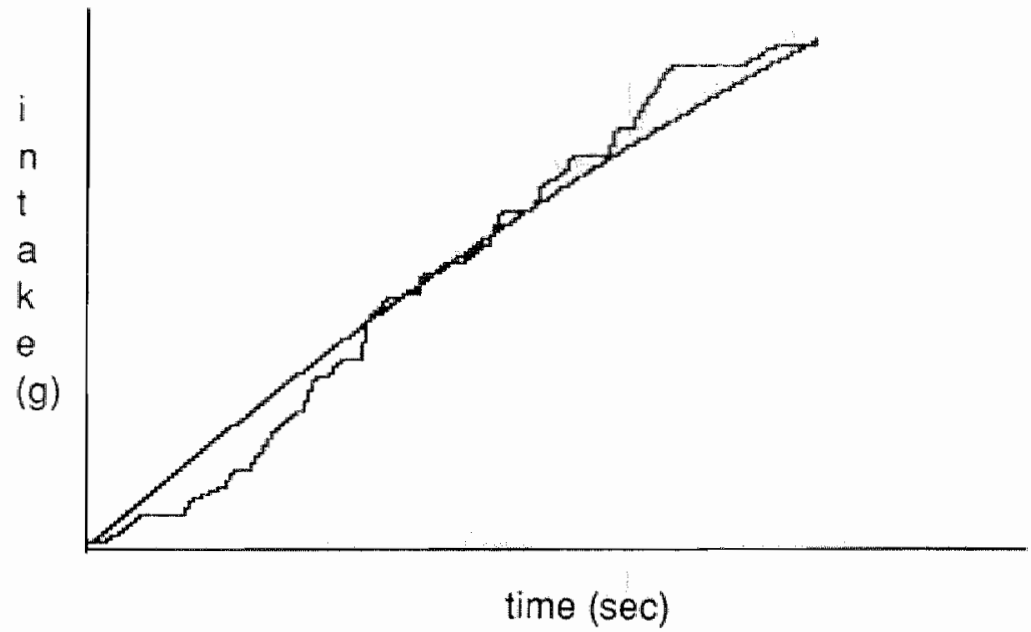

Figure 4.3 Fitting of a nondecelerated curve, a, the slope of the first $30 \%$ of the curve $=0.82$; $\mathrm{a}+2 \mathrm{bx}$, the slope of the next $70 \%$ of the curve $=0.84$. Change in slope as percentage of a, the slope of the first $30 \%:+2.9 \%$.

The recorded cumulative intake curves fell apart into two groups, namely those with a change in slope (as a percentage of the first slope) $<-10 \%$, and those with a change in slope (as a percentage of the first slope) > $10 \%$. See frequency distribution of percentages change in slope, in figure 4.4.

Within the first group of curves $(\mathrm{n}=84)$ the mean negative change in slope was $-46 \%$, (min change $-15 \%$; max. change $-104 \%$ ).

Within the second group of curves ( $n=81$ ) the mean negative change in slope was $+16 \%$, (min change $-6 \%$; max. change $+57 \%$ Subjects always fell within one group of cumulative intake curves. Their standard deviation of the mean of their percentages change in slope ranged from 0.6-4.4.

Apparently, when subjects had shown a statistically significant decrease in eating rate during the fourth temporal quarter their cumulative intake curves belonged to the first group, and if this decrease in eating rate did not appear they belonged to the second group.

An analysis of variance on the curve fitting-variables shows marked differences between subjects for the decelerated eaters with respect to the initial slope, $(F=87.00 ; \mathrm{p}<0.025)$. This does not hold for non-decelerated eaters. $(F=5.8)$. These results further show that the initial slope in decelerated eaters is steeper than in non-decelerated eaters. $(a=1.16$; $a=.81 ; p<0.05$ ). 


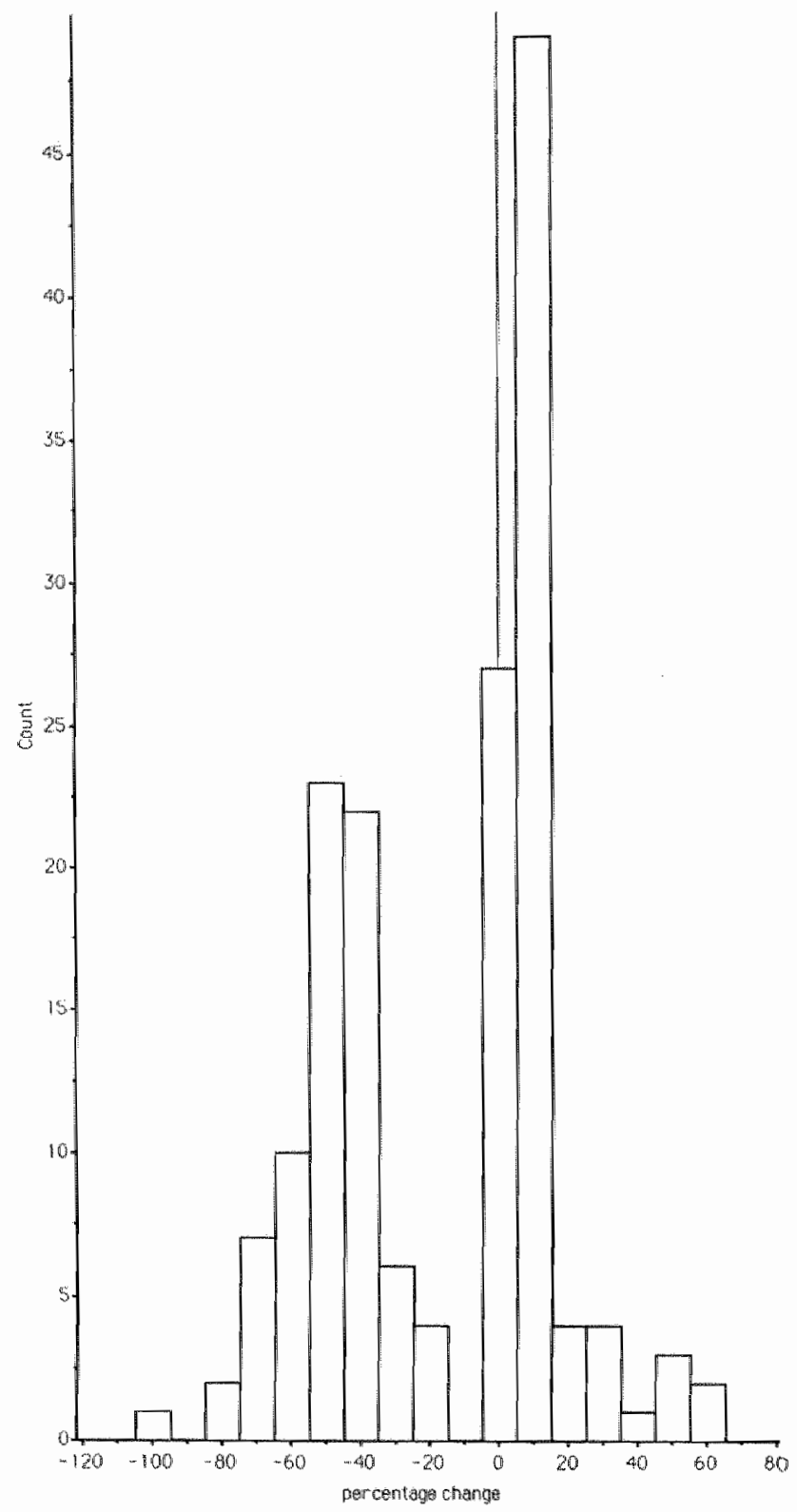

Figure 4.4 Frequency distribution of percentage change in slope of the curve. The frequency distribution of percentage change in slope of the curve yields two groups of curves: one with a percentage change in slope $<-10 \%$, and one with a percentage change in slope $>-10 \%$. 
To find out whether the change in eating rate over a meal, which is reflected by the cumulative intake curve, is influenced by the parameters 'amount eaten' and 'duration" a regression analysis for percentage change in slope versus eating rate (bite size, bite rate), amount eaten and duration, was performed for the decelerated and for the non-decelerated eaters. This analysis showed no correlations between percentage change in slope and duration, eating rate or amount eaten. The conclusion from this analysis is that a possible change in eating rate over a meal is not influenced by the amount eaten, nor by eating rate or duration of the meal.

\subsection{Manipulations}

Results of some experiments lend support to the hypothesis that the rate of eating a single relatively homogeneous food is related to an internal state which changes and leads to inhibitory processes that slow down and eventually terminate the meal [19]. If the shape of the cumulative food intake curve does reflect changes in internal state, it should be susceptible to manipulations in which, for instance it is more likely to achieve satiation.

A meal, artificially prolonged by introducing an interval, is for example likely to improve satiation, as it is reported that the maximal satiating effect of a preload occurs $15 \mathrm{~min}$ after it has been given [27]. Also an energy-enriched meal could improve satiation, being that, with the same eating rate, a subject consumes relatively more energy per time-unit [11]. Manipulation 1, Results of introducing an interval. In the first manipulation experiment, the hypothesis was tested that satiation is only achieved after a certain minimum time. People who showed a nondecelerated cumulative intake curve might have had a meal duration which was too short to achieve satiation. Eleven normally decelerated eaters and ten normally non-decelerated eaters were given two randomly scheduled interval experiments with three basic meals.

An interval experiment consisted of serving a meal in two portions in the following manner. Portion A of $150 \mathrm{~g}, 8$ minute interval, followed by portion $\mathrm{B}$ of $700 \mathrm{~g}$. A first portion of $150 \mathrm{~g}$ was chosen because it was half of the minimal total amount the subjects ate. For the basic meals as well as for the complete interval meals, $\mathrm{C}$, being $\mathrm{A}+\mathrm{B}$, curve fitting was performed. For the analysis, the parameters characterizing the whole meal $C(=A+B)$ were compared to those of the basic meals the subjects ate. If more satiation would be achieved by giving the subjects more time, deceleration in meal $\mathrm{C}$ should be stronger than deceleration in the basic meals. Fig. 4.5 gives eating rate, bite size and bite frequency for every quarter of the basic meals as well as for the interval meals. 

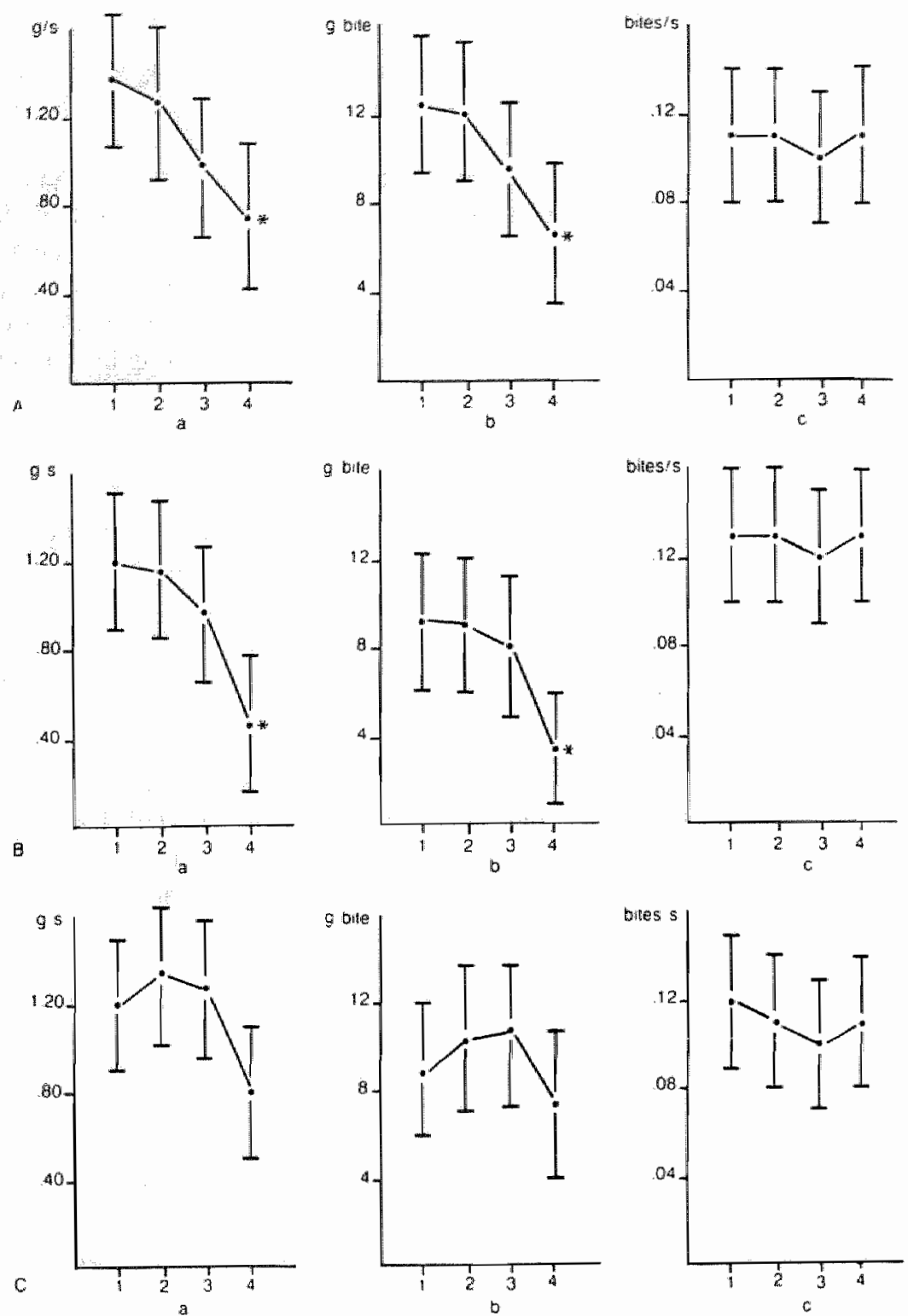

Figure 45 Temporal quarter analysis of interval meals. Eating rate (g/sec), bite size (g/bite), bite rate (bite/sec) for each temporal quarter. (A) a, b, c: decelerated eaters ( $n=$ 11); eating rate, bite size, bite rate, respectively, for each temporal quarter in basic meals. Percentage change in slope: $-49 \%$, S.D. 3.7 . (B) a, b, c: decelerated eaters $(\mathrm{n}=3$ out of 11 ); interval meals: Percentage in slope; $-52 \%$, S.D. 4.1. (C) a, b, c: decelerated eaters $(\mathrm{n}=8$ out of 11$)$; interval meals. Percentage change in slope: $2 \%$, S.D. 1.2. (D) a, b, c: nondecelerated eaters $(\mathrm{n}=10)$; eating rate, bite size, bite rate respectively for each temporal quarter in basic meals. Percentage change in slope: $0 \%$, S.D. 1.8. (E) a, b, c: nondecelerated eaters $(n=10)$; interval meals. Percentage change in slope: $-1 \%$, S.D. 2.0. *Significant differences from the data of the first temporal quarcer $(p<0.05)$. 

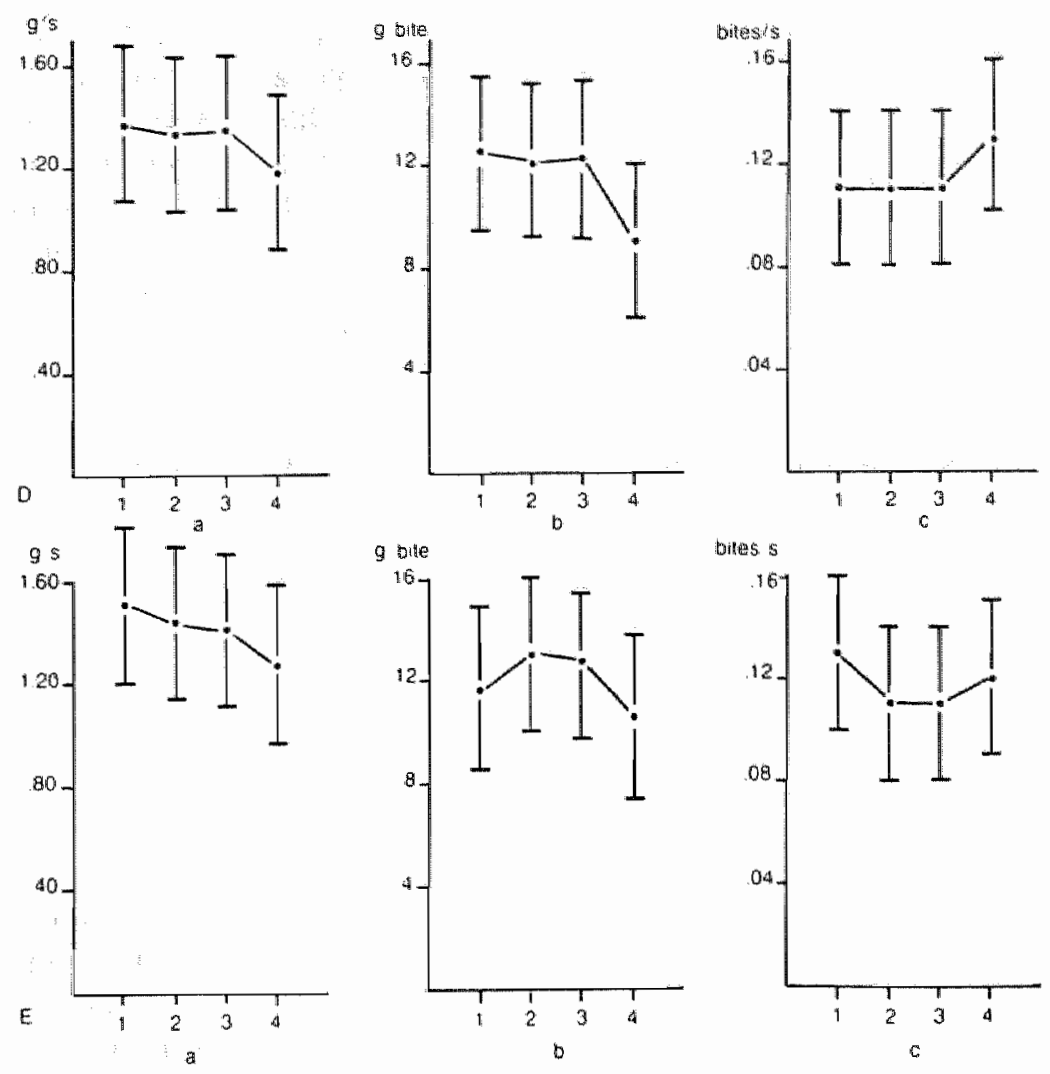

For 13 out of the 21 subjects who had three basic meals and two interval meals each, the 10 basically non-decelerated eaters remained nondecelerated eaters and 3 basically decelerated eaters remained decelerated eaters, showing no variability of the cumulative food intake curve. Eight basically decelerated eaters shifted to a non-decelerated pattern. An analysis of variance on eating rate and bite size in the same subjects during the basic-meal and interval-meal conditions showed no differences in eating rate and bite size during the first three temporal quarters at all. The only differences appeared during the fourth temporal quarter when eating rate and bite size of these eight, now non-decelerated eaters remained constant during the interval meals $(F(1,7)=5,7 ; p<0.05$ and $F(1,7)=5.9 ; p<0.05)$.

The 8 out of 11 decelerated eaters who shifted to a non-decelerated pattern showed a prolonged initial eating rate lasting during the third temporal quarter of $\mathrm{C}$. The drop in eating rate occurred in the fourth quarter of the meal by a drop in bite size which is slightly compensated by a rise in bite rate.

Thus, a fresh second start with a delayed drop in eating rate gives the whole cumulative intake curve the character of a non-decelerated one. 
A meal prolonged by an interval of $8 \mathrm{~min}$ does not result in greater satiation due to a longer meal duration. It has the significance of two meals following each other in which the second one has a prolonged initial eating rate and a delayed slowing down starting in the fourth temporal quarter instcad of in the third temporal quarter. Although this appeared to be a general pattern in part $C$ of the 11 orginally decelerated eating subjects, it only results in a decelerated cumulative food intake curve in three of the originally decelerated eaters.

Manipulation 2, Results of energy-enriched meals. To test the hypothesis that an energy enriched meal gives an earlier satiation or a satiation which fails to occur in basic meals, 34 subjects were given two energy-enriched meals, randomly scheduled with three basic meals.

These meals were enriched by $25 \%-30 \%$ by either carbohydrates (fantomalt), protein (protifar) or fat (burmanier) as described earlier.

Table 3 gives the characteristics of the cumulative intake curves of the basic and energy enriched meals by percentages change in slopes of fitted curves. According to these percentages change in slope, originally decelerated eaters can be divided into two groups ( $n=7$ and $n=6)$ and originally non-decelerated eaters can be divided into two groups $(n=18$ and $\mathrm{n}=3$ ).

For 25 out of 34 subjects who had three basic meals and two energy enriched meals each, the cumulative intake curve has no variability in shape. From these 25 subjects, 18 non-decelerated eaters and 7 decelerated eaters remained non-decelerated and decelerated respectively,(mean percentages change in slope $5 \%$, sd. $2.1 ;-43 \%$, sd.2.4) notwithstanding the change in energy density of the food. From the 9 subjects who changed towards another type of cumulative intake curve, 3 non-decelerated eaters became decelerated eaters, mean percentage change in slope $-34 \%$ sd. 2.9 , (did they achieve satiation at last?) and 6 decelerated eaters became non-decelerated eaters, mean percentage change in slope $7 \%$, sd 2.1. An analysis of variance on eating rate and bite size during the basic-meal and interval-meal conditions showed no differences in eating rate and bite size during the first three temporal quarters either. The only differences which were shown here appear during the fourth temporal quarter, when eating rate and bite size of the 6 originally decelerated eaters during the basic meal conditions were compared to eating rate and bite size of these, now non-decelerated eaters during the energy-enriched meal conditions $(F(1,5)=6.8 ; p<005)$; $F(1,5)=6,9 ; p<0.05)$. This does not hold for the 3 non-decelerated eaters who became decelerated eaters. The general conclusion from the manipulation experiments must be that the individual cumulative food intake curve has little variability despite experimentally prolonged or energy-enriched meals. 


\begin{tabular}{|c|c|c|c|c|c|c|c|c|}
\hline & \multicolumn{8}{|c|}{ Percentage Change in Slope } \\
\hline & \multicolumn{4}{|c|}{ Decelerated Eaters $(n=13)$} & \multicolumn{4}{|c|}{ Nondecelerated Eaters $(n=21)$} \\
\hline & \multicolumn{2}{|c|}{$\mathrm{n}=7$} & \multicolumn{2}{|c|}{$\mathrm{n}=6$} & \multicolumn{2}{|c|}{$\mathrm{n}=18$} & \multicolumn{2}{|c|}{$\ddot{n}=3$} \\
\hline & Mean & S.D. & Mean & S.D. & Mean & S.D. & Mean & S.D. \\
\hline Basic meals & $-40 \%$ & 3.9 & $-38 \%$ & 4.1 & $+10 \%$ & 3.6 & $+11 \%$ & 4.4 \\
\hline $\begin{array}{l}\text { Protein enriched } \\
\text { meals }\end{array}$ & $-42 \%$ & 4.2 & $+1 \%$ & 0.4 & $+8 \%$ & 4.9 & $-29 \%$ & 6.7 \\
\hline $\begin{array}{l}\text { Carbohydrate- } \\
\text { enriched } \\
\text { meals }\end{array}$ & $-48 \%$ & 5.3 & $+6 \%$ & 2.3 & $+2 \%$ & 3.1 & & \\
\hline $\begin{array}{l}\text { Fal-enriched } \\
\text { meals }\end{array}$ & $-36 \%$ & 2.9 & $+2 \%$ & 1.8 & $+1 \%$ & 1.5 & $-32 \%$ & 5.1 \\
\hline
\end{tabular}

Percentage change in slope of decelerated and nondecelerated eaters, separated according to $<-10 \%$ and $>-10 \%$, respectively (see the Curve Fitting section).

\subsection{Variability of the cumulative intake curve}

Variability was studied by calculating interindividual and intraindividual ranges for the parameters chewing time per bite, bite interval and initial eating-rate.

Variability in cumulative food intake patterns was further analysed by comparing the shape of cumulative intake curves between basic meals and manipulated meals. Intra-individual ranges for two meal parameters, chewing time per bite and bite interval indicated consistency of individual eating behaviour [29].

Comparing the shape of the cumulative food intake curves in different meals as expressed by the percentage change in slope, or temporal quarter analysis, 38 out of 55 subjects showed no change in shape of the cumulative food intake curve.

\subsection{Discussion}

The present description and analysis of the cumulative food intake curve deals with differences between decelerated eaters and non-decelerated eaters. Decelerated meals were defined by a change in eating rate over the course of a meal whereas non-decelerated meals were defined by hardly any change in eating rate over the course of a meal. Changes in eating rate, caused by different bite sizes at constant bite rates, and differences in duration contributed to the different eating patterns. Normal weight and obese subjects did not display consistent differences in meal size, meal length and change in slope of the cumulative food intake curve. Age relates to obesity and showed a positive association with individuals" 
mean deceleration of intake in both weight classes. However previous research had indicated that increasing age was associated with more linear intake curves [23], at least in subjects older than 65 years. On closer inspection of the data, it was evident that the age effect was largely confined to the younger subjects in our sample (table 4.2):the majority of subjects who displayed, on average, a non-decelerated pattern was younger than the group mean of 33 years. Concerning restrained and unrestrained eating subjects a negative relationship between percentage change in slope and 'cognitive restraint' ( $F_{1}$ in the TFEQ, [28]) as well as 'disinhibition' $\left(F_{2}\right)$ was found in the normal weight group which means that these non-decelerated eaters are partly restrained eating subjects. Effective restraint in normal-weight subjects allowed them to finish a meal arbitrarily before enough food had been consumed to produce internal feedback.

The analysis of the cumulative food intake curves of basic meals shows that decelerated eaters started their meals at a significantly higher speed than non-decelerated eaters as shown by the initial slopes. This higher speed was due to a bigger bite size as well as a higher bite frequency. However, high initial intake rate does not always result in a decelerated cumulative intake curve. We identified the following two patterns of intake.

- In decelerated eaters, we found as did some others $[9,12,21]$ a relatively high initial eating rate which was almost constant during the first half of the meal, followed by a drop in eating rate caused by a drop in bite size at a constant bite rate in the third temporal quarter of the meal, with a further decrease in eating rate during the fourth temporal quarter.

- In non-decelerated eaters, we found a relatively low initial eating rate which increased slightly during the second and third temporal quarters and then slightly decreased during the fourth temporal quarter; no statistically significant changes throughout the meal were found.

These patterns are partly consistent with patterns described in the literature. $[4,14,22,28$,]. For instance a temporal quarter analysis showed an increase in chewing time per food unit and a decrease of chewing rate, while pause duration and drinking increases, in the fourth temporal quarter of the meal.

The temporal quarter analysis as well as curve fitting deals with the meal itself as a unit, irrespective of its actual length and amount eaten. Both these analyses give a good indication of the moment at which eating rate changes. A fixed time analysis fails to give a clear indication of this moment because of the variability of meal length and of total intake.

The shape of the cumulative food intake curve has been suggested to be the expression of internal regulatory mechanisms [17], and has been shown to be sensitive to palatability and type of food eaten [5,16], as well as to food deprivation [17].

Our results concerning variability of meal parameters, and variability of the shape of the cumulative food intake curve during manipulations suggest that in $70 \%$ of the subjects the shape of the cumulative food 
intake curve, whether decelerating or non-decelerating is attributed to learning process. However, 17 out of 55 subjects showed varability in the shape of the cumulative food intake curve during manipulations: 8 decelerated eaters became non-decelerated eaters during interval meals, 3 non-decelerated eaters became decelerated eaters and 6 decelerated eaters shifted to a non-decelerated pattern during energy-enriched meals.

These 17 subjects thus show a relatively stronger expression of internal regulatory mechanisms as a reaction to manipulations.

Apart from the 3 non-decelerated eaters who became decelerated eaters and who might have achieved satiation at last by a stronger negative feedback, a more surprising result is obtained in the 14 decelerated eaters who showed a shift towards a non-decelerated pattern.

The prolonged initial eating rate during the third temporal quarter of the interval meal, in which the change in internal state is influenced by postponing the progression of the meal, and also the constant eating rate in energy-enriched meals, might be due to the effect of a negative feedback which fails to appear. So in $70 \%$ of the human subjects no variability of the shape of the individual cumulative food intake curve was shown, which is likely to be supported by the effect of learning. In $30 \%$ of the human subjects flexibility of the shape of the individual cumulative food intake curve was shown, due to relatively stronger effect of internal regulatory mechanisms.

\section{Acknowledgements}

Research supported by Dutch Heart Foundation grant 83055 and approved by the Human Subject Committee of the University of Limburg. We thank L. Hendriks and G. van Wunnik for technical assistance.

\section{$4.9 \quad$ References}

1 Adams, N., Ferguson, J., Stunkard, A. and Agras, S. The eating behaviour of obese and non obese women. Behavioural Research and Therapy, 1978, 16, 225-232.

2 Bellisle, F., Lucas, R., Amrami, J, Le Magnen J (1984). Deprivation, palatability and the micro-structure of meals in human subjects. Appetite, 1984, 5, 85-94.

3 Bellisle, F. \& Le Magnen, J.. The analysis of human feeding patterns: the edogram. Appetite 1980, 1, 14 1-150.

4 Bellisle, F. \& Le Magnen, J. The structure of meals in humans: eating and drinking patterns in lean and obese subjects. Physiology \& Behavior, 1981, 4, 27, 649-658.

5 Bobroff, E.M. and Kissileff, H.R. Effects of changes in palatability on food intake and the cumulative food intake curve in man. Appetite, $1986,7,85-96$. 
6 Booth, D.A. Hunger and satiety as conditioned reflexes. In: $H$. Weiner, M.A. Hofer, and AJ. Stunkard (eds) Brain, Behaviour, and Bodily Disease. Raven Press, New York, 1981.

7 Castonguay, T.W., Applegate E.A., Upton D.E., Stern J.S. Hunger and appetite: old concepts/new distinctions. Nutrition reviews 1983 , 41,4 .

8 Castro, de J.M. and Kreitzman, S.M. A micro regulatory analysis of spontaneous human feeding patterns. Physiology \& Behavior, 1985 , $35,329-335$.

9 Dodd, D.K. Stalling, R.B. Eating behaviour of obese and normalweight females in a natural setting. Addictive Behaviour, 1976, 1, 321-325.

10 Duncan, K.H., Bacon J.A., Weinsier R.L. The effects of high and low energy density diet on satiety, energy intake, and eating time of obese and non obese subjects. Am. J. Clin. Nutrition 1983, 37: 763-767.

11 Garrow, J.S. Treat obesily seriously: a clinical manual. Edinburgh: Churchill Livingstone, 1981.

12 Hill, S.W., Mc. Cutcheon, B.N. Eating responses of humans during dinner meals. Journ. Comp. and Physiol. Psychology, 1974, 86, 652657.

13 Hill, S.W., Mc Cutcheon, B.N. Contributions of obesity, gender, hunger, food preference and body size to bite size, bite speed, and rate of eating. Appetite, 1984, 5, 73-83.

14 Kaplan, D.L. Eating styles of obese and non-obese males. Psychosomatic Medicine, 1980, 42, 529-538.

15 Kissileff, H.R., Klingsberg, G. and van Itallie, T.B. Universal eating monitor for continuous recording of solid or liquid consumption in man. American Journal of Physiology, 1980, 238, 14-22.

16 Kissillef, H.R. and Kral, J.S. Abnormal eating behaviour in morbidly obese men and women. In Abstracts 5th International Congress on Obesity. Jerusalem, Israel, 1986: 11.

17 Kissileff, H.R, Gruss, L.P, Thomton, J.L, Jordan, H.A. The satiating efficiency of foods. Physiol. Behavior, 1984, 32, 319-332.

18 Kissileff, H.R., Thornton J., Becker E. A quadratic equation adequatly describes the cumulative food intake curve in man. Appetite, 1982, 3 , $255-272$.

19 Kissileff, H.R. and Thornton J. Facilitation and inhibiton in the cumulative food intake curve in man. In: A.J. Morrison \& P. Strick (eds.). Changing concepts of the nervous system. New York: Academic Press 1982: 585-607.

20 MacCleery, R.H. On satiation curves. Animal Behaviour, 1977, 25, 1005-1015.

21 Marston, A.R., London, P., Cooper, K., Cohen, N. In vivo observation of the eating behaviour of obese and non-obese subjects. In: A. Howard (ed.). Recent advances in obesity research: I. London, Newman, 1975. 
22 Meyer, J.E., Pudel, V. Experimental studies on food intake in obese and normal weight subjects. Journal of Psychosomatic Research, $1972,16,305-308$.

23 Meyer, J.E., Pudel, V., Huszarik-Felgendreher, M. Zum Essverhalten im hoheren Lebensalter. Nervenartz, 1980,51,493-497.

24 Pierson, A. and Le Magnen, J. Etude quantitative du processus de regulation des reponses alimentaires chez l'homme. Physiology and Behavior. 1969, 4, 61-67.

25 Pudel, V., Metzdorff, M., Oetting, M. Zur Personlichkeit Adiposer in psychologischen Tests unter Berucksichtigung latent Fettsuchtiger. Z. Psychosom. Med. Psycho anal. 1975, 21, 345-361.

26 Rosenthal, B.S. and Marx R.D. Differences in eating patterns of successful and unsuccessful dieters, untreated overweight and normal weight individuals. Addictive Behaviour, 1978, 3, 129-134.

27 Stellar, E. and Shrager E.E. Chews and swallows and the microstructure of eating. Am. J. Clin. Nutr. 1985, 42, 973-982.

28 Stunkard, A.J. and Messick, S. The three-factor eating questionnaire to measure dietary restraint, disinhibition and hunger. Journal of Psychosomatic Research, 1985, 29, 71-83.

29 Westerterp, K.R., Nicolson N.A, Boots J.M.J. Mordant A. Westerterp-Plantenga M.S. Obesity, restrained eating and the cumulative intake curve. Appetite, 1988, 11, 119-128. 


\title{
Restrained Eating, Obesity, and Cumulative Food Intake Curves during Four-Course Meals
}

\author{
M.S. Westerterp-Plantenga, L. Wouters, F. ten Hoor \\ Open University, Heerlen \\ Limburg State University, Maastricht \\ The Netherlands.
}

Appetite, 1991; 16: 149-158.

\subsection{Abstract}

A four-course meal was presented to 6 obese and 18 normal weight women in which the second course was eaten ad libitum and the other three courses were fixed in amount. Eating behaviour was observed directly and intake was monitored via an electronic scale built into the table under the plate. Intake deceleration was observed in the normal weight women who scored low on the Herman-Polivy (1980) restraint questionnaire and on the cognitive restraint factor (F1) of Stunkard and Messick 's (1985) questionnaire, whereas the normal-weight and obese restrained women displayed linear cumulative food intake. In all groups, if deceleration occurred in the second course it usually was identical in the third and fourth courses, and constant eating rate persisted from second course to the later courses. Food-specific eating rates were positively correlated to relative palatability, and removed deviation from linearity over the four courses.

\section{$5.2 \quad$ Introduction}

The rate of food intake during a meal may decrease or be constant, giving a decelerated or linear cumulative intake function. The parameters of these curves could reflect underlying physiological or cognitive processes. If cumulative food intake reflects physiological processes involved in short-term control of food intake, the parameters should relate to the amount eaten during the meal. However, no significant relationship 
has yet been found between amount eaten, eating rate, or meal duration and any aspect of the curve during a single-course meal. However, deceleration and slope have been shown sensitive to palatability (Bobroff \& Kissileff, 1986), type of food eaten (Kissileff et al ., 1984) and preloads (Kissileff, 1984). Sensitivity to these meal characteristics has been taken to indicate that the cumulative food intake curve is the expression of internal regulatory mechanisms (Meyer \& Pudel, 1972; Kissileff \& Thornton, 1982), that slow down eating and eventually terminate the meal (Westerterp et al., 1990).

Nevertheless the parameters describing the shape of the cumulative food intake curve are relatively stable despite variations in many meal characteristics, and are highly consistent within individuals (Westerterp et al., 1990). This might be taken to indicate the cognitive nature of intake control, with the effect of hunger and satiety on slope and deceleration being considered as a conditioned reflex (Booth, 1981).

Some studies show a relationship between linearity or deceleration of the cumulative food intake curve and obesity or latent-obesity (Meyer \& Pudel, 1972; Bellisle \& Le Magnen, 1981; Adams et al., 1978; Rogers \& Blundell, 1979; Stunkard et al., 1980; Kaplan, 1980). Other studies show no relationship between obesity and cumulative intake parameters (Kissileff \& Kral, 1986; Westerterp et al., 1988) but rather a relationship between 'restrained eating' (Herman and Polivy, 1980; Stunkard and Messick, 1985) and the linearity or deceleration of the curve.

An interesting aspect of all this is that parameters describing the shape of the cumulative food intake curve during a single course meal, can be relatedl to subject characteristics and meal characteristics, but not to the amount eaten which might be considered as the major effect of eating the meal. Rodin (1981) argued, from a review of the literature, that amount eaten had a significant relationship with other parameters only when the subjects ate for at least 20 minutes. Thus, if the amount eaten has thus far been found to be of little significance for other aspects of the meal, one of the reasons might be that subjects do not consider a single course to be a complete meal and therefore continue eating for a limited time only. We have therefore chosen to study parameters describing the shape of the cumulative food intake curve on offering four-course meals, thus lengthening meal duration.

Also considered are the effects of succession and relative palatability of the separate courses, which this experimental design implies. The parameters of eating rate and intake in each course and over the whole meal are related to the characteristics of the foods and to the dietary restraint and body mass index of the subjects. 


\subsubsection{Subjects}

Healthy fernale subjects $(n=24)$ were recruited via the local newspaper from the general population in the south of the Netherlands as well as from university students and employees of the Limburg State University. They were divided into women who had participated in a weight reduction group, and women without self-defined weight problems.

Informed consent was obtained. Weight and height in indoor clothes, without shoes, were used to calculate body mass index $\left(B M I=\mathrm{kg} / \mathrm{m}^{2}\right.$ ). According to the criterion used by Garrow (1981) of BMI $>25$, six subjects $(25 \%)$ were classified as overweight. The remaining 18 were classified as normal weight.

\subsubsection{Procedure}

Data presented here are based on series of three lunches, which took place at the same time of day on the same day of the week in consecutive weeks. Subjects arrived one and a half hours prior to lunch and were installed alone in a respiration chamber, for other reasons. They read, listened to music, or watched television, sitting down quietly one hour before and two hours after lunch.

Eating behaviour was observed directly by the experimenter, through a door-window of the chamber, which did not disturb the subject because of a difference in light intensity. The experimenter scored the time at which each bite occurred directly into a digital computer. Intake was monitored via an electronic weighing scale built into the table under the plate and connected to the same computer. This set-up is similar to 'the universal eating monitor' developed by Kissileff et al. (1980). All subjects were aware of this procedure and were assured that all data would be kept in strict confidence. In earlier experiments, no difference in results was found between the situation in which the subjects were told a cover story and the situation in which the subjects were aware of the actual experiment (Westerterp et al., 1990).

The meals consisted of four courses, each of a different homogeneous food. Before the series of experiments started, all subjects rated the different courses of the announced meal theoretically (from 6-10) to be moderately $(=6)$ to highly $(=9)$ palatable. The four courses were: 1$)$ cucumber salad with vinegar and sugar $(75 \mathrm{~g} ; 1,4 \mathrm{~kJ} / \mathrm{g}) ; 2)$ pasta, mixed uniformly with a sauce of ground meat, tomato puree, mild red bell peppers, onions, mushrooms and oil (700 g; $\left.4.8 \mathrm{~kJ} / \mathrm{g} ; 60-62^{\circ} \mathrm{C}\right) ; 3$ ) cold cooked rhubarb with sugar (175 g; $2.9 \mathrm{~kJ} / \mathrm{g}) ; 4)$ Bulgarian yogurt $(100 \mathrm{~g}$; $3,9 \mathrm{~kJ} / \mathrm{g})$. Three courses $(1,3$ and 4$)$ were small to normal portions, so that the amount eaten was fixed. In order to eliminate the effect of their 
succession, courses 3 and 4 were randomly assigned to third and fourth in sequence. The second course consisted of an ample portion, of a size which previously had turned out to be sufficient not to limit intake. Some of course 2 was always left over.

Subjects were instructed to eat no solid food in the three hours preceding a test meal. Before the start of the meal, they were asked to record the time they had arisen that moming, time of breakfast, and the kind and amount of food and beverages consumed at breakfast. Subjects then rated their degree of hunger on a $100-\mathrm{mm}$ line. The three cold courses were available to the subject from a side table in the room. The second course, the warm course, was delivered just before the start of the meal through an air lock. Subjects were instructed to put the courses on the table in the right place, with respect to the weighing scale, to eat the courses in a certain order, and to signal the experimenter when they had finished a course. With respect to the second course, the subjects were told to eat as much as they liked and felt comfortable with. Subjects signalled when they had finished the complete meal.

Hunger ratings were then repeated and in addition subjects rated how comfortable they felt during the meal, and how much they had eaten in comparison to their normal lunch, all on $100-\mathrm{mm}$ lines. Subjects were also asked to rate the relative palatability of the different courses of the meal from $6-10(6=$ moderately palatable, $7=$ palatable, $8=$ very palatable, $9=$ highly palatable, $10=$ extremely palatable): first they had to rate course 1 , (the course which had turned out to be moderately palatable in theory, for all subjects), and secondly the courses 2,3 and 4 , in comparison to course 1 .

Before the series of lunches started, each subject filled out a Dutch translation (Westerterp et al., 1988) of the three-factor eating questionnaire (TFEQ) developed by Stunkard and Messick (1985), and of the restrained-eating questionnaire developed by Herman and Polivy (1980). The three dimensions of response to the TFEQ were labelled 'cognitive restraint' (F1), "disinhibition" (F2), and 'hunger' (F3). The score on the Herman and Polivy questionnaire was labelled ' $H-P$ '.

\subsubsection{Data analysis}

Body mass index, scores on 'cognitive restraint, 'disinhibition," 'hunger,' 'Herman-Polivy restraint,' age, were averaged over the entire group and over subgroups split according to body mass index and restraint.

Ratings of hunger, comfort and the amount subjects felt they had eaten compared to their normal lunch were averaged per subject over the three meals. Also amount eaten of the second course, total eating time, eating rate per meal and per course and relative palatability were averaged per subject over the three meals. From previous research was concluded that three repeated meals gave sufficient consistency (Westerterp et al , 1988). These means per subject, which showed very small standard deviations, 
were successively averaged over the entire group and/or over the subgroups.

The scores of bite moments and plate-weight changes synchronized on the computer yielded individual cumulative food intake curves, both separately for every course as well as continuously over the four courses. Intake rate changes reflected in the shape of the cumulative food intake curve (linear, or decelerated) were expressed by the percentage change in slope, as derived from curve-fitting. We used the quadratic equation, previously described by Kissilleff et al. (1982) as a good fit for the decelerated cumulative intake curve. By fitting the curve over $25 \%, 50 \%$, and $75 \%$, of the eating time of an ad libitum main course, cumulative food intake was linear over about the first $50 \%$ of the course duration. For this reason our curve fitting starts with a linear part of $30 \%$, and the rest of the course is fitted to a quadratic equation. We then calculated the slope of the first $30 \%$, the linear slope of the next $70 \%$, and the change in slope as a percentage of the first slope (see also Westerterp et al., 1990). Intake rate changes expressed by this percentage change in slope over the whole meal and per course were averaged per subject over the three meals. These means per subject, with very small standard deviations, were successively averaged over the entire group and over the subgroups. Intake rate changes expressed by the percentage change in slope of the curve were correlated to the subject characteristics cognitive restraint (F1), disinhibition (F2), hunger (F3), age, Herman-Polivy restraint, body mass index, and to the meal parameters amount eaten, total eating time and eating rate.

A simple regression analysis of percentage change in slope on these predictors was performed for the entire group as well as for two subgroups, split according to restraint.

\subsection{Results}

\subsubsection{Subject characteristics}

In the entire group $(n=24)$ BMI and H-P (table 5.1) were positively correlated $(\mathrm{F} 1,23=62.63$ and $\mathrm{p}<0.0001 ; \mathrm{r}=0.86)$. Also positively correlated were $F 1$ and $H-P(F 1,23=8.04$ and $p<0.009 ; r=0.51)$ and $F 1$ and age ( $F 1,23=18.06$ and $p<0.0003 ; r=0.66)$.

Within the restrained subgroup (normal weight and obese) BMI and H-P were positively correlated too ( $F 1,14=50.05$ and $p=.0001 ; r=0.88)$, but $F 1$ and $\mathrm{H}-\mathrm{P}$, or age were not correlated. Obese restrained subjects scored significantly higher than normal weight restrained subjects on H-P (two tailed Mann-Whitney U-test: $\mathrm{p}<0.05$ ). There were no obese subjects who were unrestrained in their eating since all obese subjects included in this study had recently participated in a weight reduction group. 
The scores on the TFEQ factors F2 (disinhibition) and F3 (hunger) were low, without significant differences between groups (table 5.1).

Table 5.1 Body mass index (BMI), cognitive restraint (F1), disinhibition (F2), hunger (F3), Herman-Polivy restraint (H-P), and age, of the entire group and of subgroups.

\begin{tabular}{|c|c|c|c|c|c|}
\hline & \multirow{3}{*}{$\begin{array}{l}\text { Entire } \\
\text { group }\end{array}$} & \multirow{2}{*}{\multicolumn{2}{|c|}{ Normal weight }} & \multirow{3}{*}{$\begin{array}{l}\text { Obese } \\
\text { restrained }\end{array}$} \\
\hline & & & & & \\
\hline & & & Unrestrained & Restrained & \\
\hline \multicolumn{2}{|c|}{$n$} & 24 & 9 & 9 & 6 \\
\hline \multirow[t]{2}{*}{ BMI } & Mean & 22.7 & 21.1 & 21.3 & 27.3 \\
\hline & S.D. & 3.0 & 1.0 & 1.9 & 1.4 \\
\hline \multirow[t]{2}{*}{ F1 } & Mean & 9.1 & 6.2 & 10.2 & 11.8 \\
\hline & S.D. & 4.2 & 1.8 & 4.0 & 4.9 \\
\hline \multirow[t]{2}{*}{$\mathrm{F} 2$} & Mean & 4.7 & 5.2 & 5.1 & 3.6 \\
\hline & S.D. & 2.8 & 2.6 & 3.6 & 2.2 \\
\hline \multirow[t]{2}{*}{$\mathrm{F} 3$} & Mean & 3.1 & 4.1 & 3.1 & 1.5 \\
\hline & S.D. & 2.0 & 1.9 & 2.0 & 1.2 \\
\hline \multirow[t]{2}{*}{$\mathrm{H}-\mathrm{P}$} & Mean & $\mathbb{1 5 . 7}$ & 11.2 & 15.8 & 24.2 \\
\hline & S.D. & 5.6 & 2.3 & 1.1 & 4.1 \\
\hline \multirow[t]{2}{*}{ Age } & Mean & 31.6 & 25.6 & 33.8 & 37.0 \\
\hline & S.D. & 9.8 & 7.9 & 9.7 & 9.3 \\
\hline
\end{tabular}

\subsubsection{Hunger state}

Subjects were always hungry when they arrived for the meal tests (meant $s d=94 \pm 3$ on the $100-\mathrm{mm}$ line), and always satiated after the meal (hunger ratings $7 \pm 2$ ). Subjects felt they had eaten slightly more $(16 \% \pm 9)$ than in their normal lunch but they felt comfortable ( $82 \pm 7)$. No relationship was found between change in hunger ratings from before to after the meal and amount eaten, total eating time, eating rate or eating rate changes over the whole meal.

\subsubsection{Meal parameters}

Statistically significant differences in meal parameters between groups were not found, although the normal-weight, restrained group appeared to eat less than the normal-weight unrestrained and the obese restrained groups (table 5.2). In the entire group cognitive restraint (F1) and total amount eaten were negatively correlated ( $F 1,23=8.07$ and $\mathrm{p}<0.009$; $r=0.66)$. 
The eating rates and relative palatability of each food, averaged across three meals, were positively correlated (F4,92) $=241.06$ and $\mathrm{p}<0.0001$; $r=0.85$ ). There was no correlation between eating rate and relative palatability with third or fourth courses, i.e. this effect was food specific and not succession specific. Food from a former course did not appear to inhibit further consumption. The eating rates of the second and third courses were higher than those of the previous courses, considering all subjects together.

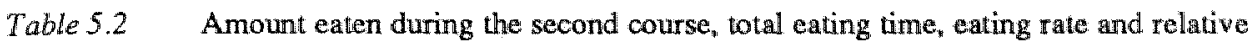
palatability, of the entire group and subgroups.

\begin{tabular}{|c|c|c|c|c|c|c|c|c|c|c|}
\hline & & & \multirow{2}{*}{\multicolumn{2}{|c|}{$\begin{array}{l}\text { Entire } \\
\text { group }\end{array}$}} & \multicolumn{4}{|c|}{ Normal weight } & \multirow{2}{*}{\multicolumn{2}{|c|}{$\begin{array}{l}\text { Obese } \\
\text { restrained }\end{array}$}} \\
\hline & & & & & \multicolumn{2}{|c|}{ Unrestrained } & \multicolumn{2}{|c|}{ Restrained } & & \\
\hline \multicolumn{2}{|r|}{$n$} & & \multicolumn{2}{|c|}{24} & \multicolumn{2}{|c|}{9} & \multicolumn{2}{|c|}{9} & \multicolumn{2}{|c|}{6} \\
\hline \multirow{2}{*}{\multicolumn{2}{|c|}{$\begin{array}{l}\text { Amount eaten during } \\
\text { 2nd course }(\mathrm{g})\end{array}$}} & Mean & \multicolumn{2}{|c|}{421} & \multicolumn{2}{|c|}{481} & \multicolumn{2}{|c|}{365} & \multicolumn{2}{|c|}{424} \\
\hline & & $S D$ & 14 & 12 & & 14 & & & & \\
\hline \multicolumn{2}{|c|}{$\begin{array}{l}\text { Totall eating } \\
\text { time(s) }\end{array}$} & $\begin{array}{l}\text { Mean } \\
S D\end{array}$ & \multicolumn{2}{|c|}{$\begin{array}{l}931 \\
154\end{array}$} & \multicolumn{2}{|c|}{$\begin{array}{r}1015 \\
157\end{array}$} & \multicolumn{2}{|c|}{$\begin{array}{l}922 \\
144\end{array}$} & \multicolumn{2}{|c|}{$\begin{array}{l}817 \\
193\end{array}$} \\
\hline \multirow{5}{*}{$\begin{array}{l}\text { Eating } \\
\text { rate } \\
\left(\mathrm{gs}^{-1} \text { and }\right. \\
\left.\mathrm{kjs}^{-1}\right)\end{array}$} & Meal & $\begin{array}{l}\text { Mean } \\
S D\end{array}$ & $\begin{array}{l}0.8 \\
0.06\end{array}$ & & $\begin{array}{l}0.8 \\
0.06\end{array}$ & & $\begin{array}{l}0.8 \\
0 \cdot 05\end{array}$ & & $\begin{array}{l}0.9 \\
0.07\end{array}$ & \\
\hline & Course 1 & $\begin{array}{l}\text { Mean } \\
S D\end{array}$ & $\begin{array}{l}0.5 \\
0.05\end{array}$ & $\begin{array}{l}0.7 \\
0.06\end{array}$ & $\begin{array}{l}0.4 \\
0.04\end{array}$ & $\begin{array}{l}0.6 \\
0.05\end{array}$ & $\begin{array}{l}0.5 \\
0.05\end{array}$ & $\begin{array}{l}0.7 \\
0.06\end{array}$ & $\begin{array}{l}0.5 \\
0.05\end{array}$ & $\begin{array}{l}0.7 \\
0.06\end{array}$ \\
\hline & Course 2 & $\begin{array}{l}\text { Mean } \\
S D\end{array}$ & $\begin{array}{l}0.9 \\
0.07\end{array}$ & $\begin{array}{l}4 \cdot 3 \\
0 \cdot 8\end{array}$ & $\begin{array}{l}0.8 \\
0.07\end{array}$ & $\begin{array}{l}3 \cdot 8 \\
0 \cdot 8\end{array}$ & $\begin{array}{l}0.7 \\
0.06\end{array}$ & $\begin{array}{l}3 \cdot 4 \\
0 \cdot 8\end{array}$ & $\begin{array}{l}1 \cdot 2 \\
0.09\end{array}$ & $\begin{array}{l}5 \cdot 8 \\
0.9\end{array}$ \\
\hline & Course 3 & $\begin{array}{l}\text { Mean } \\
S D\end{array}$ & $\begin{array}{l}1.1 \\
0.3\end{array}$ & $\begin{array}{l}3 \cdot 2 \\
0 \cdot 7\end{array}$ & $\begin{array}{l}1 \cdot 1 \\
0 \cdot 3\end{array}$ & $\begin{array}{l}3 \cdot 2 \\
0 \cdot 7\end{array}$ & $\begin{array}{l}1 \cdot 1 \\
0 \cdot 2\end{array}$ & $\begin{array}{l}3 \cdot 2 \\
0 \cdot 8\end{array}$ & $\begin{array}{l}1.0 \\
0.1\end{array}$ & $\begin{array}{l}2.9 \\
0.7\end{array}$ \\
\hline & Course 4 & $\begin{array}{l}\text { Mean } \\
\text { SD }\end{array}$ & $\begin{array}{c}0.9 \\
0 \cdot 1 \\
\left(\mathrm{gs}^{-1}\right)\end{array}$ & $\begin{array}{c}3.5 \\
0.8 \\
\left(\mathrm{~kJ}^{-1} \mathrm{~s}^{-1}\right.\end{array}$ & $\begin{array}{c}0.9 \\
0.1 \\
\left(\mathrm{gs}^{-1}\right)\end{array}$ & $\begin{array}{c}3 \cdot 5 \\
0 \cdot 8 \\
\left(\mathrm{kJs}^{-1}\right)\end{array}$ & $\begin{array}{c}0.8 \\
0.1 \\
\left(\mathrm{gs}^{-1}\right)\end{array}$ & $\begin{array}{c}3.1 \\
0.7 \\
\left.\mathrm{kJs}^{-1}\right)\end{array}$ & $\begin{array}{c}1.0 \\
0 \cdot 1 \\
\left(\mathrm{gs}^{-1}\right)\end{array}$ & $\begin{array}{c}3.9 \\
0.9 \\
\left(\mathrm{kJs}^{-1}\right)\end{array}$ \\
\hline \multirow{4}{*}{$\begin{array}{l}\text { Relative } \\
\text { palata- } \\
\text { bility }\end{array}$} & Course 1 & $\begin{array}{l}\text { Mean } \\
S D\end{array}$ & \multicolumn{2}{|c|}{$\begin{array}{l}6.1 \\
0.4\end{array}$} & \multicolumn{2}{|c|}{$\begin{array}{l}6.0 \\
0.5\end{array}$} & \multicolumn{2}{|c|}{$\begin{array}{l}6.2 \\
0.6\end{array}$} & \multicolumn{2}{|c|}{$\begin{array}{l}6 \cdot 2 \\
0 \cdot 3\end{array}$} \\
\hline & Course 2 & $\begin{array}{l}\text { Mean } \\
S D\end{array}$ & \multicolumn{2}{|c|}{$\begin{array}{l}8 \cdot 6 \\
0.3\end{array}$} & \multicolumn{2}{|c|}{$\begin{array}{l}8.7 \\
0.4\end{array}$} & \multicolumn{2}{|c|}{$\begin{array}{l}8.1 \\
0.4\end{array}$} & \multicolumn{2}{|c|}{$\begin{array}{l}89 \\
0.2\end{array}$} \\
\hline & Course 3 & $\begin{array}{l}\text { Mean } \\
S D\end{array}$ & \multicolumn{2}{|c|}{$\begin{array}{l}10 \\
0.0\end{array}$} & \multicolumn{2}{|c|}{$\begin{array}{c}10 \\
0.0\end{array}$} & \multicolumn{2}{|c|}{$\begin{array}{l}10 \\
0.0\end{array}$} & \multicolumn{2}{|c|}{$\begin{array}{l}9.9 \\
0.09\end{array}$} \\
\hline & Course 4 & $\begin{array}{l}\text { Mean } \\
S D\end{array}$ & \multicolumn{2}{|c|}{$\begin{array}{l}7 \cdot 4 \\
0.2\end{array}$} & \multicolumn{2}{|c|}{$\begin{array}{l}7.4 \\
0.3\end{array}$} & & & & \\
\hline
\end{tabular}

Course 3 always represents the rhubarb dish and course 4 the yogurt dish. Eating rates and relatiwe palatability of each food, averaged across three meals, were positively correlated, $[f(4,92)=241.06$, $p<0-0001, r=0.85]$.

\subsubsection{Intake rate}

Intake rate change over the complete meal is liable to be affected by different eating rates in the four courses and so is not analysed. The 
cumulative intake curves of the separate courses fell into two groups (fig 1), namely those with a change in slope from first $30 \%$ to second $70 \%$ of each course of only $\pm 10 \%$, indicating a linear function and those with a decrease in slope by more than $10 \%$, indicating a decelerated curve (fig. $2 \mathrm{a}$ and $2 \mathrm{~b})$.
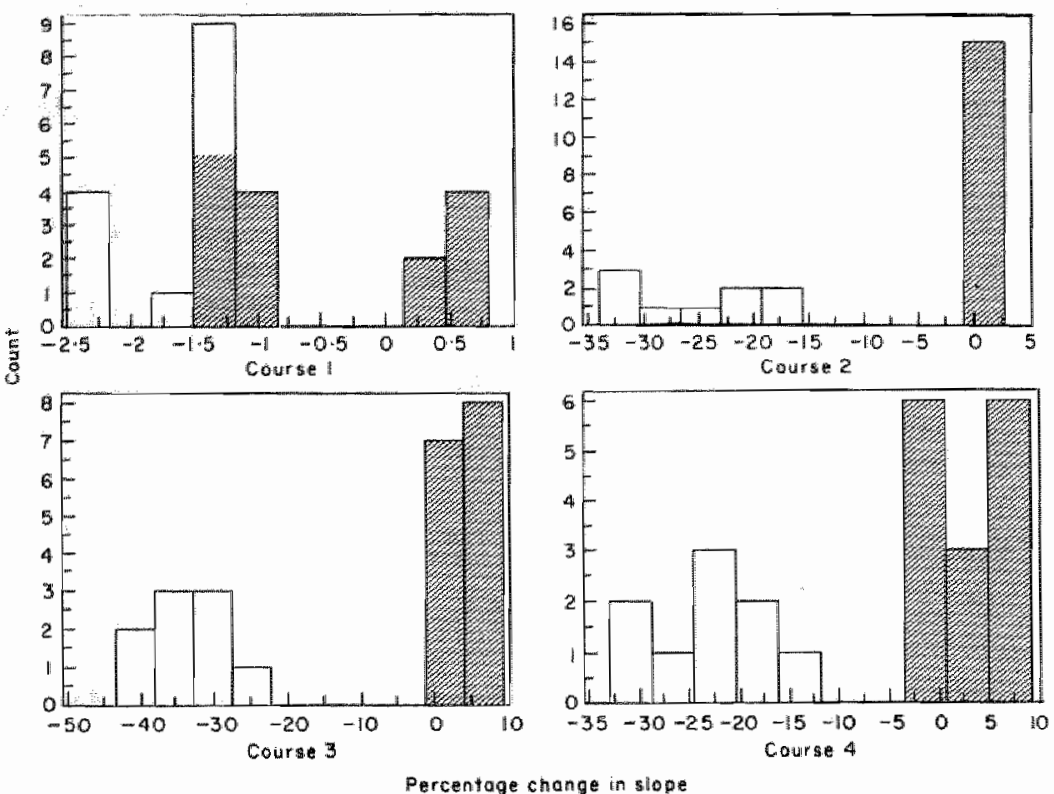

Figure 5.1 Frequency distribution of subjects' mean percentage change in slope of cumulative intake curves of the four courses of the meals. Restrained subjects are shown in the shaded areas.

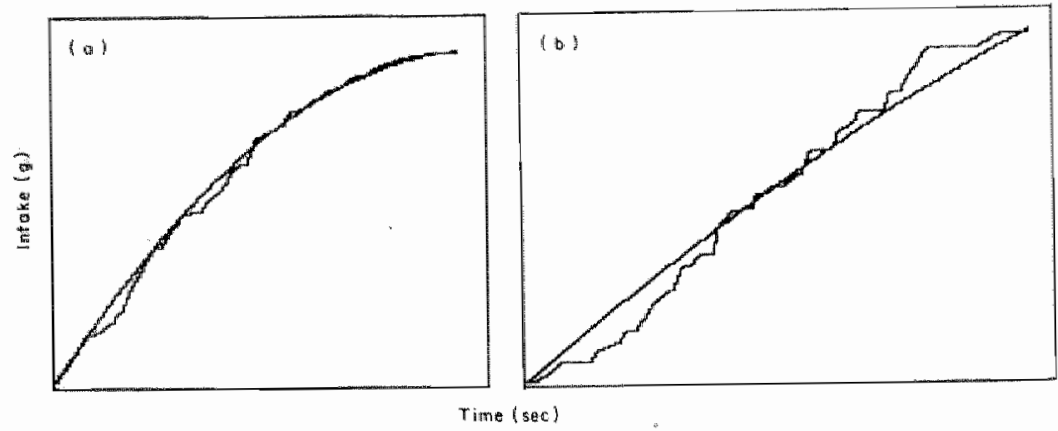

Figure 5.2 (a) Example of fitting of a decelerated curve (change in slope: $-89 \%$ ).

(b) Example of fitting in linear function (change in slope: $+2.90 \%$ ). 
The percentage changes in slope of the curves of the second course were positively correlated with the percentage changes in slope of those of the third and fourth courses ( $F 1,23=33.07$ and $p<0.0001 ; r=0.77$; $\mathrm{F} 1,23=51.49$ and $\mathrm{p}<0,0001 ; \mathrm{r}=0.84)$.

Considering the four successive courses of the meal, the cumulative food intake curves reflect succession and relative palatability. The first course was linear due to the small portions and being the first course similar to eating the first $75 \mathrm{~g}$ of an ad libitum meal or course. In previous experiments eating rate during the first temporal half of an ad libitum meal was found to be constant (Westerterp et al., 1990).

Linearity or deceleration in the curves of the third and fourth courses was similar to this aspect of the curve of the second course.

Table 5.3 Percentage change in slope of the cumulative food intake curves measured ower whole meal and per course, for the entire group and for the subgroups.

\begin{tabular}{|c|c|c|c|c|c|}
\hline & & \multirow{3}{*}{$\begin{array}{l}\overline{\text { Entire }} \\
\text { group }\end{array}$} & \multirow{2}{*}{\multicolumn{2}{|c|}{ Normal weight }} & \multirow{3}{*}{$\begin{array}{l}\text { Obese } \\
\text { restrained }\end{array}$} \\
\hline & & & & & \\
\hline & & & Unrestrained & Restrained & \\
\hline \multirow[t]{2}{*}{ Whole meal (g) } & Mean & 1 & -1 & 5 & 1 \\
\hline & S.D. & 0.5 & 0.6 & 1 & 0.4 \\
\hline \multirow[t]{2}{*}{ Whole meal $(\mathrm{kJ})$} & Mean & 1 & -0.5 & 6 & 1 \\
\hline & S.D. & 0.2 & 0.3 & 0.9 & 0.1 \\
\hline \multirow[t]{2}{*}{ Course 1} & Mean & -1 & -1.8 & -1.2 & 0.5 \\
\hline & S.D. & 0.4 & 0.7 & 0.3 & 0.2 \\
\hline \multirow[t]{2}{*}{ Course 2} & Mean & -9 & -26 & 1 & -0.05 \\
\hline & S.D. & 2.1 & 8 & 0.6 & 0.2 \\
\hline \multirow[t]{2}{*}{ Course 3} & Mean & -14 & -34 & 5 & 0 \\
\hline & S.D. & 3.8 & 9.4 & 2.2 & 0.7 \\
\hline \multirow[t]{2}{*}{ Course 4} & Mean & -15 & -24 & 6 & -0.6 \\
\hline & S.D. & 4.2 & 8.9 & 3.2 & 0.4 \\
\hline
\end{tabular}

5.4.5 Relationship of Intake Rate Changes with Subject Characteristics and Meal Parameters.

No significant correlations were found between change in slope during the ad lib course, and F2, F3, amount eaten, eating time or eating rate. As $\mathrm{F} 1$ and H-P, H-P and $\mathrm{BMI}$, and F1 and age were correlated a multiple regression analysis for the remaining predictors was impossible. Therefore a simple regression analysis was performed and showed correlations between intake rate changes and cognitive restraint, HermanPolivy restraint, body mass index, and age (table 5.4). 
Toble 5.4 Correlations between intake rate changes expressed as percentage change in slope, and cognituve restrant (F1), Heman-Polivy restraint, Body Mass Index and age, for the entire group and for the subgroups who were restrained dietaries.

\begin{tabular}{|c|c|c|c|c|c|c|}
\hline & \multicolumn{3}{|c|}{ Entire group } & \multicolumn{3}{|c|}{ Restrained } \\
\hline & $F(1,23)$ & $p<$ & $r$ & $F(1,14)$ & $p<$ & $r$ \\
\hline $\mathrm{Fl}$ & 152 & 0.0007 & -0.63 & 6.2 & 0.03 & -0.55 \\
\hline $\mathrm{HP}$ & 15.9 & 0.0006 & -0.64 & 4.9 & 0.04 & -0.51 \\
\hline BMI & 8.3 & 0.008 & -0.52 & & ns. & \\
\hline Age: & 8.6 & 0.007 & -0.52 & & ns. & \\
\hline
\end{tabular}

In the entire group, a negative relationship between change in slope and cognitive restraint (F1), and also Herman-Polivy restraint indicates that restrained subjects have linear cumulative intakes and unrestrained subjects are decelerated eaters. This is illustrated by the distribution in Fig. 1 and was also found by Westerterp et al. (1988). A negative relationship between change in slope and BMI suggests that obese subjects have linear cumulative intakes and normal weight subjects are decelerated eaters, but as BMI and H-P are correlated the main factor cannot be distinguished. Similar results concerning the relationship between body mass index and shape of the curve were found by Meyer \& Pudel (1972,1977), Bellisle \& LeMagnen (1981), Adams et al. (1978), Rogers \& Blundell (1979), Stunkard et al. (1980), and Kaplan (1980).

Within the restrained group, the negative relationships between change in slope and cognitive restraint, and also Herman-Polivy restraint indicate that the more restrained eating behaviour is, the more linear the cumulative food intake curves are. In this group, there is no relationship bewween change in slope and $\mathrm{BMI}$.

\subsection{Discussion}

Although there was a higher eating rate with a higher palatability, the change in eating rate during a course did not differ with palatability. Simillarly, Spiegel et al. (1989), Bobroff \& Kissileff, (1986), and Kissileff et al. (1984) also found that, when palatability was decreased, the linear coefficient of the curve was reduced, but the quadratic coefficient was not affected.

Food from an earlier course did not appear to inhibit further consumption. Further consumption was stimulated by a relatively high palatability, as was found previously by Rolls et al. (1981). Kissileff (1988) suggested considering a two course meal as a special case of a one course meal with a small interval, leaving open the possibility that a prior course could have both excitatory and imhibitory influences on a subsequent one. In this study we found a higher eating rate at the start of the second and third course, than during the previous course, and in an earlier study we found during Four-Course Meals 
a higher eating rate immediately after an interval within a one course meal (Westerterp et al, 1990).

The positive relationship between body mass index and Herman-Polivy restraint, and the negative relationship between amount eaten and cognitive restraint (F1), in the entire group, show that the Herman-Polivy restraint scale does relate to body weight, whereas the TFEQ by Stunkard \& Messick is related to food intake. This is also confirmed by the lack of a relationship between $\mathrm{F} 1$ and $\mathrm{H}-\mathrm{P}$ in the restrained group. Normal weight restrained women seem to be primarily food-concerned, and consequently successfully weight concerned. Thus, a subject does not necessarily have to score high on Herman-Polivy restraint if weight has been kept at a certain level preferred by the subject for a relatively long time. These subjects seem to have adopted a successful strategy in relating appetite to food intake. The obese restrained women were primarily weightconcerned, and because of their weight-reduction programme, had to be food-concerned. Obviously they scored high on Herman-Polivy restraint, but, because of they have had only limited success in weight reduction, they did not necessarily have to score high on cognitive restraint.

Age showed a positive association with restraint, and a negative association with intake -rate change. Similarly, previous research had indicated that increasing age was associated with more linear intake curves, at least in subjects older than 65 years (Meyer et al., 1980).

Finally, no relationship was found in any group between the subject's eating style and the amount of food eaten. The longer meal duration (20 minutes, compared to 9 minutes in Westerterp et al., 1990) achieved by offering a four-course meal instead of a single course meal, failed to elucidate this aspect of the cumulative food intake curve.

In summary then, cumulative food intake curves derived from ad libitum consumed meal-courses reflect a subjects' eating style independent of the amount of food consumed. In this study no aspects of the cumulative food intake curve appeared to be sensitive to the amount eaten.

The curves seem to reflect longterm, stabilized responses to learning about physiological and cognitive aspects of food (see also Westerterp et al, 1990). They do not seem to reflect immediate regulation or control of meal size.

\section{Acknowledgements}

We wish to thank Dr. H. R. Kissileff for helpful comments on the manuscript.

\subsection{References}

Adams, N., Ferguson, J., Stunkard, A. \& Agras, S. (1978). The eating behaviour of obese and non-obese women. Behavioural Research and Therapy, 16, 225-232. 
Bellisle, F. \& Le Magnen, J. (1981). The structure of meals in humans: eating and drinking patterns in lean and obese subjects. Physiology and Behavior, $4,27,649-658$.

Bobrof, E.M. \& Kissileff, H.R. (1986). Effects of changes in palatability on food intake and the cumulative food intake curve in man. Appetite, $7,85-96$.

Booth, D.A. (1981). Hunger and satiety as conditioned reflexes. In H. Weiner, M.A. Hofer, and A.J. Stunkard (eds) Brain, behavior, and bodily disease. New York: Raven Press.

Garrow, J.S. (1981). Treat obesity seriously: a clinical manual. Edinburgh: Churchill Livingstone .

Herman, C.P. \& Polivy, J. (1980) . Restrained eating. In A. Stunkard (ed.), Obesity. Pp 208 - 224. Philadelphia: W.B. Saunders.

Kaplan, D.L. (1980) Eating styles of obese and non-obese males. Psychosomatic Medicine, 42, 529-538.

Kissileff, H.R., Klingsberg, G. \& Itallie, T.B. van (1980) . Universal eating monitor for continuous recording of solid or liquid consumption in man. American Journal of Physiology 238, 14-22.

Kissileff, H.R. \& Kral, J.S. (1986). Abnormal eating behaviour in morbidly obese men and women. In Abstracts 5th International Congress on Obesity. Pp 11, Jerusalem, Israel .

Kissileff, H.R, Gruss, L.P., Thornton, J.L., \& Jordan, H.A. (1984). The satiating efficiency of foods. Physiology and Behaviour. 32, 319-332.

Kissileff, H.R., Thornton J.L. \& Becker E. (1982). A quadratic equation adequately describes the cumulative food intake curve in man. Appetite, 3, 255-272.

Kissileff, H.R. \& Thornton J. (1982). Facilitation and inhibiton in the cumulative food intake curve in man. In A.J. Morrison \& P. Strick (eds.). Changing concepts of the nervous system. Pp. 585-607, New York: Academic Press .

Kissileff, H.R. (1988) . Satiety efficiency and the satieties. Appelite, 11, 48-52.

Meyer, J.E. \& Pudel V. (1972). Experimental studies on food intake in obese and normal weight subjects. Journal of Psychosomatic Research, 16, 305-308.

Meyer, J.E.Pudel, V. \& Huszarik-Felgendreher, M. (1980). Zum Essverhalten im hoheren Lebensalter. Nervenartz, 51, 493-497.

Rodin, J. (1981) . Social and environmental determinants of eating behaviour. In:L.A. Cioffi et al, eds. The body weight regulatory system: Normal and disturbed mechanisms. New York: Raven Press.

Rogers, P.J. \& Blundell, J.E. (1979). Effect of anorexic drugs on food intake and the microstructure of eating in human subjects. Psychopharmacology, 66, 159-165.

Rolls, B.J., Rolls, E.T, Rowe, E.A. \& Sweeney, K. (1981). Sensory specific satiety in man. Physiology and Behavior, 27, 137-142. during Four-Course Meals 
Spiegel, T.A., Shrager, E.E. \& Stellar, E. (1989). Responses of lean and obese subjects to preloads, deprivation and palatability. Appetite, 13, 45-69.

Stunkard, A.J. \& Messick, S. (1985). The three-factor eating questionnaire to measure dietary restraint, disinhibition, and hunger. Journal of Psychosomatic Research, 29, 71-83.

Stunkard, A., Coll, M., Lundquist, S. \& Meyers, A. (1980) Obesity and eating style. Archives of General Psychiatry, 37, 1127-1129.

Westerterp, K.R., Nicolson, N.A., Boots, J.M.J., Mordant, A.,\& Westerterp-Plantenga, M.S. (1988) Obesity, restrained eating and the cumulative intake curve. Appetite, 11, 119-128.

Westerterp-Plantenga, M.S., Westerterp, K.R., Nicolson, N.A., Mordant, A., Schoffelen, P.F.M., \& ten Hoor, F. (1990). The shape of the cumulative food intake curve in humans during basic and manipulated meals. Physiology and Behavior, 47, 569-576. 
- 


\title{
Deceleration in Cumulative Food Intake Curves, Changes in Body- Temperature and Diet-Induced Thermogenesis
}

\author{
M.S. Westerterp-Plantenga, L. Wouters, F. ten Hoor
}

Open University, Heerlen

State University of Limburg, Maastricht

The Netherlands.

Physiology and Behavior, 1990; $48(6): 831-836$.

\subsection{Abstract}

WESTERTERP-PLANTENGA, M. S., L. WOUTERS AND F. TEN HOOR. Deceleration in cumulative food intake curves, changes in body temperature and postprandial thermogenesis. PHYSIOL BEHAV 48 (6) $831-836,1990$. -In order to assess the relationship between the shape of the cumulative food intake curve and a reflection of internal processes, eating behaviour, postprandial thermogenesis, and skin and core temperature of normal weight restrained and unrestrained eating women and of obese restrained eating women were recorded during four-course solid food lunches, eaten in a laboratory setting (respiration chamber) at a constant ambient temperature of $22^{\circ} \mathrm{C}$. The skin temperature (upper arm, upper leg, liver proximity) and core temperature were measured constantly from one hour prior to untill two hours after the lunch. Normal weight unrestrained eaters displayed decelerated cumulative food intake curves and an increase in the liver temperature data of $0,8-1,5^{\circ} \mathrm{C}$, from the beginning of the meal onwards, remaining high until $60-90$ minutes after the meal was consumed. The postprandial thermogenesis of normal weight unrestrained eaters was on average $8,1 \pm 1,3 \%$, callculated over two and a half hour from the beginning of the meal. Overweight and normal weight restrained eaters displayed linear cumulative food intake curves, almost no changes in skin and core temperatures and a postprandial thermogenesis of $4,2 \pm 0,3 \%$ and $4,8 \pm 0,7 \%$, calculated over two and a half hours from the beginning of the meal onwards. In conclusion, deceleration in cumulative food intake curves is positively correlated with 
a temperature increase in the skin in the proximity of the liver, and with postprandial thermogenesis.

\subsection{Introduction}

Food intake in humans is affected by physiological and non-physiological factors. Physiological control of food intake in animals is inferred from observations on the relative consistency in daily or weekly food intake, maintained on a diet of homogeneous composition under constant ambient temperature. This physiological control system would correct deviations in daily energy balance in order to maintain long-term energy balance $(1,9,23,40,44,59,61)$. The existence of a physiological control of food/ energy intake in humans was inferred from the observation that body weight remains relatively constant for longer periods of time in spite of environmental stimuli (56). Sometimes control of food intake in animals and in humans can be overruled by environmental stimuli $(9,18)$. Nevertheless many data are available that food intake is under physiological control $(7-9,17,35,44-46,56,58,59,61,62,64)$.

One theory to explain the physiological control is the thermostatic theory, an integration of the lipostatic, glucostatic, and aminostatic theory. The thermostatic theory considers metabolic heat production as a control of food intake (8). The thermostatic theory has been further refined in the energostatic theory (7), which states that the energy produced by the metabolism of absorbed nutrients is monitored to regulate food intake. Specific temperature receptors in the brain would activate and terminate ingestive behaviour. Major sites for homeostatic control of food intake are the hypothalamic tracts, the liver, and the gastro-intestinal tract $(19,21,41$, $42,48,52,58$ ). Thus control of food intake may consist of a feedback system in which various signals derived from the gastro-intestinal tract, liver, circulating energy, i.e. nutrient pool, depot fat or metabolizing cells, transmit information to the brain, which is responding to and integrating information from the various peripheral components (64). The brain also responds to and integrates external information.

In humans a variety of non-physiological factors may act on the brain to terminate or initiate feeding (17), so that the question may rise whether food intake in humans is still under physiological control or whether it is largely determined by exogenous factors.

Food intake behaviour during a meal is reflected in cumulative food intake curves, the shape of which may reflect short term regulation mechanisms. The shape of a decelerated cumulative food intake curve appears to depend on internal processes such as hunger and satiation; the shape of a linear cumulative food intake curve reflects primarily a cognitive eating style: the subjects seem to decide consciously and abruptly when to stop eating (65). Thus cumulative food intake curves may bo used as an instrument to study eating behaviour in relation to the relative contribution of physiological factors to the control of food intake 
during a meal. Two of these physiological factors, which, according to the thermostatic theory, are important feedback signals: diet-induced thermogenesis and body-temperature, can easily be measured in humans during and after a meal The measurement of other physiological factors in blood and in the gastro-intestinal tract might be very interesting but will influence eating behaviour to a large extent.

Diet-induced thermogenesis is the acute effect of food ingestion on resting metabolic rate, which in the average individual accounts for about $10-15$ percent of total daily energy expenditure $(57,67)$. The primary determinants of diet-induced thermogenesis are the level of energy intake and the nutrient composition of food: with increasing energy intake and proportionally increasing protein and/or carbohydrate contents, dietinduced thermogenesis increases $(2,27,37,47,54)$. Diet-induced thermogenesis is linearly related to energy intake, but consists of two distinct components: the obligatory component, involved in the postprandial metabolism of the nutrients $(27,57,67)$ and the facultative component, i.e. increased sympathetic nervous system activity. Several factors may determine this facultative component, for instance subject characteristics like degree of obesity (30), responses to food like overfeeding (57), and sensory characteristics of food $(6,22,24,26$, $33,38,50,54)$.

In order to assess a possible relationship between eating behaviour on the one hand and a reflection of internal processes and subject characteristics on the other hand, cumulative food intake curves, diet-induced thermogenesis and skin and core temperature of normal weight restrained and unrestrained eating women and of obese restrained eating women were recorded during four course solid food lunches, eaten in a laboratory setting (respiration chamber), at a constant ambient temperature.

\subsection{Method}

Healthy female subjects $(n=24)$ were recruited from several sources. They included university students and employees, women with selfdefined weight problems having participated in a weight reduction group, and women without self-defined weight problems.

For each subject, weight and height, measured in indoor clothes, without shoes, were used to calculate body mass index (BMI $=\mathrm{kg} / \mathrm{m}^{2}$ ). According to the criteria BMI $>25$ used by Garrow (20), 6 subjects (25\%) were classified as overweight and 18 as normal weight.

Data presented are based on series of 3 lunches in each subject, which took place at the same time of day on the same day of the week in 3 consecutive weeks. Subjects arrived one and a half hours prior to lunch and were installed alone in a respiration chamber, in order to measure energy expenditure. They read, listened to music, or watched television, sitting down quietly one hour before and two hours after lunch. The two similar respiration chambers are open-circuit chambers with a volume of 
$14 \mathrm{~m}^{3}$ equipped with bed, wilet, $\mathrm{t} v$, telephone, chair and table. The volume of air drawn from the chambers was measured by a dry gasmeter. Samples of in-and outgoing air were continuously analysed by a paramagnetic $\mathrm{O}_{2}$-analyser (Servomex Taylor, England) and an infrared $\mathrm{CO}_{2}$-analyser (Hartmann and Braun, West Germany). The airflow rate, $\mathrm{O}_{2}$ and $\mathrm{CO}_{2}$-concentration of the outflowing air were computed on line through an automatic acquisition system interfaced with an Apple 2E computer (53). $\mathrm{VO}_{2}, \mathrm{VCO}_{2}$, and $\mathrm{RQ}$ were calculated. Energy expenditure was calculated using the equation of Brouwer (10). Metabolic rate (MR) was calculated from values taken during the period when subjects sat down quietly one hour before the start of the meal. Diet-induced thermogenesis (DIT) was calculated from values taken during two and a half hours from the start of the meal, and expressed as a percentage of total energy ingested during the meal.

Skin temperature (upper arm, upper leg, liver proximity) and core temperature (tympanic membrane) were measured constantly from one hour prior until two hours after the lunch. These sites for measuring core and skin temperature have been chosen in a uniform way according to the literature in order to be able to compare the data $(3,4,11-16,32,51)$. The proximity of the liver has been chosen according to Berry et al (5) and $\mathrm{Ma}$ et al (43). Berry et al(5) found evidence for thermogenic processes in hepatic tissue, i.e. the enhancement of specific calorigenic metabolic processes within the liver contributed significantly to the heat production of diet induced thermogenesis and provided evidence as to the nature of those thermogenic processes. Ma et al found that about $70 \%$ of postprandial elevated VO2 of cafetaria-fed rats resided in the liver and thus points to the liver as the major effector of the diet-induced thermogenesis in these rats.

Eating behaviour was observed directly by the experimenter, through a door-window of the chamber. Due to differences in light intensity the subject was not disturbed by the experimenter, who was scoring bite moments straightforward into a digital computer. Rate of intake was monitored via an electronic balance built into the table under the plate and connected to the same digital computer, similar to 'the universal eating monitor' developed by Kissileff et al (36). All subjects knew what was happening and were assured that data would be kept in strict confidence. The meals consisted of four courses of a different homogeneous food, rated as moderately to highly palatable by all participants. The courses consisted of: 1 . cucumber salad with vinegar and sugar $(75 \mathrm{~g} ; 1,4 \mathrm{~kJ} / \mathrm{g}), 2$. pasta, mixed uniformly with a sauce of ground meat, tomato puree, mild red bell peppers, onions, mushrooms, oil $\left(700 \mathrm{~g} ; 4.8 \mathrm{~kJ} / \mathrm{g} ; 60-62^{\circ} \mathrm{C}\right), 3$. cold cooked rhubarb with sugar $(175 \mathrm{~g} ; 2.9 \mathrm{~kJ} / \mathrm{g}$ ) and 4 . Bulgarian yogurt $(100 \mathrm{~g} ; 3,9 \mathrm{~kJ} / \mathrm{g}$ ). Three courses consisted of small to normal portions each, so that the amount eaten was fixed and as an independent variable under experimental control. The second course consisted of an ample portion, which previously had turned out to be considered as an ad libitum portion. 
Subjects were instructed to eat no solid food in the three hours preceding the test meal. Upon arrival, they were asked to record the time they got up that morning, time of breakfast, and kind and amount of food and beverages consumed at breakfast. Subjects then rated their degree of hunger on a $100 \mathrm{~mm}$ line. Subjects signalled when they had finished the complete meal. Hunger ratings were then repeated and, in addition subjects rated the relative palatability of the different courses of the meal, how comfortable they felt during the meal, and how much they had eaten in comparison to their normal lunch. Each subject filled out a Dutch translation (65) of the three-factor eating questionnaire (TFEQ) (63), and of the restrained-eating scale (25). The three dimensions of response were labelled "cognitive restraint" ( $F_{1}$ : "sensible eating', being aware of the quality and energy-density of the food and hence of the quantity of the food to ingest), "disinhibition' ( $F_{2}$ : 'emotional lability", with a tendency towards disinhibition influenced by different circumstances), and 'hunger' ( $\mathrm{F}_{3}$ : 'perceived hunger', caused by chronically dieting). The response on the restraint eating scale was labelled 'H-P'.

\subsection{Data analysis}

Bite moments were scored directly on the same digital computer to which the electronic balance built into the table was connected. These synchronized scores of bite moments and plate-weight changes yielded individual cumulative food intake curves, separately for every course as well as continuously over four courses. Diet-induced thermogenesis appeared as an increase in metabolic rate from the start of the meal onwards until two and a half hours later, compared to metabolic rate one hour prior to the meal. This increase in metabolic rate was expressed as a percentage of the energy intake during the meal \pm SEM. Changes in body temperature appeared as a continuous increased body temperature from base line, omitting fluctuations.

\subsection{Results}

\subsubsection{Subject characteristics}

Subject characteristics are summarized in table 1. The characteristics are given for the entire group and are also split according to body mass index and restraint. The criteria for normal weight unrestraint are $B M 1<25$; $\mathrm{F}_{1}<9$ and $\mathrm{H}-\mathrm{P}<15$. The criteria for cognitive restraint and restraint according to Herman-Polivy are based on the median, being $F_{1}=9$ for cognitive restraint, $\mathrm{H}-\mathrm{P}=15$ for restraint according to Herman \& Polivy (see also 25). The criteria for normal weight restraint are $\mathrm{BMI}<25 ; \mathrm{F}_{\mathrm{p}}>9$ or $\mathrm{H}-\mathrm{P}>15$. The normal weight restrained eating women never have been 
obese. The criteria for obese restraint are $B M 1>25, F_{1}>9$ or $H-P>15$. There were no obese unrestrained eating subjects since all obese subjects included in this study had participated in a weight reduction group recently. Because of still being overweight and trying not to put on weight, the obese subjects were restrained eating women, scoring high on the Herman-Polivy restraint scale.

In the entire group BMI and H-P were positively correlated $\left(r^{2}=0.73\right.$; p<0.01).

Based on these criteria, restrained subjects scored, as was expected, higher than unrestrained subjects on $F_{1}$ and $H-P$. These differences were both significant (two tailed Mann-Whitney U-test: $F_{1}, p<0.05$; H-P, $\mathrm{p}<0.05$ ). Obese restrained subjects scored significantly higher than normal weight restrained subjects on H-P (two tailed Mann-Whitney Utest: $p<0.05$ ). The scores on $F_{2}$ (disinhibition) and $F_{3}$ (hunger) were low, without significant differences between groups.

Table 6.1 Subject characteristics

\begin{tabular}{|c|c|c|c|c|c|}
\hline & & \multirow[b]{2}{*}{$\begin{array}{l}\text { Entire } \\
\text { group }\end{array}$} & \multicolumn{2}{|c|}{ Normal weight } & \multirow[b]{2}{*}{$\begin{array}{l}\text { Obese } \\
\text { restrained }\end{array}$} \\
\hline & & & Unrestrained & Restrained & \\
\hline \multicolumn{2}{|c|}{$n$} & 24 & 9 & 9 & 6 \\
\hline \multirow[t]{2}{*}{ BMI } & Mean & 22.7 & 21.1 & 21.3 & 27.3 \\
\hline & S.D. & 3.0 & 1.0 & 1.9 & 1.4 \\
\hline \multirow[t]{2}{*}{ F1 } & Mean & 9.1 & 6.2 & 10.2 & 11.8 \\
\hline & S.D. & 4.2 & 1.8 & 4.0 & 4.9 \\
\hline \multirow[t]{2}{*}{$\mathrm{F} 2$} & Mean & 4.7 & 5.2 & 5.1 & 3.6 \\
\hline & S.D. & 2.8 & 2.6 & 3.6 & 2.2 \\
\hline \multirow[t]{2}{*}{ F3 } & Mean & 3.1 & 4.1 & 3.1 & 1.5 \\
\hline & S.D. & 2.0 & 1.9 & 2.0 & 1.2 \\
\hline \multirow[t]{2}{*}{$\mathrm{H}-\mathrm{P}$} & Mean & 15.7 & 11.2 & 15.8 & 24.2 \\
\hline & S.D. & 5.6 & 2.3 & 1.1 & 4.1 \\
\hline \multirow[t]{2}{*}{ Age } & Mèn & 31.6 & 25.6 & 33.8 & 37.0 \\
\hline & S.D. & 9.8 & 7.9 & 9.7 & 9.3 \\
\hline
\end{tabular}

\subsubsection{Meal characteristics}

Based on the mean values for each of the 24 subjects, average meal duration for the entire group was $19.3 \pm 3.6 \mathrm{~min}$, and average total intake was $726 \pm 187 \mathrm{~g}$, being $305 \pm 45 \mathrm{~g}$ for course 1,3 and 4 , and $421 \pm 142 \mathrm{~g}$ for course 2 . 
Changes in eating rate over a meal were characterized by comparing the amount eaten in the first half of the meal's duration with the amount eaten during the second temporal half. The "meal index" $\left(\mathbb{I}_{\mathrm{m}}\right)$ is defined as": $I_{m}=$ (consumption in first half - consumption in second half)/total consumption. Meals in which $\mathrm{I}_{\mathrm{m}}>0.1$ (that is, those in which at least $55 \%$ of the total intake occurred in the first half) were classified as decelerated: meals in which $I_{m}<0.1$ were classified as non-decelerated or linear.(65).

As $I_{m}$ does not reflect intake rate changes within two different temporal halves it is supported by curve-fitting (66).

The meal-index $\mathrm{I}_{\mathrm{m} 2}$ of the second course is used as a meal-characteristic for further analysis, as there appears to be a strong correlation between $I_{m 2}$ and $I_{m 3}, I_{m 4}$, (the meal-indices of the third and fourth courses) respectively, $(r=0.96 ; r=0.93 \mathrm{p}<0.001)$ and because $\mathrm{I}_{\mathrm{m} 2}$ is obtained from an ad libitum portion offered.

\subsubsection{Relationships between subject-and meal characteristics}

The relationship between subject and meal characteristics is inferred from the statistically negative correlations between $\mathrm{I}_{\mathrm{m} 2}$ and $\mathrm{H}-\mathrm{P}(\mathrm{r}=0.64 \mathrm{p}<.05)$ and $\mathrm{I}_{\mathrm{m} 2}$ and $\mathrm{F}_{1}(\mathrm{r}=0.63 \mathrm{p}<.05)$. Apparently unrestrained eating subjects show decelerated cumulative food intake curves, while restrained eating subjects showed non-decelerated (or linear) cumulative food intake curves.

\subsubsection{Changes in body temperature}

Skin temperature of upper arm and upper leg and the core temperature showed hardly any change during and after the meal. Some subjects, however, showed an increase in the skintemperature in the proximity of the liver of $0.8-1.5^{\circ} \mathrm{C}$, remaining high until $60-90$ mintues after the meal was consumed (Fig. 1 and 2). A negative correlation was found between a change in skintemperature in the proximity of the liver and $F_{1}(r=0.75$ $\mathrm{p}<0.05$ ) and a positive correlation between this change in skintemperature in the proximity of the liver and $\mathrm{I}_{\mathrm{m} 2}(\mathrm{r}=0.78 \mathrm{p}<0.05)$. 


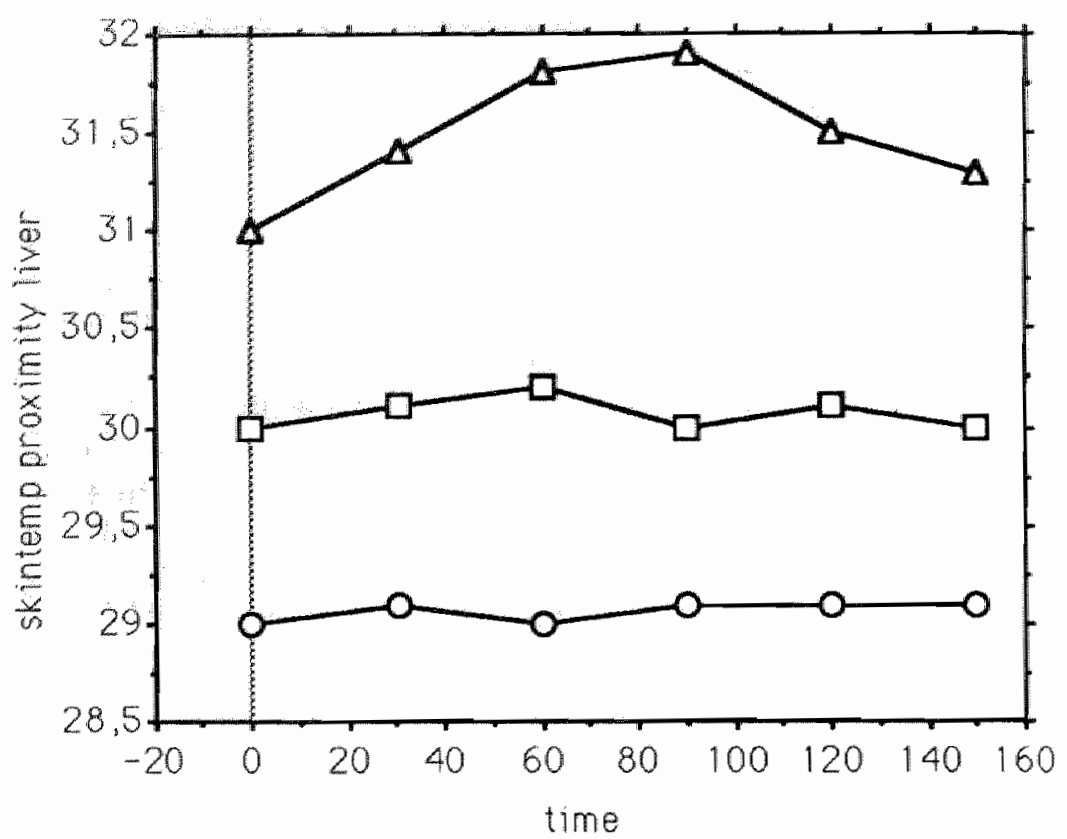

Figure 6.1 Skintemperature in the proximity of the liver. Time zero is the start of the meal. $O=$ Overweight restraint, $\square=$ normal weight restraint, $\Delta=$ normal weight unrestraint.

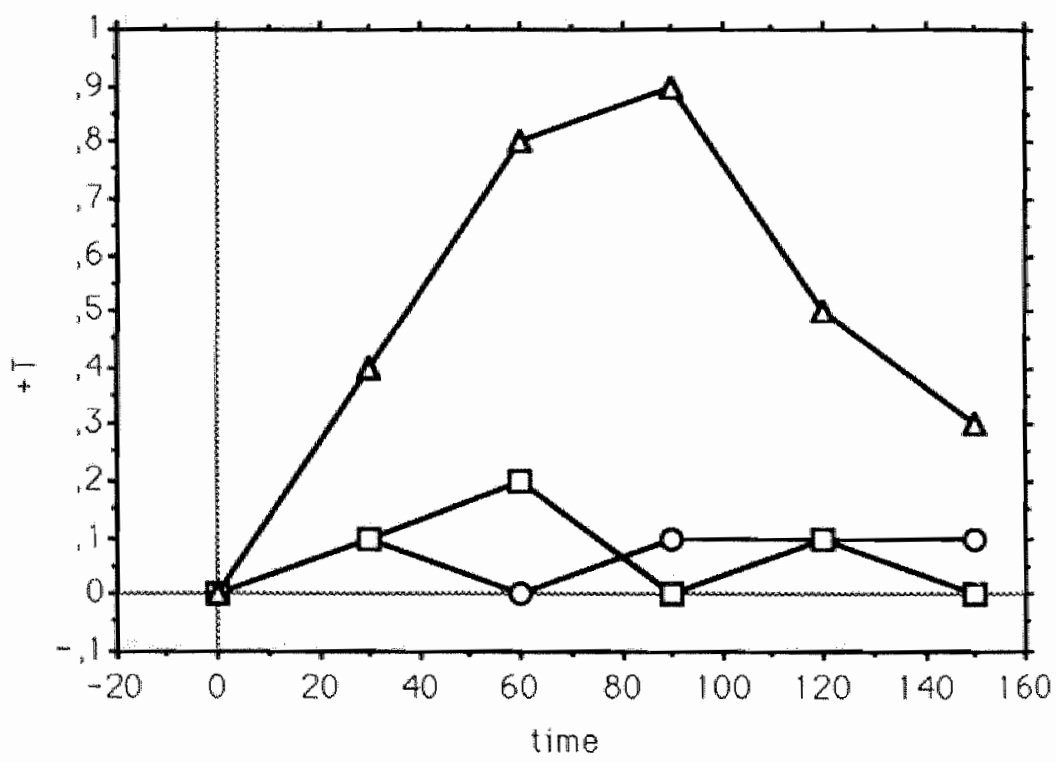

Figure 6.2 Increase in skin temperature in the proximity of the liver. Time zero is the start of the meal. $\mathrm{O}=$ Overweight restraint, $\square=$ normal weight restraint, $\Delta=$ normal weight unrestraint. 
In a stepwise regression of $\mathbb{I}_{\mathrm{m} 2}$ and $\mathrm{F}_{1}$ onto $+\mathrm{T}$ (the increase in skintemperature in the proximity of the liver), $67 \%$ of the variation in $+\mathrm{T}$ is explained; $55 \%$ is explained by $I_{\mathrm{m} 2}$ (table 6.2 ).

Table 6.2 Pearson correlation coefficients ( $\mathrm{r}$ ) and partial beta values from multiple regression of $\operatorname{Im} 2$ and $\mathrm{F} 1$ onto $+\mathrm{T}$.

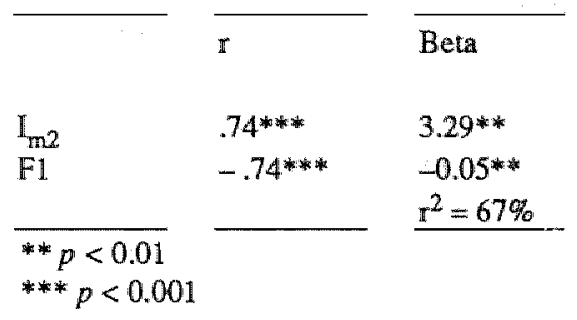

6.5.5 Diet-induced thermogenesis, changes in body temperature, subject-and meal characteristics

Metabolic rate during one hour prior to the meal was on average $5.11 \pm 0.42 \mathrm{~kJ} / \mathrm{min}$, range $4.25 \mathrm{~kJ} / \mathrm{min}-5.76 \mathrm{~kJ} / \mathrm{min}$, with no significant differences between the subject groups. Increase in metabolic rate from the beginning of the meal onwards until two and half hours later was on average $5.9 \pm 3.6 \%$ in the entire group. This increase in metabolic rate was on average $8.1 \pm 1.3 \%$, in normal weight unrestrained eaters; $4.8 \pm$ $0.7 \%$, in normal weight restrained eaters; $4.2 \pm 0.3 \%$, in overweight restrained eaters (Fig 6.3 and 6.4).

The relationship between diet-induced thermogenesis (DIT) and changes in skin temperature in the proximity of the liver shows a positive correlation ( $r=0.79 p<0.05$ ). Diet induced thermogenesis also shows a statistically significant positive correlation with $I_{\mathrm{m} 2}(r=0.67 \mathrm{p}<0.05)$, and weak, statistically non-significant negative correlations with H.P and $\mathrm{F}_{1}$. No statistically significant correlations have been found between diet induced thermogenesis and amount eaten, meal duration, or body mass index.

Normal weight unrestrained eaters displayed decelerated cumulative food intake curves and an increase in the liver temperature data of $0.8-1.5^{\circ} \mathrm{C}$, from the beginning of the meal onwards, remaining high until 60.90 minutes after the meal was consumed. The diet induced thermogenesis of this group was on average $8.1 \pm 1.3 \%$, calculated over two and a half hours from the beginning of the meal onwards.

Overweight and normal weight restrained eaters displayed linear cumulative food intake curves, almost no changes in skin and core temperatures and a diet induced thermogenesis of $4.2 \pm 0.3 \%$, and $4.8 \pm 0.7 \%$, calculated over two and a half hours from the beginning of the meal onwards. 
In summary, deceleration in cumulative food intake curves is positively correlated with a temperature increase in the skin in the proximity of the liver, and with a relatively normal diet-induced thermogenesis.

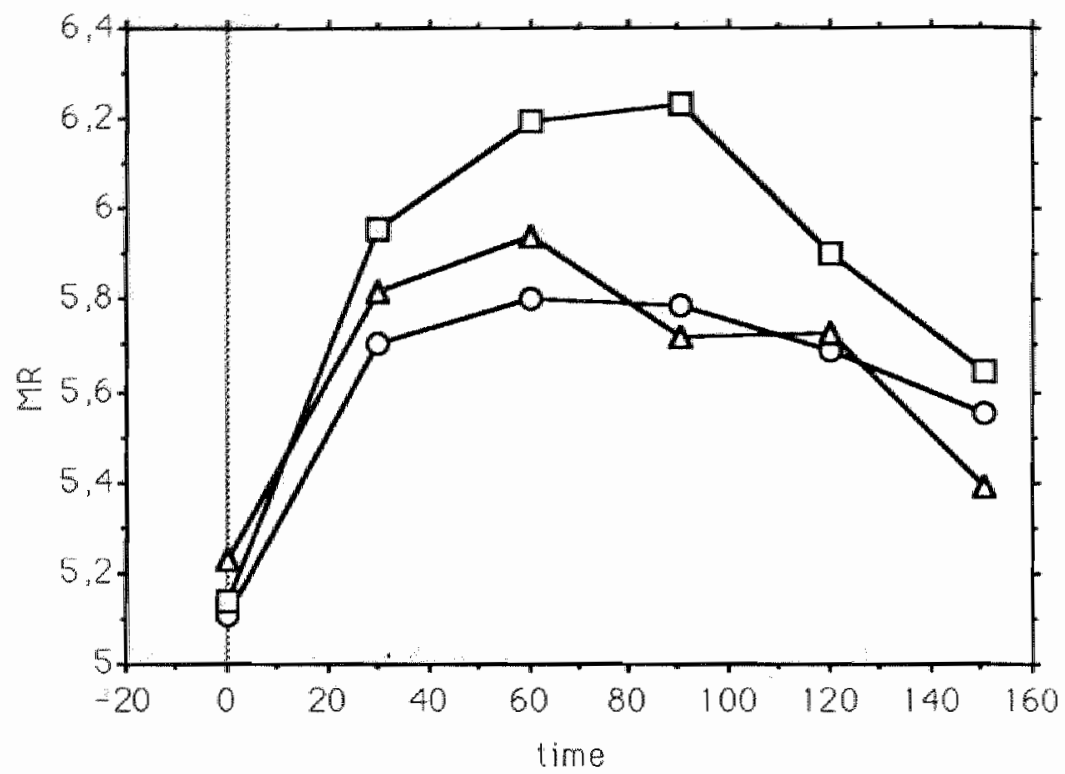

Figure 6.3 Metabolic rate from the start of the meal onwards. $\mathrm{O}=$ Normal weight restraint, $\Delta=$ overweight restraint, $\square=$ normal weight unrestraint.

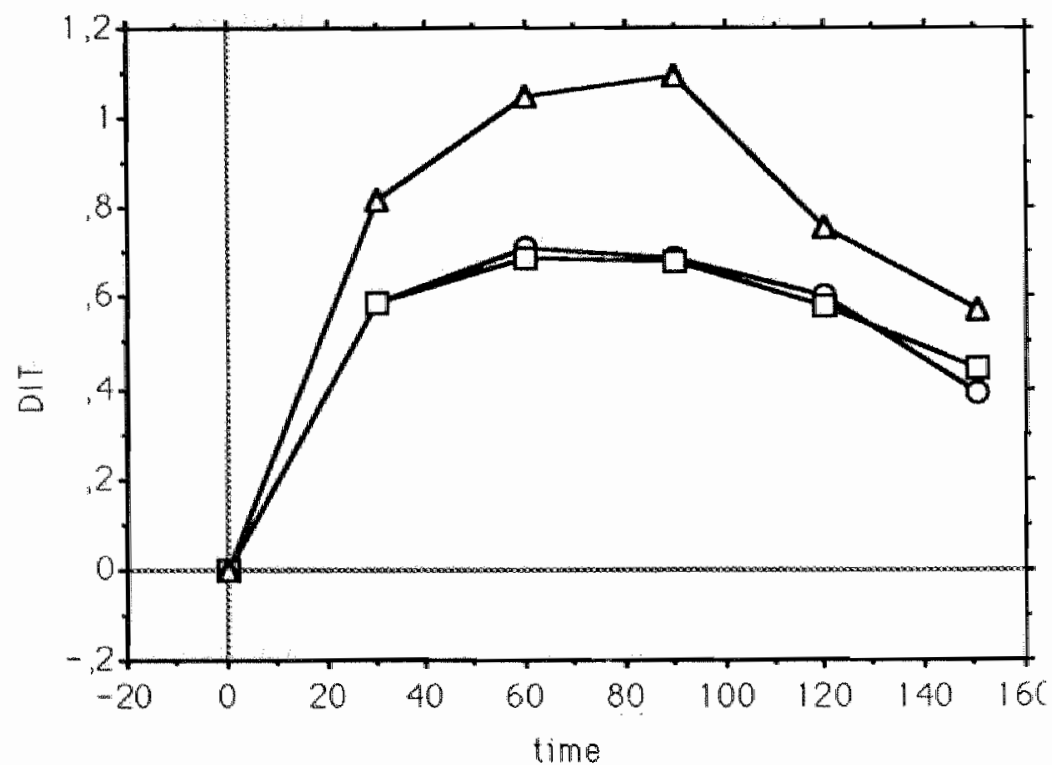

Figure 6.4 Diet-induced thermogenesis from the start of the meal onwards. $\mathrm{O}=$ Normal weight restraint, $\Delta=$ overweight restraint, $D=$ normal weight unrestraint. 
Apparently a change in skin temperature in the proximity of the liver is an indication for a sitart of metabolic processes in the body immediately after the start of a meall. In obese people, however, the constant low skin temperature, including absence of increased skin temperature in the proximity of the liver, might result from increased cutaneous thermal insulation, which induces lower heat loss and a more stable internal temperature, (see also 28,49,50). Body composition and fat distribution had not been measured. With respect to the neighbourhood of the liver, in the normal weight restrained and unrestrained eating women a thin fat layer was present, whereas in the obese women a thick fat layer was observed. Not only cutaneous thermal insulation will be responsible for the absence of a change in skin temperature in the proximity of the liver in the obese, also a lower or delayed diet -induced thermogenesis contributes to this phenomenon. This is confirmed by the same observation in the normal weight restrained eaters, who lack this increased cutaneous thermal insulation, but still show constant skin temperatures and low or delayed diet-induced thermogenesis. These subjects maintain their body weight by restrained eating behaviour, which involves a body weight below their set-point. Their low diet -induced thermogenesis and constant skin temperatures indicate metabolic efficiency, possibly contributing to an increase in body weight to a setpoint level (34). In the obese subjects (who recently had followed a weight reduction programme), the same metabolic efficiency, and the elevated body thermal insulation still might be responsible for a positive energy balance (31).Their low diet -induced thermogenesis may be caused by a thermogenic defect that had not disappeared during weight reduction, as was also found before $(6,29)$. Since basal metabolic rate decreases with weight loss, the overall diet -induced thermogenesis of postobese individuals can be lower than that of lean controls. Although some studies did not find consistent differences in diet -induced thermogenesis in obese and lean subjects, (69), most studies show a blunted thermogenic response in the obese $(6,29,33,49,54,60)$. As we found a blunted thermogenic response in the restrained (post)- obese group and in the effective restrained normal weight group, we agree to consider this as a cause rather than the result of obesily, and as constitutive rather than the result of developmental or enwironmental factors. The relationship between linearity in cumulative food intake curves and a low diet -induced thermogenesis, in restrained normal weight and restrained overweight subjects underlines lack of short term regulation due to lack of thermogenic feedback: the absence of metabolic heat production cannot provide a signal for food intake regulation.

The observation that normal -weight unrestrained eaters displayed decelerated cumulative food intake curves, an increase in skintemperature in the proximity of the liver, and a relatively normal dietinduced thermogenesis, supports the hypothesis that in normal weight 
unrestrained eaters food intake is more under physiological control than in restrained nomal weight and restrained obese eaters.

The mean diet-induced thermogenesis of $8,1 \pm 1,3 \%$ in this group may be part of the thermogenic response to the meal because the experiments were discontinued two and a half hours after the start of the meal, when energy expenditure might not have returned to premeal base-line yet. Therefore, our figure of $8,1 \pm 1,3 \%$ might seem low compared to $14,8 \pm 1,1 \%$, measured over 24 hrs (54), but still indicates a normal dietinduced thermogenesis. The relationship between deceleration in cumulative food intake curves and a relative normal diet -induced thermogenesis underlines short term regulation of food intake. This corresponds with other findings where eating behaviour, influenced by sensory and cognitive stimulations from food characteristics like spiced food and palatability, enhances diet induced thermogenesis $(24,38,39)$.

In this normal weight unrestrained group mean skin temperature of upper arm and upper leg remained unchanged during and after the meal, which was also found in a non-obese group during and after a glucose load, but this nonobese group showed an internal temperature which tended to increase with $0,18^{\circ} \mathrm{C}(54)$. We found very little fluctuations in core temperature and no statistically significant increase. Measuring mean skin temperature usually does not include measuring skin temperature in the proximity of the liver. The increase in skin temperature data in that area, as we found, may be caused by the enhancement of specific calorigenic metabolic processes within the liver (5), and, therefore, a more intensive blood circulation in the skin in the proximity of the liver.

Thus the important physiological feedback signals, i.e. diet -induced thermogenesis, and to a lesser extent body temperature, operate, related to decelerated cumulative food intake curves, as a control of food intake in the sense of the thermostatic theory.

\section{$6.7 \quad$ References}

1 Adolph, E.F. Urges to eat and drink in rats. Am. J. Physiol. 1947, 151:110-125

2 D'Alessio, D.A., Kavle, E.C., Mozzoli, M.A., Smalley, K.J., Polansky, M., Kendrick, Z.V., Owen, L.R., Bushman, M.C., Boden, G., Owen, O.E. Thermic effect of food in lean and obese men. J. Clin. Invest. 1988, 81:1781-1791.

3 Benzinger, T.H. Heat regulation: Homeostasis of central temperature in Man. Physiol. Rev. 1969 49: 671-759.

4 Benzinger, T.H. The thermal homeostasis of man. In: Les concepts de Claude Bernard sur le Milieu Interieur, La Fondation Siger-Polygnac, ed. Paris: Masson et Cie, Editeurs, 1967, 325-358, 361, 374-377.

5 Berry, M.N., Clark, D.G., Grivell, A.R. and Wallace, P.G. The contribution of hepatic metabolism to diet-induced thermogenesis. Metabolism 1985, 34: 141-147. 
6 Bessard, T., Schutz, Y., and Jéquier, E. Energy expenditure and postprandial thermogenesis in obese women before and after weight loss. Am. J. Clin. Nutr. 1983, 38: 680-693.

7 Booth, D.A. Postabsorptively induced suppression of appetite and the energostatic control of feeding. Physiol. Behav. 1972, 9: 199-202.

8 Brobeck, J.R. Food and temperature. Rec. Adv. Horm. Res. 1960, 16:439-459.

9 Brobeck, J.R. Neural regulation of food intake. Ann. NY. Acad. Sci. 1955, 63: 44-55.

10 Brouwer, E. Report of sub-committee on constants and factors. In: Energy Metabolism, ed. Blaxter, K.I. Proceedings of 3rd symposium on energy metabolism. EAAP. Publ.11. Acad. Press, London, 1965, 440-443.

11 Bruck, K. and Zeisberger, E. Adaptive changes in thermoregulation and their neuropharmacological basis. Pharmac. Ther. 1987, 35: 163215 .

12 Brück, $\mathrm{K}$. and Olschewski, H. Body temperature related factors diminishing the drive to exercise. Can. J. Physiol. Pharmacol. 1987, 65: 1274-1280.

13 Cabanac, M. and Massonnet, B. Pathologie de la thermorégulation. Rev. Neurol. (Paris) 1980, 136, 4, 285-302.

14 Cabanac, M. and Massonnet, B. Thermoregulatory responses as a function of core temperature in humans. J. Physiol. 1977, 265, 587 . 596.

15 Cabanac, M. Temperature regulation. Ann. Rev. Physiol., 1975, 37: 415-439.

16 Cabanac, M., Germain, M. and Brinnel, H. Tympanic temperatures during hemiface cooling. Eur. J. Appl. Physiol. 1987, 56: 534-539.

17 Castonguay, T.W., Applegate, E.A., Upton, D.E., Stern, J.S. Hunger and appetite: old concepts/new distinctions. Nutr.Rev. 1983, 41:101110.

18 Davidson S., Passmore, R., Brock, J.F., Truswell, A.S. Human nutrition and dietetics. 6 th ed. London; Churchill Livingstone, 1975 , 35.

19 Deutsch, J.A. The stomach in food satiation and the regulation of appetite. Prog. Neurobiol. 1978, 10: 135-153.

20 Garrow, J.S. Treat obesity seriousiy: a clinical manual. Edinburgh Churchill Livingstone, 1981.

21 Gibbs, J., Young, R.C., Smith, G.P. Cholecystokinin decreased food intake in rats. J. Comp. Physiol. Psychol. 1973, 84: 488-495.

22 Glick, Z., Svartz, E., Magazanik, A., Modan, M. Absence of increased thermogenesis during short-term overfeeding in normal and overweight women. Am. J.Clin.Nutr. 1977, 30: 1026-1035

23 Hamilton, C.L. Long term control of food intake in the monkey. Physiol. Behav. 1972, 9: 1-6.

24 Henry, C.J.K. and Emery, B. Effect of spiced food on metabolic rate. Human Nutrition: Clinical Nutrition 1986, 40C, 165-168. 
25 Herman, C.P. and Polivy, I. Restrained eating.In A.Stunkard(ed.) Obesity. W B Saunders, Philadelphia, 1980, 208-224.

26 James, W.P.T. and Trayhurn, P. Thermogenesis and obesity. Brit. Med. Bull. 1981, 37, 1. 43-48.

27 Jéquier, $E$. Thermogenesis induced by nutrient administration in man. Infusionstherapie 1984. 11: 184-188.

28 Jequier, E., Gygax, P.H., Pittet; Ph. and Vannotti, A. Increased thermal body insulation:relationship to the development of obesity. J.Appl.Physiol 1974, 36(6): 674-678.

29 Jequier, E. and Y. Schutz. New evidence for a thermogenic defect in human obesity. Intern. Journ. of Obesity, 1985, 9, suppl. 2, 1-7.

30 Jéquier, E. Energy expenditure in obesity. Clin. Endocrinol. Metab. 1984, 13: 563-580.

31 Jéquier, E., Pittet, P.H. and Gygax, P.H. Thermic effect of glucose and thermal body insulation in lean and obese subjects: a calorimetric approach. Proc. Nutr. Soc. 1987, 37, 45-53.

32 Jessen, $C$. Thermal afferents in the control of body temperature. Pharmac. theor. 1985, 28: 107-134.

33 Jung, R.T., Shetty, P.S. and James W.P.T. Reduced thermogenesis in obesity. Nature 1978, 279, 322-323.

34 Keesey, R.E. and Corbett, S.W. Metabolic defense of the body weight set-point. in: Eating and its disorders. eds. A.J. Stunkard and E. Stellar. Raven Press New York, 1984.

35 Kennedy, G.C. The role of depot fat in the hypothalamic control of food intake in the rat. Proc.R.Soc.Lond.Ser.B. 1953, 140: 578-592.

36 Kissileff, H.R., Klingsberg, G. and VanItallie, T.B. Universal eating monitor for continuous recording of solid or liquid consumption in man. Am. J. Physiol., 1980, 238: 14-22.

37 LeBlanc, J., Mercier, P., Samson, P. Diet-induced thermogenesis with relation to training state in female subjects. Can. J. Physiol. Pharmacol. 1984, 62: 334-337.

38 LeBlanc J., Brondel, L. Role of palatability on meal-induced thermogenesis in human subjects. Am.J.Physiol. 1985, 248: E333E336.

39 LeBlanc, J., Cabanac, M. and Samson, P. Reduced postprandial heat production with gavage as compared with meal feeding in human subjects. Am. J. Physiol. 1984, 246 (Endocrinol. Metab. 9): E95E101.

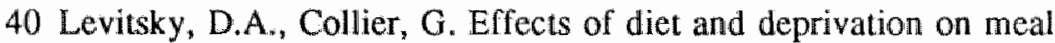
eating behaviour in rats. Physiol. Behav.1968, 3: 137-140.

41 McHugh, P.R., Moran, T.H., Barton, G.N. Satiety:a graded behavioral phenomenon regulating caloric intake. Science 1975, 190: 167-169.

42 McHugh, P.R., Moran, T.H. Calories and gastric emptying: a regulatory capacity with implications for feeding. Am J Physiol.1979, 236: T254-T260. 
$43 \mathrm{Ma}$, S.W.Y., Nadean, B.E. Foster, D.O. Evidence for liver as the major site of the diet-induced thermogenesis of rats fed a "cafetaria" diet. Can. J. Physiol Pharmacol. 1987, 65, 1802-1804.

44 Mayer, J. Regulation of energy intake and the body weight. The glucostatic and the lipostatic hypothesis: Ann. NY. Acad. Sci. 1955. 63: $15-43$.

45 Mellinkhoff, S.M., Frankland, M., Boyle, D., Greipel, M. Relationship between serum amino acid concentration and fuctuation in appetite. J Appl.Physiol. 1956, 8: 535-538.

46 Morley, J.E., Levine, A.S. The central control of appetite. Lancet $1983,2: 398-401$.

47 Nair, K.S., Halliday, D., Garrow, J.S. Thermogenic response to isoenergetic protein, carbohydrate or fat meals in lean and obese subjects. Clin. Sci. 1983, 65: 307-312.

48 Novin, D., Sanderson, J.D., Vanderweele, D.A. The effect of isotonic glucose on eating as a function of feeding conditions and infusionsite. Physiol. Behav. 1974, 13: 3-7.

49 Pittet, P.H. Gygax, P.H. and Jéquïer, E. Thermic effect of glucose and amino acids in man studied by direct and indirect calorimetry. Br. $\mathrm{J}$. Nutr. 1974, 31, 343.

50 Pittet, P.H., Chappuis, P.H., Acheson, K., Techterman, F. de and E. Jéquier. Thermic effect of glucose in obese subjects studied by direct and indirect calorimetry. Br. J. Nutr. 1976, 35, 281-292.

51 Ramanathan, N.L. A new weighting system for mean surface temperature of the human body. J. Appl. Physiol, 1964, 19(3): 531533.

52 Russek, M. A hypothesis on the participation of hepatic glucoreceptors in the control of food intake. Nature 1963, 197: 79-80.

53 Schoffelen, P., Saris, W.H.M., Westerterp, K.R., Ten Hoor, F. Evaluation of an automatic indirect calorimeter for measurement of energy balance in man. In: Human energy metabolism: Physical activity and energy expenditure measurement in epidemiological research based upon direct and indirect calorimetry. Ed. A.J.H. van Es. Euro Nut report Wageningen, 5, 1985: 51-54.

54 Schutz, $Y_{\text {. }}$ Bessard, "T. and Jéquier, E. Diet-induced thermogenesis measured over a whole day in obese and non-obese women. Am.J. Clin.Nutr. 1984, 40:542-552.

55 Schwartz, R.S., Ravussin, E., Massari. M., O'Connell M., Robbins, D.C. The thermic effect of carbohydrate versus fat feeding in men. Metabolism 1985, 34: 285-293.

56 Sclafani, A., Springer, D. Dietary obesity in adult rats:similarities to hypothalamic and human obesity studies. Physiol. Behav. 1976, 17: 461-471.

57 Sims, E.A.H., Danforth, E. Expenditure and storage of energy in man. J. Clin. Inwest. 1987, 79: 1019-1025.

58 Smith, G.P. The peripheral control of appetite. Lancet $1983,3: 88-90$. 
59. Steffens, A.B., Strubbe, J.H. Regulation of body weight and food intake. Sci Progr. (Oxford) 1987, 71: 545-562.

60 Steiniger, J., Karst, H. Noack, R. and Steglich, H.D. Diet-induced thermogenesis in man: thermic effects of single protein and carbohydrate test meals in lean and obese subjects. Ann. Nutr. Metab.1987, 31: 117-125.

61 Strominger, J.L., Brobeck, J.R., Cort, R.L. Regulation of food intake in normal rats and rats with hypothalamic hyperphagia. Yale J. Biol Med. 1953, 26: 55-74.

62 Strubbe, J.H. Food intake regulation in the rat. In: Addink A.D.F., Spronk, N., eds. Exogenous and endogenous influences on metabolic and neural control. Oxford: Pergamon Press, 1982; 31-39.

63 Stunkard, A.J. and Messick, S. The three factor eating questionnaire to measure dietary restraint, disinhibition and hunger. Journ. Psych. Res. 1985, 29: 71-83.

64 VanItallie, T.B., Kissileff, H.R. The physiological control of energy intake: an economic perspective. Am. J. Clin. Nutr. 1983, 38: 978 988.

65 Westerterp, K.R., Nicolson, N.A., Boots, J.M.J., Mordant, A. Westerterp-Plantenga, M.S. Obesity,restrained eating and the cumulative food intake curve. Appetite, 1988. 11, 119-128.

66 Westerterp-Plantenga, M.S., Westerterp, K.R., Nicolson, N.A. Mordant, A., Schoffelen, P.F.M., ten Hoor, F. The shape of the cumulative food intake curve in humans, during basic and manipulated meals. Physiol. and Behav. 1990, 47, 569-576.

67 Woo, R.,Daniels-Kush R., Horton, E.S. Regulation of energy balance. Ann. Rev. Nutr. 1985, 5: 411-433.

68 York, D.A., Morgan, J.B. and Taylor, T.G. The relationship of dietary induced thermogenesis to metabolic efficiency in man. Nutr. Soc. $1980,39,57 \mathrm{~A}$.

69 Zed, C. and James, W.P.T. Dietary thermogenesis in obesity, response to carbohydrate and protein meals: the effect of $\beta$-adrenergic blockade and semistarvation. Intern. Journ. Obesity. 1986, 10, 391-405. 


\section{Diet induced thermogenesis and cumulative food intake curves, as a function of familiarity with food and dietary restraint in humans}

M. S. Westerterp-Plantenga, E. Van den Heuvel, L. Wouters, and F. ten Hoor.

Open University, Heerlen

State university of Limburg, Maastricht

The Netherlands

Physiology and Behavior, 1992; 51 (2).

\subsection{Abstract}

WESTERTERP-PLANTENGA, M . S., E . VAN DEN H EUVEL, L. WOUTERS, F. TEN HOOR. Diet induced thermogenesis and cumulative food intake curves, as a function of familiarity with food and dietary restraint in humans. PHYSIOL. BEHAV. 51 (2), 1992. Cumulative food intake curves and diet-induced thermogenesis were recorded in women during four course solid food lunches, consisting of familiar and unfamilar food, offered in ad libitum or restricted portions, in order to assess a possible relation between eating behaviour on the one hand and a reflection of internal processes and subject characteristics on the other.

The subjects were characterized as normal weight restrained, normal weight unrestrained, and obese restrained.

A negative relation was found between degree of restraint and deceleration of the cumulative food intake curve during the ad libitum courses of any menu, and between degree of restraint and diet-induced thermogenesis $(p<0.001)$. Consequently a positive relation was found between deceleration of the cumulative food intake curves during the ad. lib courses of any menu and diet-induced thermogenesis $(p<0.001)$. Diet-induced thermogenesis during the first time a meal consisting of unfamiliar food was served, was significantly higher in all groups than during the other two times, when meals consisting of more familiar food were served $(+0.98 \% ; 0.71 \%, \mathrm{p}<0.05)$. 
THERMOGENESIS generated by food ingestion cannot be explained exclusively by the so-called specific dynamic action of food (15). The initial phase of a meal, when sensory stimulations are experienced, is at the origin of some increase in heat production not necessarily identified with the digestion, absorption, or storage of nutrients (13).

LeBlanc et al found that an early thermogenic response to a meal coincides with a rapid increase in plasma norepinephrine and insulin. In the situation of gavage a reduced thermogenesis was noted and the initial enhanced secretion of norepinephrine and insulin failed to occur (13). Le Blanc et al found also that reduction of food palatability caused a significant diminution in meal thermogenesis. In situations where unpalatable food was given and in situations when feeding by gavage occurred it was found that the sensory stimulations caused by eating were not experienced and plasma norepinephrine failed to increase $(12,13)$. This suggests that palatability increases the activity of the sympathetic nervous system, and consequently enhances thermogenesis. From these and other studies (5) it was concluded that a part of the meal thermogenesis may be generated through sensory stimulation and this action may be generated through the activation of the sympathetic nervous system. On the other hand, Weststrate et al. concluded from experiments where the impact of variation in palatability on diet-induced thermogenesis was studied with liquid test meals being palatable or unpalatable in a random order, that the difference in palatability did not have a significant impact on postprandial metabolism (25). Possible activation of the sympathetic nervous system does not necessarily contribute at a constant level to diet-induced thermogenesis. This activation may vary with different sensory characteristics of food (5) and may be conditioned by familiar menus. Moreover, considering the different subject characteristics, it has been reported that diet induced thermogenesis is relatively low or delayed in obese women $(1,7,8,14$, 17, 18), and in normal weight restrained eating women (21).

In previous experiments a relation between eating behaviour, subject characteristics and diet induced thermogenesis was shown, when subjects were eating a familiar menu (21). The question may arise, of how different thermogenic responses may be related to familiarity with the sensory characteristics of the presented food.

Therefore, in this study we try to elucidate the question of how thermogenic responses,- related to different subject characteristics and to eating behaviour,- may be related to familiarity with the presented menu. 


\subsubsection{Subjects}

Healthy female subjects $(n=28)$ were recruited via a local newspaper from the general population in the south of the Netherlands as well as from university students and employees of the Limburg State University. They were divided into women who had participated in a weight reduction group, and women without self-defined weight problems. Informed consent was obtained. Weight and height in indoor clothes, without shoes, were used to calculate body mass index (BMI ; $\mathrm{kg} / \mathrm{m}^{2}$ ). According to the criterion used by Garrow (4), BMI $>25$, nine subjects (32\%) were classified as overweight. The remaining 19 subjects were classified as normal weight.

\subsubsection{Procedure}

Data presented here are based on series of three lunches, which took place at the same time of the day on the same day of the week in consecutive weeks. Subjects arrived one and a half hour prior to lunch and were installed alone in a respiration chamber, in order to measure energy expenditure. They read, listened to music, or watched television, sitting down quietly one hour before and two hours after lunch.

The respiration chamber is an open-circuil chamber, with a volume of $14 \mathrm{~m}^{3}$ equipped with bed, toilet, $t v$, telephone, chair and table. The volume of air drawn from the chambers is measured by a dry gasmeter. Samples of in- and out going air are continuously analysed by a paramagnetic $\mathrm{O}_{2}$-analyser (Servomex Taylor, England) and an infrared $\mathrm{CO}_{2}$-analyser (Hartman and Braun, West Germany). From the air flow rate, and the $\mathrm{O}_{2}$ and $\mathrm{CO}_{2}$-concentration of the in- and outflowing air, $\mathrm{VO}_{2}, \mathrm{VCO}_{2}, \mathrm{RQ}$ and consequently energy expenditure were calculated on line, using an Apple $2 \mathrm{E}$ computer (16). Energy expenditure was calculated using the equation of Brouwer (3). Metabolic rate (MR) was calculated from values taken during the period when subjects sat down quietly one hour before the start of a meal. Diet-induced thermogenesis (DIT) was calculated from values taken during two and a half hours from the start of the meal, and was expressed as a percentage of energy ingested during the meal.

Eating behaviour was observed directly by the experimenter, through a door-window of the chamber, which did not disturb the subject because of a difference in light intensity. The experimenter scored the time at which each bite occurred directly into a digital computer. Intake was monitored via an electronic weighing scale built into the table under the plate and connected to the same computer. This set-up is similar to "the universal eating monitor" developed by Kissileff et al (9). All subjects were aware 
of this procedure and were assured that all data would be kept in strict confidence. In earlier experiments no difference in results was found between the situation in which the subjects were told a cover story or were aware of the actual experiment (23).

The meals were isocaloric, with the same protein, carbohydrate and fat proportions in the comparable courses of both mealtypes and consisted of four courses, each of a different homogeneous food. All subjects rated the familiar meal in advance to be moderately to highly palatable. The four courses consisted respectively of:

familiar meal:

1 vegetable soup $\left(150 \mathrm{~g} ; 5,4 \mathrm{~kJ} / \mathrm{g} ; 65-68^{\circ} \mathrm{C}\right)$;

2 pasta, mixed uniformly with a sauce of ground meat, tomato puree, mild red bell peppers, onions, mushrooms and oil $\left(700 \mathrm{~g} ; 4,8 \mathrm{~kJ} / \mathrm{g} ; 60-62^{\circ}\right.$ C) ;

3 applesauce $(175 \mathrm{~g} ; 3,2 \mathrm{~kJ} / \mathrm{g})$;

4 ice cream $(100 \mathrm{~g} ; 4,0 \mathrm{~kJ} / \mathrm{g})$.

unfamiliar meal:

1 miso soup (150g; $\left.5.6 \mathrm{~kJ} / \mathrm{g} ; 65-68^{\circ} \mathrm{C}\right)$;

2 japanese rice with tempura, soy sauce, salad $(700 \mathrm{~g} ; 4,7 \mathrm{~kJ} / \mathrm{g} ; 60-$ $\left.62^{\circ} \mathrm{C}\right)$

3 'olvarit' babyfood (a fruit mixture $175 \mathrm{~g} ; 3,2 \mathrm{~kJ} / \mathrm{g}$ );

4 bulgarian mint yogurt $(100 \mathrm{~g} ; 3,9 \mathrm{~kJ} / \mathrm{g})$.

Three courses ( 1,3 and 4$)$ were small to normal portions, so that the amount eaten was fixed. The second course consisted of an ample portion, of a size which was previously considered an ad libitum portion, not limiting intake. Some of course 2 was always left over. Subjects were instructed to eat no solid food in the three hours preceding a test meal. Before the start of the meal, they were asked to record the time they had arisen that morning, time of breakfast, and the kind and amount of food and beverages consumed at breakfast. Subjects then rated their degree of hunger on a $100 \mathrm{~mm}$ line. The two cold courses were available to the subject from a side table in the room. The first and second course, (the warm courses), were served just before the start of the meal through an air lock in the respiration chamber. Subjects were instructed to eat the courses from the table and in a certain order, and to signal the experimenter when they had finished a course. With respect to the second course, the subjects were told to eat as much as they liked and felt comfortable with. Subjects signalled when they had finished the complete meal. Hunger ratings were then repeated and in addition subjects rated how comfortable they had felt during the meal, and how much they had eaten in comparison to their normal lunch, all on 100 -mm lines. Subjects were also asked to rate the relative palatability of the different courses of the meal from $6-10(6=$ moderately palatable, $7=$ palatable, $8=$ wery palatable, $9=$ highly palatable, $10=$ extremely palatable): first they had to rate course 1 , and secondly the courses 2,3 , and 4 , in comparison to course 1. Finally they rated familiarity of each course: 0,1 or 2 ( $0=$ unfamiliar, $1=$ at least one experience, $2=$ familiar). 
Before the series of lunches started, each subject completed a Dutch translation (22) of the three factor eating questionnaire (TFEQ) developed by Stunkard \& Messick (19), and of the restrained-eating questionnaire developed by Herman \& Polivy (6).

The three dimensions of response to the TFEQ were labelled 'cognitive restraint" $\left(F_{1}\right)$, "disinhibition" $\left(F_{2}\right)$, and 'hunger" $\left(F_{3}\right)$. The score on the Herman \& Polivy questionnaire was labelled ' $\mathrm{H}-\mathrm{P}$ '.

\subsubsection{Data analysis}

Bodly mass index and age were averaged over subgroups split according to body mass index and restraint. From the scores on 'cognitive restraint', 'disinhibition', 'hunger', 'Herman-Polivy restraint', the median and range were calculated for the same subgroups.

Body mass index distinguishes between being normal weight or overweight. Following the criterion used by Garrow (4), subjects with a quetelet index $>25$ were classified as overweight and subjects with a quetelet index $\leq 25$ were classified as normal weight. The restraint questionnaires discriminate between being unrestrained or restrained, following Herman-Polivy (6). In this population, as in our former populations of subjects $(21,23,24)$ the median of the Herman-Polivy scores was 15 . Thus, subjects with a score $>15$ were classified as restrained (6). From the other restraint questionnaire, the three factor eating questionnaire (19), we used the discrimination between 'cognitive restraint' and unrestraint (24). This concerns the scores on the cognitive restraint factor F1. In this population, as was the case in our former populations of subjects $(21,23,24)$, the median of the scores on $\mathrm{F} 1$ was 9 . Thus, subjects with a score on F1 $>9$ were classified as cognitive restrained (24). The subjects who are restrained eaters by being foodconcerned are classified by $\mathrm{F} 1>9$; the subjects who are restrained eaters by being weight concerned are classified by $\mathrm{H}-\mathrm{P}>15$. Therefore, the discrimination between restraint and unrestraint implies an F1 score $>9$, or an H-P score $>15$.

The amount subjects felt they had eaten compared to their normal lunch, was averaged per subject over the three meals and over the entire group. Amount eaten of the second course, total eating time, eating rate per meal and per course, were averaged over the entire group (as subgroups did not. show significant differences) for each of the three meals .

For the ratings of hunger and comfort, as well as for the ratings of familiarity and relative palatability, the median and range is given over the entire group.

The scores of bite moments and plate-weight changes synchronized on the computer yielded individual cumulative food intake curves, both separately for every course as well as continuously over the four courses. Intake rate changes reflected in the shape of the cumulative food intake curve (linear, or decelerated) were expressed by the percentage change in 
slope, as derived from curve-fitting. We used the quadratic equation, previously described by Kissileff et al. (1982) as a good fit for the decelerated cumulative intake curve. By fitting the curve over $25 \%, 50 \%$, and $75 \%$, of the eating time of an ad libitum main course, cumulative food intake was linear over about the first $50 \%$ of the course duration. For this reason our curve fitting starts with a linear part of $30 \%$, and the rest of the course is fitted to a quadratic equation. We then calculated the slope of the first $30 \%$, the linear slope of the next $70 \%$, and the change in slope as a percentage of the first slope (see also Westerterp et al ., 1990). From intake rate changes expressed by this percentage change in slope over the whole meal and per course the median and range were calculated per subject over the three meals. Also the medians and ranges were calculated for the subgroups.

Diet induced thermogenesis appeared as an increase in metabolic rate from the start of the meal onwards until two and a half hours later, compared to metabolic rate one hour prior to the meal. This increase in metabolic rate was expressed as a percentage of the energy intake during the meal; median and range are given.

Diet-induced thermogenesis and intake rate changes were related to subject characteristics for the three different meals.

\subsection{Results}

\subsubsection{Subject characteristics}

Subject characteristics are summarized in table 1 . The characteristics are split according to body mass index and restraint. The criteria for normal weight unrestraint are $\mathrm{BMI} \leq 25 ; \mathrm{F} 1 \leq 9$ and $\mathrm{H}-\mathrm{P} \leq 15$. The criteria for cognitive restraint and restraint according to Herman-Polivy are based on the median, being $F_{1}=9$ for cognitive restraint, $\mathrm{H}-\mathrm{P}=15$ for restraint according to Herman-Polivy (6).

The criteria for normal weight restraint are $\mathrm{BMI} \leq 25 ; \mathrm{F} 1>9$ or $\mathrm{H}-\mathrm{P}>15$. The criteria for obese restraint are $\mathrm{BMI}>25 ; \mathrm{F} 1>9$ or $\mathrm{H}-\mathrm{P}>15$. There were no obese unrestrained eating subjects since all obese subjects included in this study had recently participated in a weight reduction group. 
Table 7.1 Body mass index (BMI), cognitive restraint (F1), disinhibition (F2), hunger (F3), Herman-Polivy restraint and age, of the subgroups.

\begin{tabular}{lllll}
\hline & $\begin{array}{l}\text { Normal weight } \\
\text { unrestrained } \mathrm{n}=12\end{array}$ & $\begin{array}{l}\text { Normal weight } \\
\text { restrained } \mathrm{n}=7\end{array}$ & $\begin{array}{l}\text { Overweight } \\
\text { restrained } \mathrm{n}=9\end{array}$ \\
& mean $\pm \mathrm{sd}$ & & mean $\pm \mathrm{sd}$ & mean $\pm \mathrm{sd}$ \\
BMI & $19.9 \pm 1.6$ & $20.8 \pm 1.2$ & $27.4 \pm 2.9$ \\
Age & $26.9 \pm 7.1$ & $29.6 \pm 12.3$ & $36.2 \pm 16.2$
\end{tabular}

The following relations are shown (Spearman's rho; $\mathrm{p}$; $\mathrm{df}=27$ ):

BMI is positively correlated with H-P $(r=0.75 ; p<0.0001)$, with F1 $(r=0.58 ; p<0.001)$, and with age $(r=0.49 ; p<0.007)$.

Also $F 1$ and H-P $(r=0.78 ; p<0.0001)$, and $F 1$ and age $(r=0.44 ; p<0.016)$ are positively correlated.

Moreover, there is a positive correlation between H-P and age ( $r=0.49$; $\mathrm{p}<0.025$ ).

\subsubsection{Hunger state}

Subjects were always hungry when they arrived for the meal tests (median 92; range 87 - 98 on the 100-mm line), and always satiated after the meal (hunger ratings median 8 ; range $3-12$ ). Subjects felt they had eaten slightly more (median $+15 \%$; range $6-22 \%$ ) than in their normal lunch but they felt comfortable (median 83 ; range $78-89$ ). No relationship was found between change in hunger ratings from before and after the meal and amount eaten, total eating time, eating rate or eating rate changes over the meal.

\subsubsection{Meal parameters}

Statistically significant differences in meal parameters between subgroups were not found, therefore the meal parameters are given for the entire group. 
Amount eaten during the second course, total eating time, eating rate and relative palatability of the three meal types.

Total eating time is nett eating time; meal duration is about 30 min. Palatability scale: 6 -10 (from moderately palatable to extremely palatable); Familiarity scale: 0,1 , or 2 (unfamiliar, one experience at least, familiar).

\begin{tabular}{|c|c|c|c|c|c|c|c|c|}
\hline $\begin{array}{l}\text { Amoi } \\
\text { durin } \\
\text { coturs }\end{array}$ & $\begin{array}{l}\text { teaten } \\
\text { the } 2 \text { nd } \\
\text { (g) }\end{array}$ & $\begin{array}{l}\text { Total } \\
\text { time ( }\end{array}$ & ating & $\begin{array}{l}\overline{\text { Eatin }} \\
\mathrm{G} \cdot \mathrm{s}\end{array}$ & & $\begin{array}{l}\text { Relative } \\
\text { palatabi }\end{array}$ & dity & $\begin{array}{l}\text { Familiarit } \\
\text { 2nd cours }\end{array}$ \\
\hline mean & sd & mean & sd & mean & sd & median & range & median $\mathbb{I}$ \\
\hline 392 & 139 & 929 & 153 & 0.8 & 0.07 & 8 & $7-9$ & 2 \\
\hline 378 & 146 & 985 & 162 & 0.7 & 0.07 & 8 & 7.9 & 0 \\
\hline 397 & 142 & 988 & 157 & 0.8 & 0.06 & 8 & $7-9$ & 1 \\
\hline
\end{tabular}

\subsubsection{Intake rate change}

Intake rate change over the complete meal is liable to be affected by different eating rates in the four courses and so is not analysed. The cumulative food intake curves of the separate courses fell into two groups, namely those with a change in slope from first $30 \%$ to second $70 \%$ of each course of only $\pm 10 \%$ indicating a linear function and those with a decrease in slope by more than $10 \%$, indicating a decelerated curve (fig 7.1a and b).

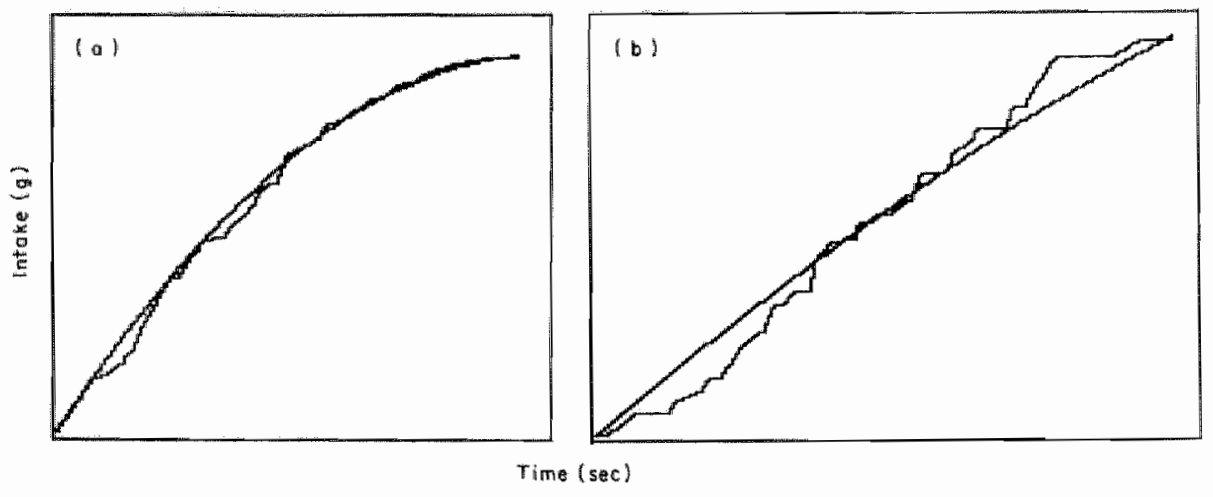

Figure 7.1 (a) Example of fitting of a deceler ated curve (change in slope: $-89 \%$ ).

(b) Example of fitting of a linear function (change in slope: $+2.9 \%$ ), 
The percentages change in slope of the curves of the second courses were positively correlated with the percentages change in slope of those of the third and fourth courses ( Spearman's rho; $p$; $d f=26$ ) .

For the farmiliar meals: $r=0.74 ; p<0.0001$ and $r=0.72 ; p<0.0001$.

For the unfamiliar meal: $r=0.86 ; p<0.0001$ and $r=0.72 ; p<0.0001$.

For the unfamiliar meal, 2nd time: $r=0.59 ; p<0.001$ and $r=0.63 ; p<0.0004$. Considering the four successive courses of a meal, the cumulative food intake curves reflect succession and relative palatability. The first course was linear due to the small portions and being the first course, similar to eating the first $75 \mathrm{~g}$ of an ad libitum meal or course. In previous experiments, eating rate during the first temporal half of an ad libitum meal was found to be constant (23). Linearity or deceleration in the curves for the third and fourth courses was similar to this aspect of the curve of the second course. In the entire group, a negative relation between change in slope and cognitive restraint (F1) and also HermanPolivy restraint indicates that restrained subjects have linear cumulative intakes and unrestrained subjects are decelerated eaters. This is illustrated by the distribution in figure 7.2 and was also found before (24). Figure 7.2 shows an example of the frequency distribution of subjects' percentage change in slope of cumulative intake curves, namely that of the second course of the third meal. In table 3 the frequency distribution of subjects' percentage change in slope of the four courses of the three meals is assigned to two categories that characterize the shape of the curves, namely : percentage change in slope $<-10 \%$ (decelerated), and $10 \%<$ percentage change in slope $<+1$

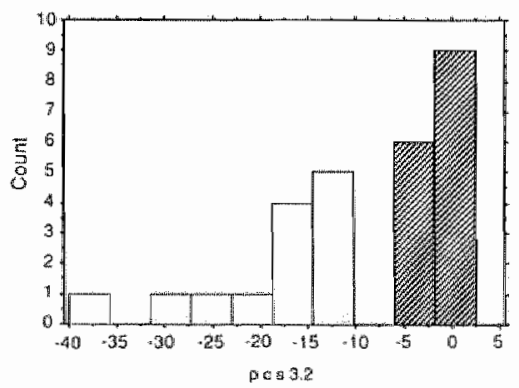

Figure 7.2 Frequency distribution of subjects' percentage change in slope (p c i s) of cumulative food intake curves of the second course of the third meal. Restrained eating subjects are shown in the shaded areas. 
Table $7.3 \quad$ Frequency distribution of subjects" percentage change in slope of the cumulative food intake curves of the four courses of three mealrypes which differ in familiarity, assigned to two different categories, namely: percentage change in slope $<-10 \%$ (decelerated), and $-10 \%<$ percentage change in slope $<+10 \%$ $(n=28)$.

\begin{tabular}{|c|c|c|c|c|c|c|c|c|c|c|}
\hline \multirow[b]{3}{*}{ Mealoppe: } & \multicolumn{5}{|c|}{$\begin{array}{l}\text { Percetiluge change in slope < } \\
10 \% \text {. }\end{array}$} & \multicolumn{5}{|c|}{$\begin{array}{l}-10 \%<\text { Percentage change in } \\
\text { slope }<+10 \%\end{array}$} \\
\hline & course: & 1 & 2 & 3 & 4 & course: & 1 & 2 & 3 & 4 \\
\hline & & & & & & & & & & \\
\hline Pamiliar meal & & 0 & 12 & 13 & 13 & & 28 & 16 & 15 & 15 \\
\hline $\begin{array}{l}\text { Unfamiliar meal } \\
\text { Ist time }\end{array}$ & & $a$ & 12 & 12 & 13 & & 28 & 16 & 16 & 15 \\
\hline $\begin{array}{l}\text { Unfamiliar meal } \\
\text { 2nd time }\end{array}$ & & 0 & 13 & $\mathbb{1 3}$ & 14 & & 28 & 15 & 15 & 13 \\
\hline
\end{tabular}

\subsubsection{Metabolic rate and diet induced thermogenesis .}

Metabolic rate before, during and after the meal is calculated per 30 minutes, from values obtained per 5 minutes. Metabolic rate is averaged per subject-type and it is given per subject type for the different meal situations, and per mealtype for the different groups of subjects. Metabolic rate data are expressed in Watts as well as in percentages of metabolic rate values during the first 30 minutes of observation.

Figure 7.3 shows two examples of metabolic rate during one hour prior to the meal, and increase in metabolic rate from the beginning of the meal onwards until two and a half hours later. For the different mealtypes and the different subgroups, these metabolic rates are given in table 4. Dietinduced thermogenesis expressed as percentage of the energy ingested during the meal, is also given in table 7.4. 

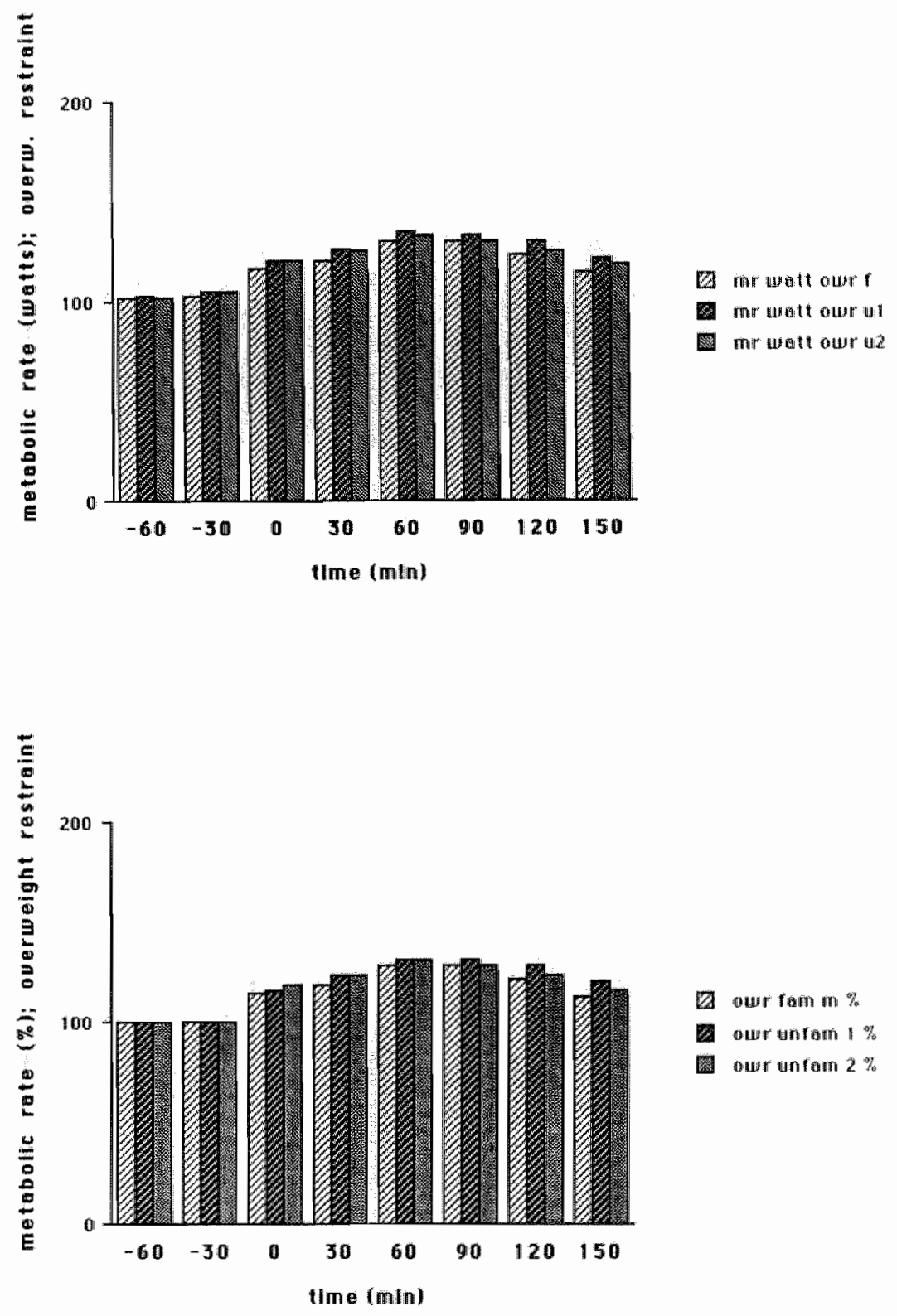

7.3.a: metabolic rate in watts for overweight restrained eaters before, during and after three mealtypes.

$7.3 \mathrm{~b}$ : the same in percentages of the metabolic rate during the first half hour 

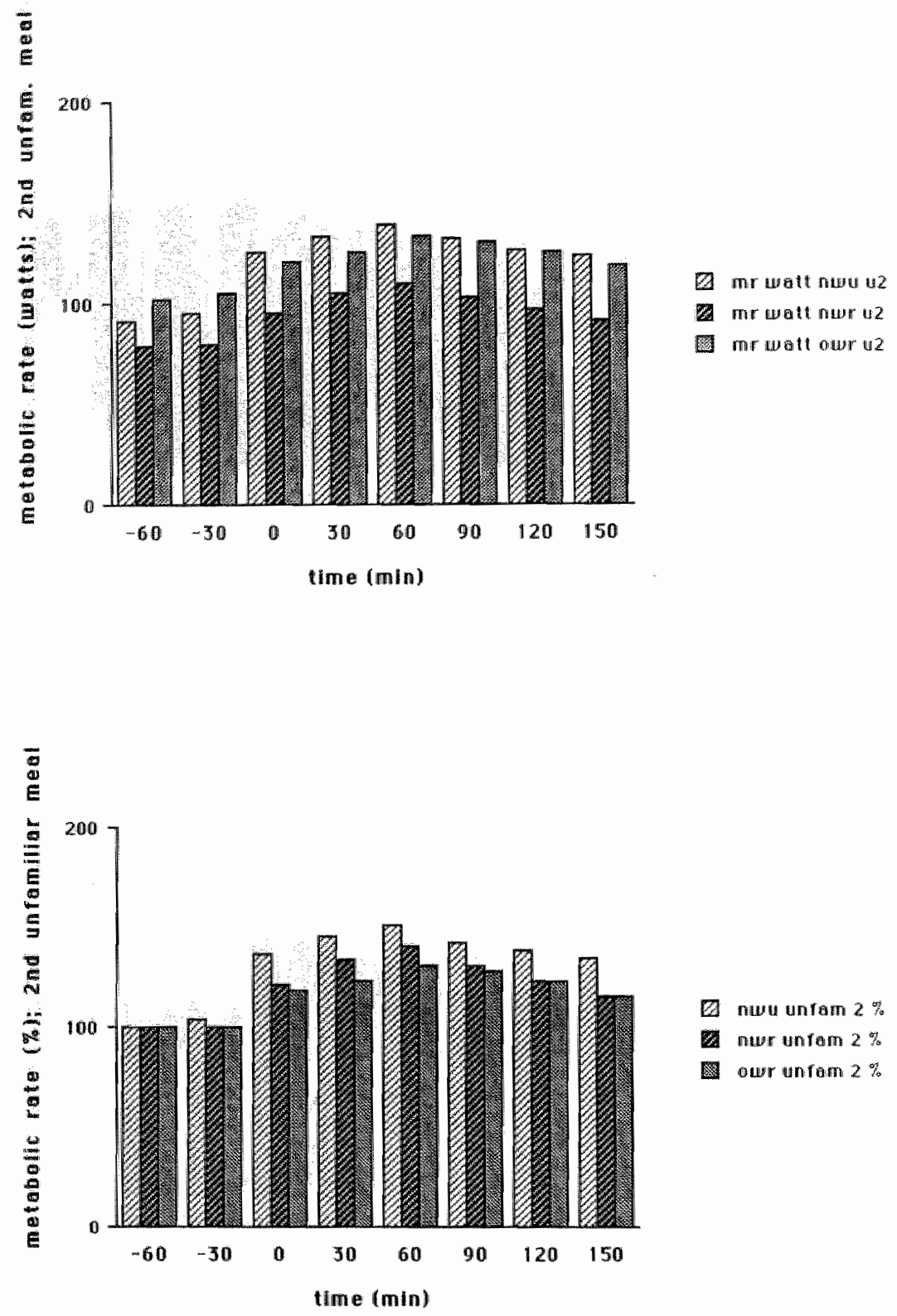

$7.3 \mathrm{c}$ : metabolic rate in watts during the second confrontation with the unfamiliar meal, in three subject types.

$7.3 \mathrm{~d}$ : the same in percentages of the metabolic rate during first half hour. 
Tabie 7.4 Average metabolic rates during one hour prior to the meal and from the beginuing of the meal onwards until two and a half hours later. Metabolic rates are given in Watts (standard deviations are between 0.2 and 6.7) and as a percentage of the value of the first 30 minutes. Diet-induced thermogenesis is given, expressed as a percentage of the energy ingested during the meal.

\begin{tabular}{l}
\hline Subject type: \\
Meallype: \\
Time in minutes \\
60 \\
$\%$ \\
30 \\
$\%$ \\
0 \\
$\%$ \\
30 \\
$\%$ \\
60 \\
$\%$ \\
90 \\
$\%$ \\
120 \\
$\%$ \\
150 \\
$\%$ \\
\%iet-induced \\
thermogenesis: \\
median: \\
range: \\
\hline
\end{tabular}

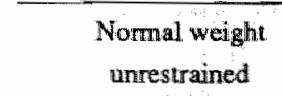

Familiar, Unfarn. $1 ; 2$

$\begin{array}{lll}88 & 95 & 92 \\ 100 & 100 & 100\end{array}$

$\begin{array}{lll}90 & 97 & 95 \\ 100 & 100 & 100\end{array}$

$120 \quad 132 \quad 125$

$\begin{array}{lll}136 & 138 & 137\end{array}$

$128 \quad 140 \quad 133$

$\begin{array}{lll}145 & 147 & 146\end{array}$

$133 \quad 143 \quad 138$

$151 \quad 151 \quad 151$

$\begin{array}{lll}125 & 137 & 132\end{array}$

142. $144 \quad 143$

$\begin{array}{lll}122 & 133 & 127\end{array}$

138 $\quad 140 \quad 139$

$116 \quad 130 \quad 123$

$134 \quad 136 \quad 135$

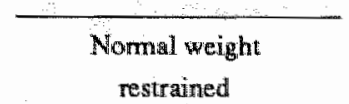

Familiar, Unfam. 1; 2

$\begin{array}{lll}75 & 80 & 78 \\ 100 & 100 & 100 \\ 77 & 82 & 80 \\ 100 & 100 & 100 \\ 90 & 98 & 95 \\ 120 & 123 & 121 \\ 100 & 108 & 105 \\ 133 & 138 & 134 \\ 105 & 113 & 110 \\ 140 & 142 & 141 \\ 97 & 107 & 103 \\ 129 & 133 & 131 \\ 92 & 100 & 97 \\ 122 & 124 & 123 \\ 87 & 93 & 92 \\ 116 & 117 & 115\end{array}$

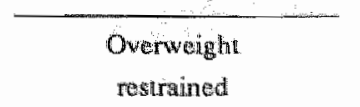

Fanulliar; Unfarm. 1:2

$\begin{array}{lll}102 & 103 & 102 \\ 100 & 100 & 100 \\ 103 & 105 & 105 \\ 100 & 100 & 100 \\ 117 & 120 & 120 \\ 115 & 116 & 118 \\ 120 & 127 & 125 \\ 118 & 123 & 123 \\ 130 & 135 & 133 \\ 128 & 131 & 131 \\ 130 & 133 & 130 \\ 128 & 131 & 128 \\ 123 & 130 & 125 \\ 121 & 128 & 123 \\ 115 & 122 & 118 \\ 113 & 120 & 116\end{array}$

\begin{tabular}{|c|c|c|c|c|c|c|c|c|}
\hline $8,8 \%$ & $9,2 \%$ & $8,9 \%$ & $3,9 \%$ & $4,9 \%$ & $4_{n} 6 \%$ & $3.8 \%$ & $5,0 \%$ & $5,0 \%$ \\
\hline $8,4-9,2$ & $8,7-9,3$ & $8,5-9,3$ & $3,2-4,6$ & $4,4-5,4$ & $4,1-4,9$ & $3,1-4,5$ & $4,3-5,6$ & $3,5 \times 4,6$ \\
\hline
\end{tabular}

7.4.6 Diet-induced thermogenesis and familiarity with the food.

Diet induced thermogenesis (DIT) of first confrontation with the unfamiliar meal was compared to a) the DIT of the confrontation with the familiar meal; b) the DIT of the second confrontation with the unfamiliar meal.

The diet-induced thermogenesis was significantly higher in the first confrontation with the unfamiliar meal, compared to the confrontation with the familiar meal, and also when compared to the second confrontation with the unfamiliar meal (two tailed Mann-Whitney U-test; $\mathrm{p}<0.05$ ). 

induced thermogenesis.

Diet-induced thermogenesis and intake rate changes were related to the subject characteristics 'cognitive restraint', Herman-Polivy restraint, body mass index and age, for the three different mealtypes. Intake rate change during the ad libitum course expressed as percentage change in slope was found to be negatively correlated with body mass index, "cognitive restraint", and Herman-Polivy restraint in every meal (Spearmans' rho; $p$; $\mathrm{df}=26)$ :

for the familiar meal : intake rate change with BMI: $r=-0.54 ; p<0.003$; with F1: $r=-0.71$ : $p<0.0006$; with H-P $r=-0.69 ; p<0.0001$.

for the unfamiliar meal: intake rate change with BMI: $r=-0.58: p<0.001$; with F1: $r=-0.71: p<0.0001$; with H-P: $r=-0.65 ; p<0.0002$;

for the unfamiliar meal 2nd time: intake rate change with BMI: $r=-0.43$; $\mathrm{p}<0.02 ; \mathrm{r}=-0.43$; with F1: $\mathrm{r}=-0.66 ; \mathrm{p}<0.0001$; with $\mathrm{H}-\mathrm{P}: \mathrm{r}=-0.51$; $\mathrm{p}<0.005$.

No significant correlations were found between intake rate change and F2, F3, age, or meal parameters.

Diet induced thermogenesis was found to be negatively correlated with body mass index ( $r=-0.58 ; \mathrm{p}<0.001)$, 'cognitive restraint' $(\mathrm{r}=-0.82$; $p<0.0001)$, and Herman-Polivy restraint $(r=-0.68 ; p<0.0001)$, (Spearmans' rho; $\mathrm{p} ; \mathrm{df}=26$ ).

Consequently, for each of the different mealtypes diet inducedthermogenesis was positively correlated with intake rate change during the ad libitum course ( $d f=26)$ :

for the familiar meal: DIT 1 and percentage change in slope during the ad libitum course: $r=0.67 ; \mathrm{p}<0.0001$.

for the unfamiliar meal: DIT 2 and percentage change in slope during the ad libitum course: $r=0.77 ; p<0.0001$.

for the unfamiliar meal 2nd time: DIT 3 and percentage change in slope during the ad libitum course: $r=0.74 ; p<0.0001$.

\subsection{Discussion}

Restrained eating normal weight and obese women showed a relatively low diet-induced thermogenesis and a linear cumulative food intake curve during meals consisting of familiar as well as unfamiliar food. Moreover the normal weight restrained eaters showed a non-significant lower metabolic rate during one hour before the start of the meal, compared to the unrestrained eaters. A slightly increased metabolic rate and an increased diet-induced thermogenesis in all groups appeared during the first confrontation with the meal with unfamiliar food, compared to the situations with the familiar meal and with the second confrontation with the unfamiliar meal. 
The increased diet-induced thermogenesis in all groups during the first meal with unfamiliar food may be caused by an increased sympathetic activity of the nervous system due to a higher alertness when confronted with unfamiliar food. This corresponds with other findings where eating behaviour, influenced by sensory and cognitive stimulations from food characteristics like palatability, enhanced diet-induced thermogenesis (12).

The relatively low or blunted diet induced thermogenesis in restrained eating normal weight and overweight women indicate an increase in metabolic efficiency (21). Their low diet induced thermogenesis may be caused by a thermogenic defect that had not disappeared during weight reduction in the still overweight group, as was also found before $(1,7)$. Since basal metabolic rate decreases with weight loss, the overall diet induced thermogenesis of overweight individuals who had followed a weight reduction programme, and of normal weight restrained eating individuals, who are always under dietary restrictions, can be lower than that of lean controls. Although some studies did not find consistent differences in diet induced thermogenesis in obese and lean subjects (25), most studies show a blunted thermogenic response in the obese $(1,7,14$, 17, 18). The relation between the percentage change in slope of the cumulative food intake curve and the magnitude of diet induced thermogenesis is coincidental. Diet-induced thermogenesis and the shape of the curve are characteristics of the subjects, which coincide in these three subject-types. In overweight unrestrained eaters the coincidence might be different. It could be that they display decelerated cumulative food intake curves because of being unrestrained, but a blunted dietinduced thermogenesis because of being overweight. If they have reached a new 'setpoint", considering body weight, and if their intake is not like that, that weight gain is likely, the body will defend the newly achieved level with metabolic efficiency, and a blunted diet-induced thermogenesis is likely. On the other hand, in overweight subjects, who are still in the dynamic phase "the energy intake obviously exceeds energy expenditure, and the surplus is stored as weight gain. In that case metabolic efficiency is not required, and a blunted diet-induced thermogenesis might be the cause of easy weight gain, but does not necessarily have to appear. .

The diet induced thermogenesis of $8.8 \%$ in the group of unrestrained eaters may be part of the thermogenic response to the meal because the experiments were discontinued two and a half hours after the start of the meal, when energy expenditure had not returned to premeal base-line yet. Therefore our figure of $8.8 \%$ might seem low compared to $14.8 \%$ measured over 24 hours (17), but still indicates a normal diet induced thermogenesis. An other imperfection is the comparison of metabolic rate during and after the meal to metabolic rate one hour prior to the meal. This imperfection is kept as small as possible because the subjects had to sit down quietly, before, during and after the meal, with the only activities contributing to metabolic rate being writing before and after the meal, and handling spoon, fork, and knive, during the meal. The coincidence of 
deceleration in cumulative food intake curves and diet-induced thermogenesis in normal weight unrestrained eaters, indicating physiological, 1.e. thermogenic feedback, which might contribute to a control of food intake in the sense of the thermostatic theory (21), is only a part of the relation between eating behaviour and physiological parameters. This relation needs to be further elucidated.

Laessle (11) argues that restrained eaters might need less energy than unrestrained caters, to maintain the same weight, because of a relatively low energy expenditure. Such a decreased energy expendiure might be genetically determined and restrained eaters might be people with a biological predisposition to a low energy expenditure. However, evidence from other studies shows that frequent dieting and weight cycling (2) in itself is able to cause a long standing decrease in energy expenditure. Our overweight restrained eaters had a history of multiple dieting periods indeed, indicated by the scores on H-P restraint.

Normal weight restrained eaters maintain their planned, relatively low body weight, constantly and succesfully. From their scores on H-P restraint it may be concluded that they diet more frequently than unrestrained eaters do, but less frequently than the overweight restrained eaters. They showed a lower level of metabolic rate before the start of the meal, compared to unrestrained eaters. This lower level of energy expenditure in normal weight restrained eaters was also found by Tusch et al (20). However, they measured over 24 hrs while we measured over one hour only. Their restrained eaters had, similar to our normal weight restrained eaters, a slightly higher actual BMI than the unrestrained group, but reported consumption of less energy. The authors state that this is not due to underreporting by their subjects. This apparent contradiction was explained by results concerning energy expenditure. The restrained group had diminished energy requirements without elevated starvation (as indicated by biochemical variables), and consistent weight stability throughout the measuring period. 24 Hour energy expenditure may be subdivided into basal metabolic rate and thermogenesis, due to physical activity, temperature regulation and diet induced thermogenesis. The particular components of total $24 \mathrm{~h}$ energy expenditure that account for the lower energy expenditure in normal weight restrained eaters could be diet induced thermogenesis and resting metabolic rate, both being lower. Although their BMI is mostly slightly higher than in the unrestrained group, normal weight restrained eaters regulate their weight below the level at which they would without dietary restrictions. Eating style could have led to compensatory changes in energy expenditure on the one hand, and may therefore be the reason why metabolic rate has declined below the biologically given level.

On the other hand the blunted thermogenic response we found as before (21) in the restrained overweight group and in the restrained normal weight group could support the idea of a genetically determined decreased energy expenditure as a cause rather than the result of obesity and as constitutive rather than the result of developmental factors. The 
relatively low or blunted thermogenic responses in overweight restrained eaters and in nomal weight restrained eaters might have two different explanations. In restrained eaters decreased energy expenditure might be partly genetically determined. In overweight restrained eaters this might be phenotypically confirmed by their eating style: eating with alternating dietary restrictions and disinhibitions easily leads to maintenance of overweight by the mechanism of weight cycling. In normal weight restrained eaters the phenotypical margin might be larger: their eating style of continuous dietary restriction might contribute to the phenomenon of decreased energy expenditure, but their dietary restriction in connection with decreased energy expenditure results in a BMI in the normal range.

\subsection{References}

1 Bessard, T.; Schutz, Y.; Jéquier, E. Energy expenditure and postprandial thermogenesis in obese women before and after weight loss. Am. J. Clin. Nutr. 38: 680-693; 1983.

2 Blackburn, G.L.; Wilson, G.T.; Kanders, B.S.; Stein, L.J.; Lavin, P.T.; Adler, J.; Brownell, K.D. Weight cycling: the experience of human dieters. Am. J. Clin. Nutr. 49: 1105-1109; 1989.

3 Brouwer, E. Report of sub-committee on constants and factors. In: Energy Metabolism, ed Blaxter, K. I. Proceedings of 3rd symposium on energy metabolism. EAAP Publ. 11.Acad. Press, London, 440$443 ; 1965$.

4 Garrow, J.S. Treat obesity seriously: a clinical manual.Edinburgh Churchill Livingstone, 1981.

5 Henry, C.J.K.; Emery, B. Effect of spiced food on metabolic rate. Human Nutrition: Clinical Nutrition 40C:165-168; 1986.

6 Herman, C.P.; Polivy, J. Restrained eating. In A.Stunkard(ed.) Obesity 208-224. W B Saunders, Philadelphia 1980.

7 Jéquier, E.; Schutz, Y. New evidence for a thermogenic defect in human obesity. Intern.Journ. of Obesity 9, 2,: 1-7; 1985.

8 Jung, R.T.; Shetty, P.S.; James, W.P.T. Reduced thermogenesis in obesity. Nature 279: 322-323; 1978.

9 Kissileff, H.R.; Klingsberg, G.; VanItallie, T.B. Universal eating monitor for continuous recording of solid or liquid consumption in man.Am. J. Physiol. 238: 14-22; 1980.

10 Kissileff, H.R.; Thornton, J.L.; Becker, E. A quadratic equation adequately describes the cumulative food intake curve in man. Appetite 3: 255-272; 1982.

11 Laessle, R.G.; Tuschl, R.J.; Kotthaus, B.C.; Pirke, K.M. Behavioral and biological correlates of dietary restraint in normal life. Appetite, 12: 83-94; 1989. 
12 LeBlane, $I$. Brondel, L. Role of palatability on meal-induced thermogenesis in human subjects. Am. Physiol. 248:E333-E336; 1985.

13 LeBlanc, J * Cabanac, M. Samson, P. Reduced postprandial heat production with gavage as compared with meal feeding in human subjects. Am. J. Physiol. 246 (Endocrinol. Metab. 9): E95-E101 ; 1984.

14 Pittet, P.H.; Gygax, P.H.; Jéquiler, E. Thermic effect of glucose and amino acids in man studied by direct and indirect calorimetry. Br. J. Nutr. $31: 343 ; 1974$.

15 Samueloff, S.; Beer, G.; Blondheim, S.H. Influence of physical activity on the thermic effect of food in young men. Isr. J. Med. Sci. 18: 193-196, 1982.

16 Schoffelen, P.; Saris, W.H.M.; Westerterp, K.R.; Ten Hoor, F. Evaluation of an automatic indirect calorimeter for measurement of energy balance in man. In: Human energy metabolism: Physical activity and energy expenditure measurement in epidemiological research based upon direct and indirect calorimetry. ED.A.J.H.van Es.Euro Nut report 5: 51-54, Wageningen 1985.

17 Schutz, Y.; Bessard, T.; Jéquier, E. Diet-induced thermogenesis measured over a whole day in obese and non-obese women. Am.J. Clin.Nutr. 40: 542-552; 1984.

18 Steiniger, J.; Karst, H.; Noack, R.; Steglich, H.D. Diet-induced thermogenesis in man: thermic effects of single protein and carbohydrate test meals in lean and obese subjects. Ann.Nutr.Metab. $31: 117-125 ; 1987$.

19 Stunkard, A.J.; Messick, S. The three factor eating questionnaire to measure dietary restraint, disinhibition and hunger. PSych.Res. 29:71$83 ; 1985$.

20 Tuschl, R.J.; Platte, P.; Laessle, R.G.; Stichler, W.; K.M. Pirke. Energy expenditure and every day eating behavior in healthy young women. Am. J. Clin. Nutr. 52,81-6; 1990.

21 Westerterp-Plantenga, M.S.; van den Heuvel E.; Wouters, L.; ten Hoor, $F$. Deceleration in cumulative food intake curves, changes in body temperature, and diet-induced thermogenesis. Physiol and Behav, 48(6) 831-836, 1990 .

22 Westerterp, K.R.; Nicolson, N.A.; Boots, J.M.J.; Mordant, A.; Westerterp-Plantenga, M.S. Obesity, restrained eating and the cumulative food intake curve. Appetite 11: 119-128; 1988.

23 Westerterp-Plantenga, M.S.; Westerterp, K.R.; Nicolson, N.A.; Mordant, A.; Schoffelen, P.F.M.; ten Hoor, F. The shape of the cumulative food intake curve in humans, during basic and manipulated meals. Physiol. and Behav. 47: 569-576; 1990.

24 Westerterp-Plantenga ${ }$ M. S.; van den Heuvel, E.; Wouters, L.; ten Hoor, F. Restrained eating, obesity and cumulative food incake curves during four-course meals. Appetite, 1991, 16, 149-158. 
25 Weststrate, J.A.; Dopheide, T.; Robroch, L.; Deurenberg, P.; Hautvast, J.G.A.J. Does variation in palatability affect the postprandiall response in energy expenditure? Appetite, 15, 209-219, 1990.

26 Zed, C.; James, W. P. T. Dietary thermogenesis in obesity, response to carbohydrate and protein meals: the effect of $B$ adrenergic blockade and semistarvation. Intern. Journ. Obesity, 10, 391-405, 1986. 


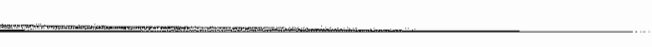




\title{
Accuracy of Estimates of Forthcoming Ingestion as a Function of Menu Familiarity and Dietary Restraint
}

\author{
M. S. Westerterp-Plantenga, E. Van den Heuvel, L. Wouters, and \\ F. ten Hoor. \\ Open University, Heerlen \\ State university of Limburg, Maastricht \\ The Netherlands \\ submitted
}

8. 1 Abstract

Estimates of forthcoming intake were compared with amount eaten in normal-weight restrained eating women, normal-weight unrestrained eating women and overweight restrained eating women for three fourcourse lunches of which the first one mainly consisted of an Italian menu, the second and third one mainly of a Japanese menu. A negative relation was found between the difference in estimated and eaten amount for the first and third lunch and degree of restraint $(r=-0.56 \mathrm{p}<0001)$. This indicates that those who score high on a restraint scale, have learnt better ways of estimating their intake. No relation was found between the difference in estimated and eaten amount and degree of restraint during the second lunch $(p>0.8)$. This indicates that the unfamiliarity of a meal makes it more difficult to predict how much of it would be satiating.

\subsection{Introduction}

The capacity to estimate intake is implicitly tested in Stunkards Three Factor Eating Questionnaire, in questions like: 'I have a pretty good idea of the number of calories in common foods', true $=F_{1}$ " or: "I of ten stop eating when I am not full as a conscious means of limiting the amount that I eat', true = FI; or 'I do not eat some foods because they make me fat', true $=F_{1}$; or "How likely are you to shop for low calorie foods?", very $=F_{1}$. Scoring on $F 1$ means scoring on the factor cognitive restraint. 
High scores on this type of questions label subjects as cognitively restrained: subjects who might have a high degree of accuracy of the estimate of their forthcoming food intake.

Unrestrained cating subjects, who score low on $F_{1}$ questions, belong to the category of subjects who experience physiological parameters in the regulation of food intake more adequately. For instance their diet-induced thermogenesis shows values in the normal range, whereas these values in overweight and normal weight restrained eating subjects were significantly lower (Westerterp et all, 1990).

Theoretically, the accuracy of the estimate will be stabilized with farniliar menus but has yet to be developed with an unfamiliar menu.

In order to assess the possible relation between cognitive restraint and estimate accuracy in situations with familiar and unfamiliar meals, we offered different meal types to different types of subjects. Normal- and overweight restrained eating women and normal weight unrestrained eating women were served a familiar meal, and the same unfamiliair meal twice, respectively. We analysed accuracy of estimate as a function of familiarity with the meal type and dietary restraint, by comparing estimated and eaten amount of food and relating the differences to the restraint scores, for the unfamiliar as well as for the familiar menus.

\subsection{Method}

\subsubsection{Subjects}

Healthy female subjects $(n=28)$ were recruited via the local newspaper from the general population in the South of the Netherlands as well as from university students and employees of the Limburg State University. They were divided into women who had participated in a weight reduction group, but were still overweight, and women without selfdefined weight problems of normal weight. Informed consent was obtained. Weight and height in indoor clothes, without shoes, were used to calculate body mass index $\left(\mathrm{BMI}=\mathrm{kg} / \mathrm{m}^{2}\right)$. According to the criterion used by Garrow (1981), BMI > 25, nine subjects (32\%) were classified as overweight. The remaining 19 subjects were classified as normal weight. Before the series of lunches started, each subject completed a Dutch translation (Westerterp et $\mathrm{al}_{1}, 1988$ ) of the three factor eating questionnaire (TFEQ) developed by Stunkard \& Messick (1985), and of the restrainedeating questionnaire developed by Herman \& Polivy (1980).

The three dimensions of response to the TFEQ were labelled 'cognitive restraint" $\left(F_{1}\right)$. 'disinhibition" $\left(F_{2}\right)$, and 'hunger' $\left(F_{3}\right)$. The score on the Herman \& Polivy questionnaire was labelled ' $\mathrm{H}-\mathrm{P}$ '.

By the criteria for weight and for restraint the women could be classified in three different groups, namely normal weight unrestrained; normal weight restrained; overweight restrained. No overweight unrestrained 
eaters participated, as the overweight subjects all were recruited from a weight reduction group. We were sure that these subjects still would be restrained in their eating behaviour. This was also confirmed by the consistency in the answers on the three factor eating questionnaire, and by the interview conducted by the dietician. This procedure was chosen, since in overweight eaters the distinction between restrained and unrestrained was not reliable, because about $60 \%$ of them showed inconsistency in answering the three factor eating questionnaire. As consistency of answering the TFEQ the representativity of the answer on the question whether a subject eats what, when and how much she desires, for scoring as restrained or unrestrained considering the entire questionnaire, is taken as a criterion.

In three subject types with two differences the types can be compared two by two, namely concerning weight, and concerning restraint.

\subsubsection{Meal components}

The meals consisted of four courses, each of a different homogeneous food, and were isocaloric. The proportion of carbohydrate, protein and fat was the same in the comparable courses of both meals. All subjects had rated the familiar meal to be moderately to highly palatable. The four courses consisted respectively of:

familiar meal:

1) vegetable soup $\left(150 \mathrm{~g} ; 5,4 \mathrm{~kJ} / \mathrm{g} ; 65-68^{\circ} \mathrm{C}\right)$;

2) pasta, mixed uniformly with a sauce of ground meat, tomato puree, mild red bell peppers, onions, mushrooms and oil $\left(700 \mathrm{~g} ; 4,8 \mathrm{~kJ} / \mathrm{g} ; 60-62^{\circ}\right.$

C) ; 3) applesauce $(175 \mathrm{~g} ; 3,2 \mathrm{~kJ} / \mathrm{g})$;

4) ice cream $(100 \mathrm{~g} ; 4,0 \mathrm{~kJ} / \mathrm{g})$.

unfamiliar meal:

1) miso soup (150g; $\left.5,6 \mathrm{~kJ} / \mathrm{g} ; 65-68^{\circ} \mathrm{C}\right)$;

2) japanese rice with tempoera, soy sauce, salad $(700 \mathrm{~g} ; 4,7 \mathrm{~kJ} / \mathrm{g} ; 60$ $62^{\circ} \mathrm{C}$ );

3) 'olvarit' babyfood (a fruit mixture $175 \mathrm{~g} ; 3,2 \mathrm{~kJ} / \mathrm{g}$ );

4) bulgarian mint yogurt $(100 \mathrm{~g} ; 3,9 \mathrm{~kJ} / \mathrm{g})$.

Three courses (1, 3 and 4 ) were small to normal portions, of a fixed size, which had to be fully consumed. The second course consisted of an ample portion, of a size which was previously considered an ad libitum portion, not limiting intake. Some of course 2 was always left over.

\subsubsection{Procedure}

Data presented here are based on series of three lunches, which took place at the same time of day on the same day of the week in consecutive weeks. Subjects arrived one and a half hour prior to lunch and were installed alone in a respiration chamber, for other reasons. They read, 
listened to music, or watched television, sitting down quietly one hour before and two hours after lunch.

Eating behaviour was observed directly by the experimenter, through a door-window of the chamber, which did not disturb the subject because of a difference in light intensity. The experimenter scored the time at which each bite occurred directly into a digital computer. Intake was monitored via an electronic weighing scale built into the table under the plate and connected to the same computer. This set-up is similar to the universal eating monitor" developed by Kissileff et al (1980). All subjects were aware of this procedure and were assured that all data would be kept in strict confidence.

Subjects were instructed to eat no solid food in the three hours preceding a test meal. Before the start of the meal, they were asked to record the time they had arisen that morning, time of breakfast, and the kind and amount of food and beverages consumed at breakfast. Subjects then rated their degree of hunger on a $100 \mathrm{~mm}$ line.

The first and second course, the warm courses, were served just before the start of the meal through an air lock. The two cold courses were available to the subject from a side table in the room.

Before they started the meal, subjects estimated the percentage they would ingest of the second course.

Subjects were instructed to eat the courses from the table and in a certain order, and to signal the experimenter when they had finished a course. With respect to the second course, the subjects were told to eat as much as they liked and felt comfortable with.

Subjects signalled when they had finished the complete meal. Hunger ratings were then repeated and in addition subjects rated how comfortable they had felt during the meal, and how much they had eaten in comparison to their normal lunch, all on 100 -mm lines.

Subjects were also asked to rate the relative palatability of the different courses of the meal from 6-10 $(6=$ moderately palatable, $7=$ palatable, $8=$ very palatable, $9=$ highly palatable, $10=$ extremely palatable): first they rated course 1 , and secondly the courses 2,3 , and 4 , in comparison to course 1.

Finally they rated familiarity of each course as 0,1 or $2(0=$ unfarniliar, $1=$ at least one experience with, 2 =familiar).

\subsubsection{Data analysis}

Body mass index and age were averaged over subgroups split according to body mass index and restraint. From the scores on "cognitive restraint", 'disinhibition', 'hunger', 'Herman-Polivy restraint', the median and range were calculated for the same subgroups.

Body mass index distinguishes between being normal weight or overweight. Following the criterion used by Garrow (1981), subjects with a Quetelet index $>25$ were classified as overweight and subjects with a 
Quetelet Index $\leq 25$ were classified as nomal weight. The restraint questionnaires discriminate between being unrestrained or restrained, following Herman-Polivy (1980). In this population, as in our former populations of subjects (Westerterp-Plantenga et al., 1990, 1991) the median of the Herman-Polivy scores was 15 . Thus, subjects with a score $>15$ were classified as restrained. From the other restraint questionnaire, the three factor eating questionnaire (Stunkard and Messick, 1985), we used the discrimination between 'cognitively restrained' and unrestrained (Westerterp-Plantenga et al., 1991). This concerns the scores on the cognitive restraint factor $\mathrm{F}$ l. In this population, as was the case in our former populations of subjects, the median of the scores on F1 was 9 . Thus, subjects with a score on $\mathrm{F} 1>9$ were classified as cognitively restrained (Westerterp-Plantenga et al., 1991). The subjects who were restrained eaters by being food-concerned were classified by $F 1>9$; the subjects who were restrained eaters by being weight concerned were classified by $\mathrm{H}-\mathrm{P}>15$. Therefore, the discrimination between restraint and unrestraint implies an F1 score $>9$, or an H-P score $>15$. Summarizing, the criteria for normal weight unrestraint are $\mathrm{BMI} \leq 25 ; \mathrm{Fl}$ $\leq 9$ and $\mathrm{H}-\mathrm{P} \leq 15$. The criteria for normal weight restraint are $\mathrm{BMI} \leq 25$; $\mathrm{F} 1>9$ or $\mathrm{H}-\mathrm{P}>15$. The criteria for obese restraint are $\mathrm{BMI}>25 ; \mathrm{F} 1>9$ or H-P $>15$. There were no obese unrestrained eating subjects since all obese subjects included in this study had recently participated in a weight reduction group.

The amount subjects felt they had eaten compared to their normal lunch, was averaged per subject over the three mealls and over the entire group. Amount eaten of the second course, total eating time, eating rate per meal and per course, were averaged over the entire group (as subgroups did not show significant differences) for each of the three meals .

For the ratings of hunger and comfort, as well as for the ratings of familiarity and relative palatability, the median and range is given over the entire group.

Subjects estimated their forthcoming ingestion of the second, the ad libitum course, as a percentage of the food served on the plate. The percentage estimated of the served food $(700 \mathrm{~g})$, consequently gave the amount of grammes the subjects imagined they would eat. This estimate was then compared to the amount the subjects ate subsequently. The difference between estimated and eaten amount of this course was calculated for the familiar meal, the unfamiliar meal and again for the unfamiliar meal when it was offered the second time. These differences were related to degree of restraint. 


\subsection{Results}

\subsubsection{Subject characteristics}

Subject characteristics are summarized in table 1. In order to identify the different subject types, the characteristics are also split according to body mass index and restraint.

Table 8:1 Body mass index (BMI), cognitive restraint (F1), disinhibition (F2), hunger (F3), Herman-Polivy restraint and age, of the subgroups.

\begin{tabular}{|c|c|c|c|c|c|c|}
\hline & \multicolumn{2}{|c|}{$\begin{array}{l}\text { Normal weight } \\
\text { unrestrained } \\
n=12 \\
\text { mean } \pm \text { sd }\end{array}$} & \multicolumn{2}{|c|}{$\begin{array}{l}\text { Normal weight } \\
\text { restrained } \\
n=7 \\
\text { mean } \pm \mathrm{sd}\end{array}$} & \multicolumn{2}{|c|}{$\begin{array}{l}\text { Overweight } \\
\text { restrained } \\
n=9 \\
\text { mean } \pm \text { sd }\end{array}$} \\
\hline \multirow[t]{2}{*}{$\begin{array}{l}\text { BMI } \\
\text { Age }\end{array}$} & \multicolumn{2}{|c|}{$\begin{array}{l}19.9 \pm 1.6 \\
26.9 \pm 7.1\end{array}$} & \multicolumn{2}{|c|}{$\begin{array}{l}20.8 \pm 1.2 \\
29.6 \pm 12.3\end{array}$} & \multicolumn{2}{|c|}{$\begin{array}{l}27.4 \pm 2.9 \\
36.2 \pm 16.2\end{array}$} \\
\hline & median; & range & median; & range & median; & range \\
\hline $\mathrm{F}_{1}$ & 4 & $2-6$ & 11 & 10.13 & 11 & $7-14$ \\
\hline $\mathrm{F} 2$ & 4 & $2-7$ & 7 & $4-10$ & 10 & $7-13$ \\
\hline F3 & 3 & $2-5$ & 4 & $3-6$ & 5 & $4-7$ \\
\hline $\mathrm{H}-\mathrm{P}$ & 10 & $7-12$ & 15 & $13-17$ & 19 & $16-22$ \\
\hline
\end{tabular}

Table 8.2 Correlationcoefficients (Spearman's rho; $\mathrm{p}$ values; $\mathrm{df}=27$ ).

\begin{tabular}{|c|c|c|c|}
\hline & H-P restraint & $\mathrm{F} 1$ & Age \\
\hline BMII & $\begin{array}{l}r=0.75 \\
(p<0.001)\end{array}$ & $\begin{array}{l}r=0.58 \\
(p<0.001)\end{array}$ & $\begin{array}{l}r=0.49 \\
(p<0.025)\end{array}$ \\
\hline $\mathrm{H} \sim \mathrm{P}$ & & $\begin{array}{l}r=0.78 \\
(p<0.0001)\end{array}$ & $\begin{array}{l}r=0.49 \\
(p<0.025)\end{array}$ \\
\hline F1 & & & $\begin{array}{l}r=0.44 \\
(p<0.016)\end{array}$ \\
\hline
\end{tabular}

\subsubsection{Hunger state}

Subjects were always hungry when they arrived for the meal tests (median 92; range $87-98$ on the 100-mm line), and always satiated after the meal (hunger ratings median 8 ; range $3-12$ ). Subjects felt they had eaten slightly more (median $+15 \%$; range $6-22 \%$ ) than in their normal lunch but they felt comfortable (median 83 ; range $78-89$ ). No relationship was found between change in hunger ratings from before and 
after the meal and amount eaten, total eating time, eating rate or eating rate changes over the meal.

\subsubsection{Meal parameters}

Statistically significant differences in meal parameters between subgroups were not found, therefore the meal parameters are given for the entire group.

Table 8.3 Meal parameters

Amount eaten during the second course, total eating time, eating rate and relative palatability of the three meal types.*)

\begin{tabular}{|c|c|c|c|c|c|c|c|c|c|}
\hline \multicolumn{2}{|c|}{$\begin{array}{l}\text { Amount eaten } \\
\text { during the } 2 \text { nd } \\
\text { course }(g)\end{array}$} & \multicolumn{2}{|c|}{$\begin{array}{l}\text { Total eating } \\
\text { time (s) }\end{array}$} & \multicolumn{2}{|c|}{$\begin{array}{l}\text { Eating rate } \\
\left(\mathrm{g} \cdot \mathrm{s}^{-1}\right)\end{array}$} & \multicolumn{2}{|c|}{$\begin{array}{l}\text { Relative } \\
\text { palatability } \\
2 \text { nd course }\end{array}$} & \multicolumn{2}{|c|}{ Familiarity } \\
\hline mean & sd & mean & sd & mean & sd & & and & & and \\
\hline 392 & 139 & 929 & 153 & 0.8 & 0.07 & 8 & 7.9 & 2 & $2-2$ \\
\hline 378 & 146 & 985 & 162 & 0.7 & 0.07 & 8 & 7.9 & 0 & 0.1 \\
\hline 397 & 142 & 988 & 157 & 0.8 & 0.06 & 8 & 7.9 & 1 & $1-1$ \\
\hline
\end{tabular}

*) Total eating time is nett eating time; meal duration is about $30 \mathrm{~min}$. Palatability scale: 6-10 (from moderately palatable to extremely palatable); Familiarity scale: 0,1 , or 2 (unfamiliar, one experience at least, familiar).

\subsubsection{Estimate and amount eaten}

During the first confrontation with the unfamiliar meal, there was only underestimate, where as during the first and third meals there was overestimate, as well as underestimate. See for the amounts eaten and the amounts over- and underestimated, as well as the percentages of the ingested food over- and underestimated table 8.4. Since the degree of estimation accuracy appears irrespective of over- or underestimate, the differences between estimates and intake are given as absolute values as well. The differences between the estimate and the amount eaten were correlated to degree of restraint (table 8.5). There were no significant correlations between these differences and body mass index, age or F3 scores. 
Table 8.4 Amounts estimated by the subjects; amounts eaten by the subjects, during the three different meals. Over-and underestimates are given seperately, as well as the absolute values of the differences between estimated and ingested amounts. Also the percentage over-and underestimated is given, as a percentage of the amount ingested.

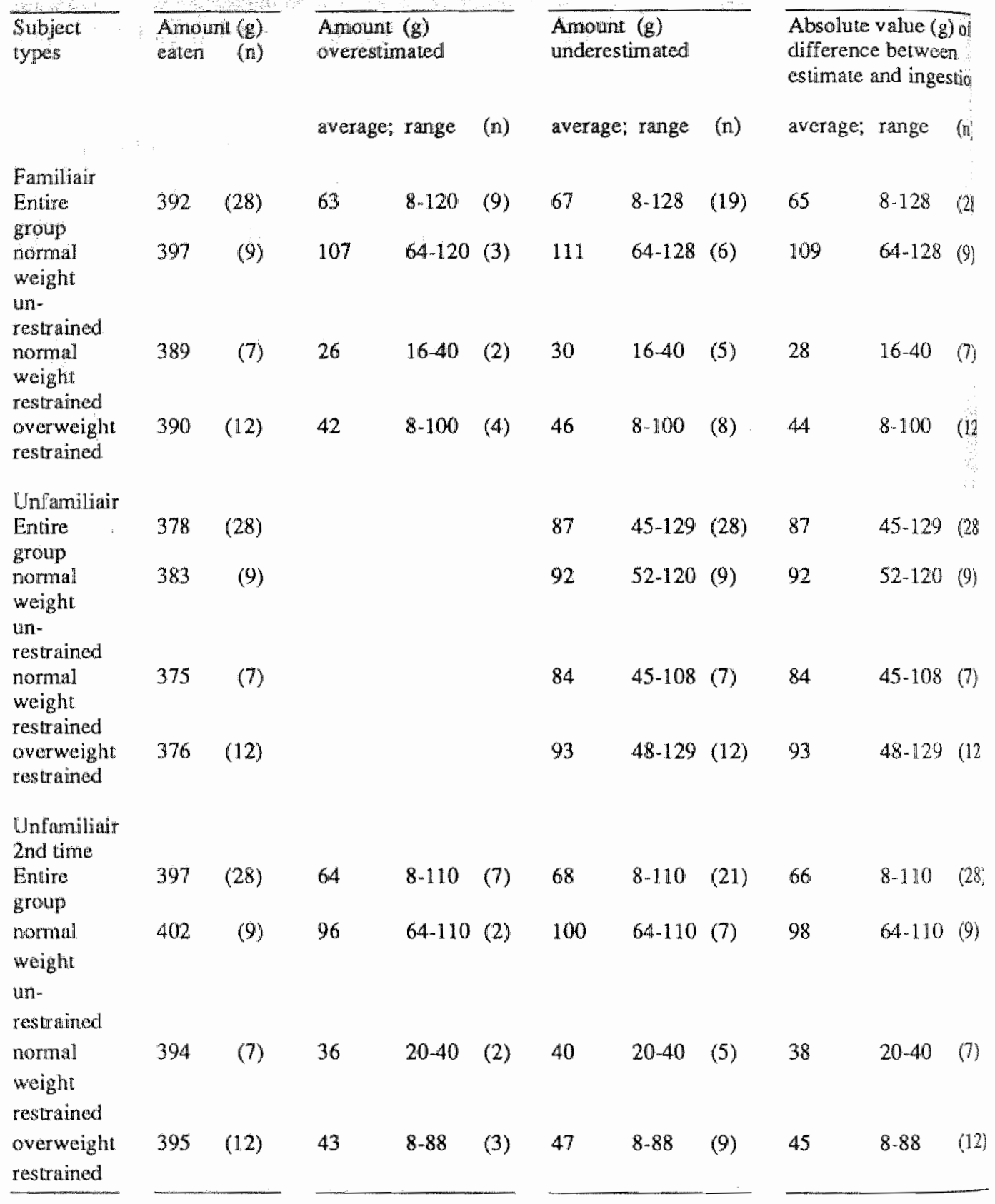


Subject

types:
Amount (g)

eaten
Percentage

overestimated
Percentage

underestmated
Absohute value $(9 \%)$ of difference between

esituate and ingestion

median; range (n) median; range (n) median; range (n)

\begin{tabular}{|c|c|c|c|c|c|c|c|c|c|c|c|}
\hline \\
\hline \multicolumn{12}{|l|}{$\begin{array}{l}\text { Entire } \\
\text { group }\end{array}$} \\
\hline $\begin{array}{l}\text { normal } \\
\text { weight }\end{array}$ & 397 & (9) & 23 & $16-30$ & (3) & 24 & $16-32$ & (6) & 24 & $16 \cdot 32$ & (9) \\
\hline $\begin{array}{l}\text { un- } \\
\text { restrained }\end{array}$ & & & & & & & & & & & \\
\hline $\begin{array}{l}\text { nomal } \\
\text { weight }\end{array}$ & 389 & (7) & 7 & $4-10$ & (2) & 7 & $4-10$ & $(2)$ & 7 & $4-10$ & (7) \\
\hline $\begin{array}{l}\text { restrained } \\
\text { overweight } \\
\text { restrained }\end{array}$ & 390 & $(12)$ & 12 & $2-25$ & (4) & 13 & $2-25$ & (8) & 13 & $2-25$ & (1.2) \\
\hline Unfamilair & & & & & & & & & & & \\
\hline $\begin{array}{l}\text { Entite } \\
\text { group }\end{array}$ & 378 & $(28)$ & & & & 23 & $12-34$ & (28) & 23 & 12.34 & $(28)$ \\
\hline $\begin{array}{l}\text { normal } \\
\text { weight }\end{array}$ & 383 & (9) & & & & 23 & $13 \cdot 34$ & $(9)$ & 23 & $13-34$ & (9) \\
\hline $\begin{array}{l}\text { un } \\
\text { restrained }\end{array}$ & & & & & & & & & & & \\
\hline $\begin{array}{l}\text { normal } \\
\text { weight } \\
\text { restrained }\end{array}$ & 375 & (7) & & & & 20 & $12-27$ & (7) & 20 & $12-27$ & (7) \\
\hline $\begin{array}{l}\text { overweight } \\
\text { restrained }\end{array}$ & 376 & (12) & & & & 23 & $12-34$ & (12) & 23 & $12-34$ & (12) \\
\hline $\begin{array}{l}\text { Unfamilair } \\
\text { 2nd time }\end{array}$ & & & & & & & & & & & \\
\hline $\begin{array}{l}\text { Entire } \\
\text { group }\end{array}$ & 397 & $(28)$ & 16 & $2-30$ & (7) & 17 & $2-30$ & (21) & 17 & $2-30$ & $(28)$ \\
\hline $\begin{array}{l}\text { normal } \\
\text { weight }\end{array}$ & 402 & $(9)$ & 21 & $14-30$ & (2) & 22 & $14-30$ & (7) & 22 & 14.30 & (9) \\
\hline $\begin{array}{l}\text { un- } \\
\text { restrained }\end{array}$ & & & & & & & & & & & \\
\hline $\begin{array}{l}\text { nomal } \\
\text { weight } \\
\text { restrained }\end{array}$ & 394 & (7) & 10 & $5-16$ & (2) & 10 & $5-16$ & (5) & 10 & $5-16$ & (7) \\
\hline $\begin{array}{l}\text { overweight } \\
\text { restrained }\end{array}$ & 395 & (12) & 11 & $3-22$ & (3) & 12 & $3-22$ & (9) & 12 & 3.22 & (12) \\
\hline
\end{tabular}


Table 8.5 Correlationcoefficients (Spearman's rho; $\mathrm{p}$ values; $\mathrm{df}=27$ ) between degree of restraint and difference between estimated and actual amount eaten during the three meal types.

\begin{tabular}{ll}
\hline mealiype & $\begin{array}{l}\text { H-P and difference } \\
\text { estimate/eaten }\end{array}$ \\
Familiar & $r=-0.82(p<0.0001)$ \\
Unfamiliar & $r=0.12(p>0.58)$ \\
$\begin{array}{l}\text { Unfamiliar } \\
\text { 2nd time }\end{array}$ & $r=-0.73(p<0.0001)$ \\
\hline
\end{tabular}

F1 and difference estimate/eaten

$\mathbf{r}=-0.91(\mathrm{p}<0.0001)$

$r=0.11(p>0.57)$

$\mathbf{r}=-0.83(\mathrm{p}<0.0001)$

A negative relation was found between degree of restraint and the absolute value of the difference in the estimated and the amount eaten during the first and third meal $(r=-0.91 ; p<0.0001 ;$ and $r=-0.83 ; p$ $<0.0001$ ). No relation was found between degree of restraint and the difference in the estimated and the amount eaten during the second, the unfamiliar meal( $p>0.58)$. See also fig. 8.1, 8.2 and 8.3. Differences between estimates and intakes were not related to the amount eaten.

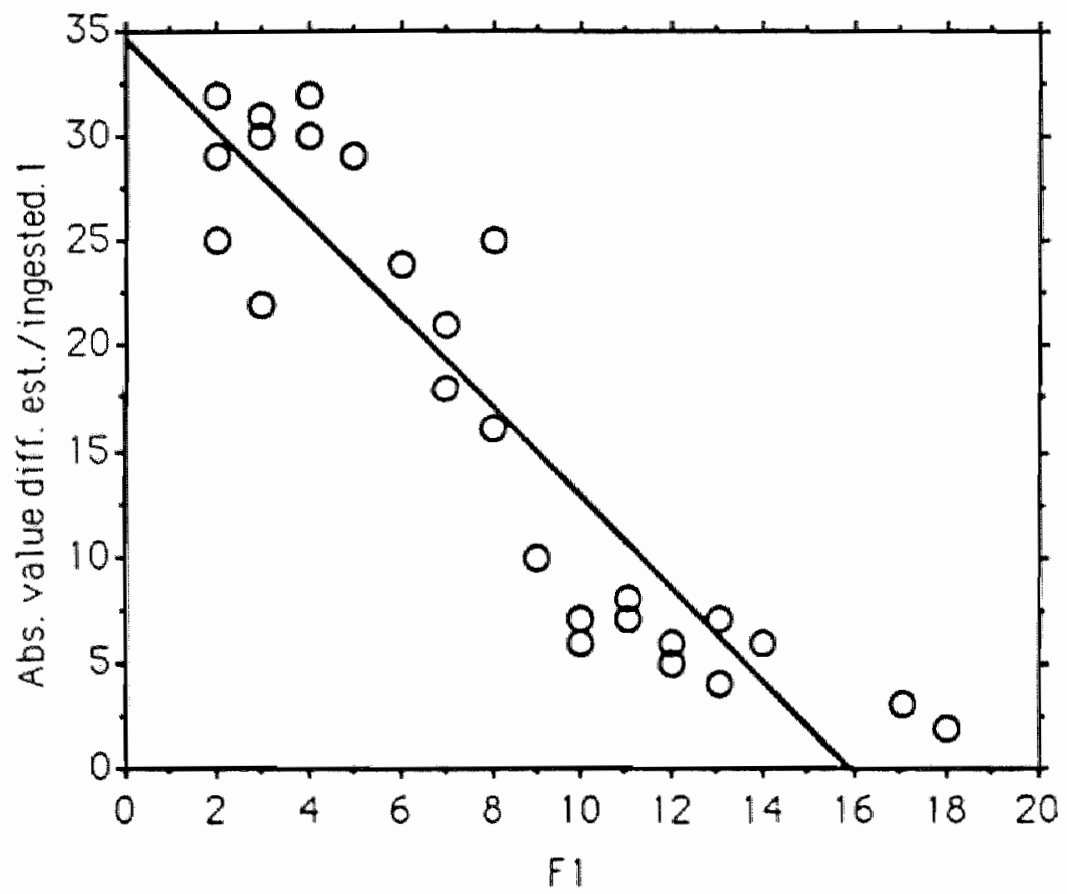

Figure 8.1 The relation between restraint score (F1) and the absolute value of the difference between the amount estimated to ingest and the amount ingested, expressed as a percentage of the anount ingested. 


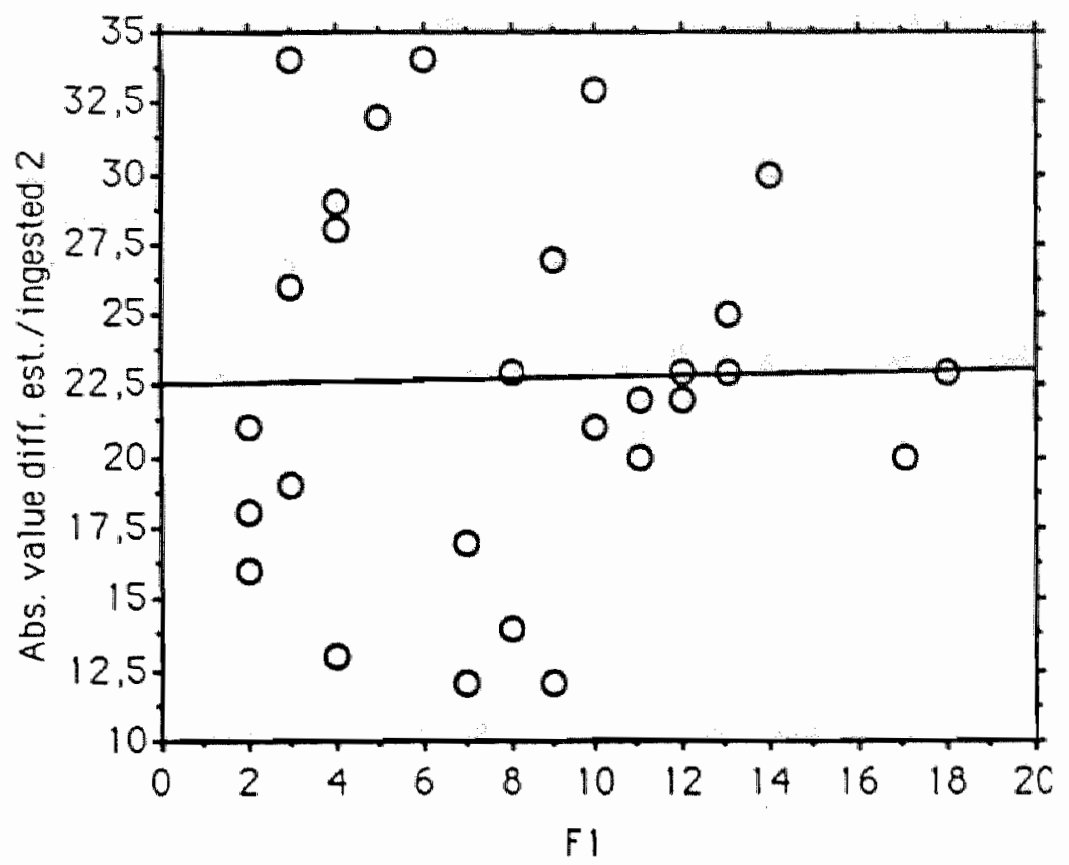

Figure 8.2 The relation between restraint score (F1) and the absolute value of the difference between the amount estimated to ingest and the amount ingested, expressed as a percentage of the amount ingested.

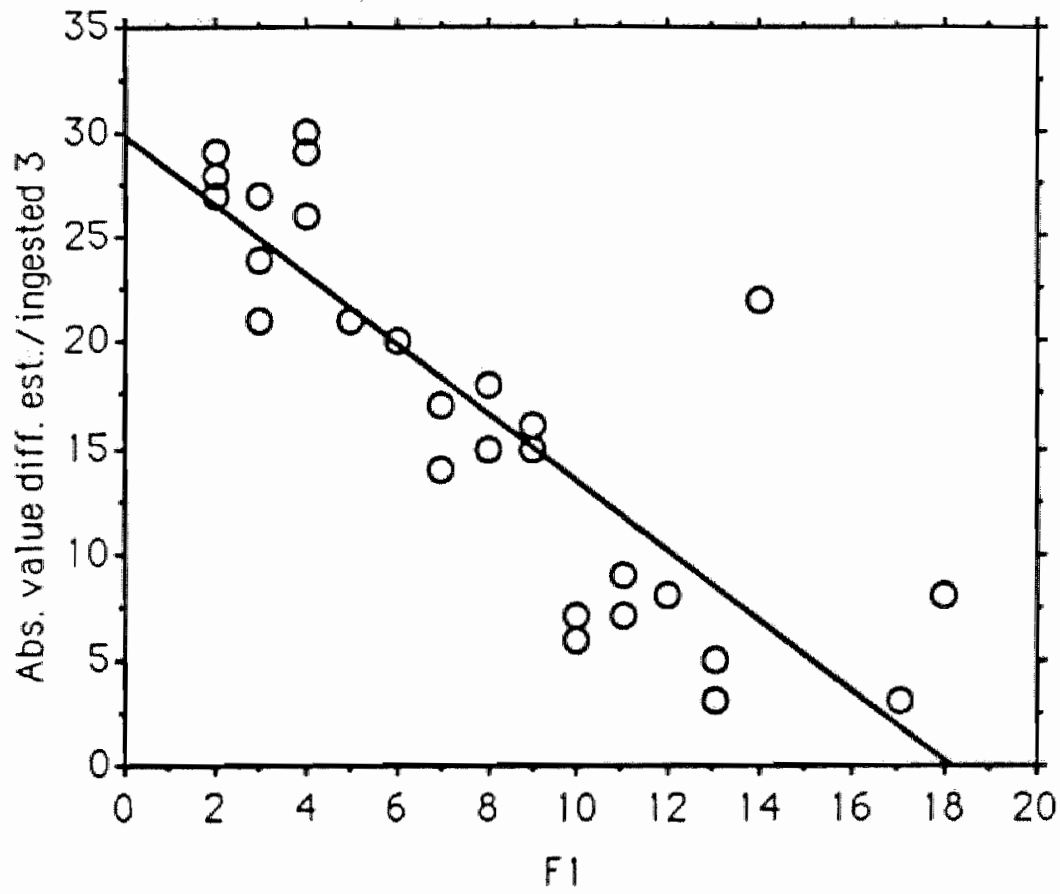

Figure 8.3 The relation between restraint score (F1) and the absolute value of the difference between the amount estimated to ingest and the amount ingested, expressed as a percentage of the amount ingested. 
Nomal weight and overweight restrained eating women estimated their forthcoming ingestion better than unrestrained eating women did. While eating an unfamiliar meal this cognitive aspect of eating behaviour still had to be established. This was achieved during the second confrontation with the unfarmiliar meal.

Although the resulting meal sizes showed no differences between restrained and unrestrained eaters, and no differences between familiar and unfamiliar meals, there was a remarkable difference in estimate accuracy, both between subject types and between meal types. The remarkable difference in estimate accuracy between subject types in the situation of familiar meals is a difference in accuracy indeed, irrespective of over- or underestimate. The differences in estimate accuracy between mealtypes can be taken as a response to unfamiliarity, as there was only underestimate during the first confrontation with the Japanese meal. As soon as this mealtype had become familiar, the difference in estimate accuracy had become a difference in accuracy between subject types again. The present results confirm the presumption derived from the answers on the three factor eating questionnaire.

The accurate estimates in restrained eaters were not only consistent with the type of answers on questions in Stunkards TFEQ, but also with the scores on the Herman-Polivy restraint scale. Obviously being food concerned, as well as being weight concerned, are reasons to improve a certain accuracy to estimate one"s own food intake well.

Whether the restrained eating subjects need their accuracy to estimate forthcoming meal size remains a question, because the amount they ate did not differ in accordance with their estimates, comparing the results of the second and third meal. However, they only needed one experience to adjust estimate (and not to adjust amount eaten).

Age relates to obesity, and is positively correlated with body mass index, Herman-Polivy restraint, and F1, cognitive restraint, as was found before (Westerterp-Plantenga et all, 1991). Age did not relate to estimate accuracy.

In unrestrained eating women estimate accuracy did not seem necessary, probably owing to their physiological feedback mechanisms (WesterterpPlantenga et al., 1990), as their resulting meal sizes did not differ in different situations.

Familiarity enhances accurate estimate in restrained eaters. Unfamiliarity causes underestimate, but a certain degree of palatability and hunger, playing their roles in food intake regulation ( Porikos et al., 1982), might provide nevertheless a "normal "meal size. During the second confrontation with the unfamiliar meal the food is treated according to the past experience of the relation between its sensory qualities and aftereffects of ingestion, which was similarly found by Booth, et al, (1976). 
Booth, D.A., Lee, M. \& Mc. Aleavey, C. (1976). Aquired sensory control of satiation in man. British Journal of. Psychology, 2, 67, 137-147.

Garrow, J.S. (1981). Treat obesity seriously: a clinical manual. Edinburgh Churchill Livingstone

Herman, C. P. \& Polivy, J. (1980). Restrained eating. In A. Stunkard (ed.), Obesity pp 208-224. W.B. Saunders, Philadelphia.

Kissileff, H.R., Klingsberg, G. \& .van Itallie, T. B. (1980) Universal eating monitor for continuous recording of solid or liquid consumption in man. American Journal of Physiology, 238, 14-22.

Porikos, K.P., Hesser, M.F. \& van Itallie, T. B..(1982). Caloric regulation in normal-weight men maintained on a palatable diet of conventional foods. Physiology \& Behavior, 29, 293-300.

Stunkard, A.J. \& Messick., S. (1985). The three factor eating questionnaire to measure dietary restraint, disinhibition and hunger. Journal of Psychosomatic Research, 29, 71-83.

Westerterp, K. R., Nicolson, N. A., Boots, J. M. J., Mordant, A. \& Westerterp-Plantenga, M. S. (1988) . Obesity, restrained eating and the cumulative food intake curve. Appetite ${ }_{\star} 11,119-128$.

Westerterp-Plantenga, M. S., Wouters, L., ten Hoor, F. (1990). Deceleration in cumulative food intake curves, changes in body temperature, and diet-induced thermogenesis. Physiology \& Behavior, 48(6) 831-836.

Westerterp-Plantenga, M. S., Wouters, L., ten Hoor, F. (1991). Restrained eating, obesity, and cumulative food intake curves during four course meals. Appetite, 16, 149-158. 



\section{Dietary Restraint and Disinhibition in Overweight Women During a Four Month Dieting Period}

M. S. Westerterp-Plantenga, E. Van den Heuvel, L. Wouters, and F. ten Hoor.

Open University, Heerlen

State university of Limburg, Maastricht

The Netherlands

submitted

9.1 Abstract

Most dieters do not succeed in maintaining uninterrupted restriction of intake. Periods of restraint are often punctuated by episodes of disinhibited eating. Identifying dieters or successful dieting means measuring restraint, i.e. weight-concern, food-concern, and susceptibility to disinhibition. The Herman-Polivy restraint-scale measures weightconcern and chronically dieting, so is designed to identify dieters. The three factor eating questionnaire (TFEQ, 13) isolates successful caloric restriction and disinhibition.

In order to assess the consequences of dietary restraint during a four month weight reduction programme in overweight restrained eating women, repeated scores on both restrained eating questionnaires were compared to those of normal weight and overweight conspecifics without a weight reduction programme. This experimental period of four months included four-course solid food lunches once in two or three weeks with preload-experiments for the different subject types.

In the overweight restrained eaters the Herman-Polivy scores were significantly higher than in the normal weight groups $(\mathrm{p}<0.001)$ and remained unchanged throughout the four month period of controlled or non-controlled dieting. From the TFEQ scores of the controlled dieting group cognitive restraint increased where as disinhibition decreased significantly during this period; the medians of both scores being higher than in the normal weight unrestrained eaters. These overweight restrained eaters had a constant energy intake at lunchtime $(1908 \pm 252 \mathrm{~kJ})$, 
notwithstanding preloads of 660 or $420 \mathrm{~kJ}$. They compensated for the preloads in the evenings, and their daily energy intake never exceeded $4200 \mathrm{~kJ}$ during this dieting period. The normal weight unrestrained eaters compensated partly for the preload energy intake, during the main course of the lunch, namely by $53 \%$ (median); range $48 \%-58 \%$. Counterregulation after preloads in restrained eaters did not occur, probably due to the within boundary preload sizes.

After the controlled dieting period energy intake at lunch time in the overweight restrained group increased immediately by $26 \%$; range $18 \%$ $34 \%$, and total energy intake by $22 \% ; 15 \%-29 \%$, while scores on cognitive restraint and disinhibition returned to their original values.

In conclusion the Herman-Polivy restraint scale identifies dieters irrespective of being on a controlled or non-controlled diet. The TFEQ measures successful dieting effectively by the cognitive restraint factor. Moreover, a decrease in the disinhibition scores under circumstances with controlled dieting is shown and an immediate relapse of the scores on the disinhibition as well as the cognitive restraint factor thereafter.

\subsection{Introduction}

Most dieters do not succeed in maintaining uninterrupted restriction of intake. The average dieter exhibits periods of restraint punctuated by episodes of disinhibited overeating, and, does not achieve significant weight loss in relation to physiologically defended levels (8). A "restrained eater" is no doubt restrained, but such a restraint is likely to be accompanied by these lapses, or such a restraint may even be a major contributor to such lapses.

Differences between the methods to measure restraint are as much conceptual as psychometric. The Herman - Polivy restraint-scale measures the extent to which people display concern with their weight and chronically diet to control it (1). The task of dieting may be very difficult and accumulation of dieting failures may lead to eating disorders (11). In that case, dieters are not typically "successful". Thus in the Herman-Polivy restraint construct disinhibition is measured as well.

The three factor eating questionnaire (TFEQ, 13), does not appear to measure the same behavioural tendencies as does the Herman-Polivy restraint scale, but discriminates between successful caloric restriction and disinhibition. In this questionnaire pure restraint without disinhibition is measured as cognitive restraint (F1), and disinhibition is measured seperately (F2).

Resumingly, the Herman-Polivy restraint scale is designed to identify dieters, whereas the TFEQ is designed to measure successful dieting.

According to this statement, we have found relatively higher scores on the Herman-Polivy restraint scale in overweight restrained eaters compared to the scores of normal weight restrained eaters $(19,21)$. 
The overweight restrained eaters appear to be less successful dieters. They show lapses of restraint, as well as restraint per se $(2,3)$.

Normal weight restraned eaters appear to be very successful in keeping their weight at a certain level for a relatively long time, by maintaining their low energy intake, in relation to a relatively low energy expenditure (14). They do not necessarily have to score high on the Herman-Polivy restraint scale, as they appear to be mainly food-concerned and less weight concerned (19).

In the TFEQ the coupling of cognitive restraint with disinhibition is not always clear. We found this to be age dependent, as well as weight dependent. In the younger age group $\mathrm{F} 1$ and $\mathrm{F} 2$ were positively correlated, which means that restrained eating behaviour was often susceptible to disinhibition, but among the older age group $F 1$ and $F 2$ were negatively correlated, indicating that these subjects were either restrained, or susceptible to disinhibition (18). In the normal weight group F1, and F2 were positively correlated, while in the overweight group the correlation between these scores was negative $(20)$. Which scale is appropriate for measuring restraint depends on the questions research focuses on. The appropriate subscales of the TFEQ might provide adequate measurements of restriction, when the research focus involves the effects of simply restricting food intake. If the research concerns eating behaviour that characterize dieters irrespective of their extent of weight loss, then the Herman-Polivy restraint scale might be the adequate instrument (1). In former research, where we used both scales, there always has been a positive correlation between the scores on both scales (19).

Notwithstanding these small distinctions both the Herman-Polivy restraint and the cognitive restraint scores (TFEQ), showed relations with actual eating behaviour. Restraint scores were negatively correlated with intake rate change during the ad lib course of a meal, and with the magnitude of diet induced thermogenesis (21). Moreover, restraint scores were positively correlated with the degree of accuracy of subjects" estimates of their forthcoming ingestion (22).

However, a relation between degree of restraint and amount eaten has been found incidentically (19), but not in general.

The question whether and how restraint relates to the amount of food eaten, is partly answered by the questionnaire: restrained eaters do not always eat what, when, and how much they want. How much they eat is not necessarily related to how much they restrain themselves. The relationship between restraint and eating behaviour has been given in terms of a relationship between restraint and eating rate change during a single course meal irrespective of its actual length and amount eaten (20). In some situations the amount eaten is an exponent of restraint or vice versa. If the amount to eat is very limited (for instance during a strict diet), the subject may show exceptional restraint as a the consequence. Reversily, in case of disinhibition of restraint a raise in the amount eaten may be the consequence. 
The first question we try to elucidate is: how does a strict diet affect "restraint" in the course of some months?

A phenomenon like counterregulation - which is the regulation of the amount of food intake depending on the size of a preload in restrained and unrestrained eaters - elucidates eating behaviour during the meal with regard to the amount eaten. Counterregulation has been shown in restrained eaters who were given a preload. Eating this preload was perceived as overeating and led to a successive deliberate increased intake. Consequently, disinhibition led to increased food intake, which was positively correlated with preload size. (2).

Herman and Polivy (4) proposed that biological pressures maintain consumption within a certain range between the boundaries of hunger and satiety, which they call the range of 'biological indifference'. Within this range, psychological factors would have their greatest impact on the regulation of food intake. The boundary model postulates that the zone of biological indifference is wider in dieters than in non-dieters. (Fig 9.1). Dileters are said to have lower hunger boundaries and higher satiety boundaries than non-dieters. Also, dieters have a third, self-imposed 'diet' boundary, located between hunger and satiety boundaries, marking their maximum desired consumption. Herman and Polivy (4) suggest that once restrained eaters transgress this diet boundary, they eat until they reach the satiety boundary. This has been called the disinhibition which explains the phenomenon of counterregulation in restrained eaters: when the self control of restrained eaters is disrupted, overeating ensues. The perception of having overeaten disinhibits restrained eaters $(8,12)$. Consequently, if a preload is given within the diet boundary, counterregulation does not have to occur.

Therefore the second question is: if restraint appears strongly during a period of strict dieting, how likely is disinhibition as a consequence of a modest preload, and how does this affect the amount eaten?

In connection with assessing the consequencies of dietary restraint during a four month weight reduction programme in overweight restrained eating women, low and high caloric prelload effects on food intake were measured. During this period of four months body mass index and fat mass were measured regularly, and repeated scores on both restraint questionnaires of this group were compared to those of normal weight and overweight conspecifics without the weight reduction programme. In order to obtain meal parameters as a part of eating behaviour, the subjects were invited for lunch to the laboratory about once a fortnight. In two of these seven lunches the preload experiments were conducted. 
non-dieters:

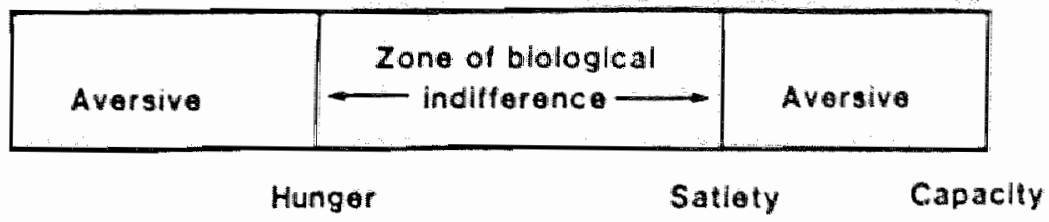

dieters:

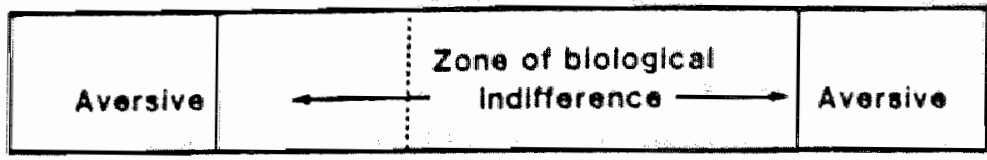

Hunger Diet

Satlety Capaclty

Figure 9.1 The boundary model of Herman \& Polivy.

\subsection{Method}

\subsubsection{Subjects}

Healthy female subjects were recruited via a local newspaper from the general population in the south of the Netherlands as well as from university students and employees of the Limburg State University. From 124 respondents 80 subjects, age $20-45 \mathrm{yrs}$, were selected in four categories:

20 normal weight unrestrained eaters $(\mathrm{BMI}<25$; scores on the TFEQ (13) $\mathrm{F} 1<9, \mathrm{~F} 2<9$; scores on the Herman-Polivy restraint questionnaire $<15 ; 9$ and 15 being the median in formerly studied groups $(20,21)$.

20 normal weight restrained eaters $(\mathrm{BMI}<25 ; \mathrm{F} 1>9$ or $\mathrm{H} \sim \mathrm{P}>15)$;

40 overweight restrained eaters $(\mathrm{BMI}>25 ; \mathrm{F} 1>9$ or $\mathrm{H}-\mathrm{P}>15)$. From the overweight restrained group

20 subjects had followed a weight reduction program recently, and 20 subjects were selected to follow a weight reduction program, run by our dietician. These subjects were instructed how to keep a $1000 \mathrm{kcal}(4200$ kJ) diet of their own compositions, and with sufficient variation. They were also instructed how to keep a dietary record. The four selected groups were as homogeneous as possible, considering age and weight.

Informed consent was obtained. The experimental period lasted four months per subject. During this period BMI was measured and calculated, the \% body fat was calculated from skin-fold measurements, and the questionnaires (TFEQ, 13; Herman-Polivy-restraint questionnaire 6) were 
completed. These measurements and scores were taken in week $0,8,16$, 18.

During the experimental period subjects came to lunch in our laboratory restaurant seven times, with two or three week intervals.

\subsubsection{Procedure}

The overweight restrained eaters with the controlled diet were regularly seen by the dietician. They were instructed how to keep a dietary record, including how to calculate the amount of energy ingested, divided in protein, fat, and carbohydrate. The subjects with the controlled diet were advised to consume $55 \mathrm{~g}$ protein, $35 \mathrm{~g}$ fat, and $100 \mathrm{~g}$ carbohydrate per day. The normal weight unrestrained and - restrained subjects $(n=40)$ and the overweight control group $(\mathrm{n}=20)$ did not keep a food intake diary.

Data presented here are based on series of seven lunches, which took place at the same time of the day, on the same day of the week, with a two or three week interval. Subjects arrived one and a half hour prior to lunch and they were installed alone in a breakfast room. They read, listened to music, or watched television, sitting down quielly one hour before and two hours after lunch.

Intake was monitored via an electronic weighing scale built into the table under the plate and connected to a digital computer. This set-up is similar to "the universal eating monitor" developed by Kissileff et al. (9). All subjects were aware of this procedure and were assured that all data would be kept in strict confidence. In earlier experiments, no difference in results was found between the situation in which the subjects were not informed about the situation and in which the subjects were aware of the actual experiment (20).

The meals consisted of four courses, which were all theoretically rated as attractive, (palatability ratings $7-8$ on a scale of $6-10$, where $6=$ palatable). The courses consisted of the following components:

1 vegetable soup $(150 \mathrm{~g} ; 5,4 \mathrm{~kJ} / \mathrm{g})$;

2 rice $(200 \mathrm{~g} ; 6,3 \mathrm{~kJ} / \mathrm{g})$ and sauce $(400 \mathrm{~g} ; 3,6 \mathrm{~kJ} / \mathrm{g})$;

3 cucumber $(50 \mathrm{~g} ; 0,8 \mathrm{~kJ} / \mathrm{g})$;

4 mango ( $100 \mathrm{~g} ; 1,8 \mathrm{~kJ} / \mathrm{g})$.

Three courses ( 1,3 and 4 ) were small to normal portions, so that the amount eaten was fixed. The second course consisted of an ample portion, of a size which was previously considered an ad libitum portion, not limiting intake. Some of course 2 was always left over.

Subjects were instructed to eat no solid food in the three hours preceding a test meal. Before the start of the meal, they were asked to record the time they had arisen that morning, time of breakfast, and the kind and amount of food and beverages consumed at breakfast. Subjects then rated their degree of hunger on a $100 \mathrm{~mm}$ line, which they repeated after every course. The three small courses were available to the subject from a side table in the room. The second course, the main course, was served just 
before the start of the meal through an airlock. Subjects were instructed to eat the courses in a certain order, and to signal the experimenter when they had finished a course. With respect to the second course, the subjects were told to eat as much as they liked and felt comfortable with. Subjects signalled when they had finished the complete meal. In addition to the last hunger ratings subjects rated how comfortable they felt during the meal, and how much they had eaten in comparison to their normal lunch, all on $100 \mathrm{~mm}$ lines.

One and a half hour prior to the third and fifth lunch subjects were given a fruit yogurt preload, randomly a high caloric one $(150 \mathrm{~g} ; 4,4 \mathrm{~kJ} / \mathrm{g}$, resulting in $660 \mathrm{~kJ})$ and a low caloric one $(150 \mathrm{~g} ; 2,8 \mathrm{~kJ} / \mathrm{g}$, resulting in $420 \mathrm{~kJ}$ ).

\subsubsection{Data analysis}

Body mass index, the \% body fat, age, were averaged over the subjects split according to the four groups described before. This is given for week $0,8,16$ and 18 in table 9.1. The median and ranges are given similarly for the scores on cognitive restraint, disinhibition, hunger, and H-P restraint. The amount eaten, the eating time and eating rate were averaged over the subgroups split according to these four groups. These meal parameters are given for the seven lunches seperately, in table 9.4. Preloads preceeding the third and the fifth lunch, with different caloric contents were offered randomly. As there was no difference in results considering the order in which a high or low caloric preload was offered, the high caloric preload results are presented as belonging to the third meal in week 6-8, and the low caloric preload results are presented as belonging to the fifth meal in week 12-14.

The amount subjects felt they had eaten compared to their normal lunch were averaged per subject over the seven meals. The median and ranges of the hunger ratings before the meals and after the courses are given per subject and split according to the four groups as described, for the five normal meals and for the two meals preceded by a preload, seperately (see table 9.5). Also the median and range of ratings of comfort are given. The food intake diaries were analysed with a computer program, to obtain the amount of energy ingested, divided in carbohydrate, fat, and protein. Also vitamins and minerals ingested were calculated.

\subsection{Results}

\subsubsection{Subject characteristics}

In all groups the following subject characteristics remained constant over the four month dieting period: Body fat \%, F3 score, H-P score, age. 
Table 9.2 Significant changes (Mann Whitney $U$ test) in $B M I, F 1$ and $F 2$, from week 0 to week 16, in the overweight restrained group with the controlled diet $(n=20$; $d f=19)$.

\begin{tabular}{|c|c|c|c|c|c|}
\hline \multirow{4}{*}{ BMI } & \multicolumn{2}{|l|}{ week 0} & \multicolumn{2}{|l|}{ week 16} & $p<$ \\
\hline & \multicolumn{2}{|c|}{ mean $\pm s d$} & \multicolumn{2}{|c|}{ mean $\pm s d$} & \\
\hline & \multicolumn{2}{|c|}{$34.4 \pm 4.1$} & \multicolumn{2}{|c|}{$31.3 \pm 3.1$} & 0.0001 \\
\hline & median; & range & median; & range & \\
\hline $\mathrm{F} 1$ & 8 & $5-11$ & 15 & $12-18$ & 0.0001 \\
\hline $\mathrm{F}_{2}$ & 10 & $7-13$ & 6 & $3-9$ & 0.0001 \\
\hline
\end{tabular}

For the entire group the correlations between the subject characteristics $B M I$, age, $H-P, F 1$, and $F 2$, are given in table 3 . As the significancy of these correlations might be artificial, due to the selected groups of $n=60$ restrained and $n=20$ unrestrained eating subjects, the correlations are also calculated for the following subgroups:

$\mathrm{n}=40$ normal weight unrestrained with normal weight restrained eaters, thus eliminating the effect of overweight

$n=40$ normal weight unrestrained with overweight restrained eaters, thus eliminating the effect of the controlled diet

$\mathrm{n}=40$ normal weight unrestrained with overweight restrained with the controlled diet.

Except for the correlation between BMI and age, all correlations are present in these subgroups too $(d f=39 ; p<0.0001$ and $r=0.6$ till 0.8 ; Spearmans ' $r$ ).

Table 9.3 Correlationcoefficients (Spearmans " $\mathrm{r} ; \mathrm{p} ; \mathrm{df}=79$ ) of the subject characteristics $B M I$, age, $\mathrm{H}-\mathrm{P}, \mathrm{Fl}$, and $\mathrm{F} 2$ for the entire group.

\begin{tabular}{|c|c|c|}
\hline Correlations & $\begin{array}{l}\text { positive or } \\
\text { negative }\end{array}$ & $p<$ \\
\hline BMI - Age & positive & 0.008 \\
\hline BMI - HP & positive & 0.0001 \\
\hline $\mathrm{BMI}-\mathrm{F1}$ & positive & 0.0008 \\
\hline $\mathrm{BMI}-\mathrm{F} 2$ & positive & 0.0001 \\
\hline $\mathrm{H}-\mathrm{P}-\mathrm{F} 1$ & positive & 0.0001 \\
\hline $\mathrm{H}-\mathrm{P}-\mathrm{F} 2$ & positive & 0.0001 \\
\hline$F_{1}-F_{2}$ & positive & 0.0012 \\
\hline
\end{tabular}

\subsubsection{Food intake diaries}

On average the overweight restrained group with controlled diet consumed $45 \pm 4 \mathrm{~g}$ protein, $40 \pm 5 \mathrm{~g}$ fat, $120 \pm 22 \mathrm{~g}$ carbohydrate per day, during the first four weeks. After calculation and instruction (the subjects 
with the controlled diet were advised to consume $55 \mathrm{~g}$ protein, $35 \mathrm{~g}$ fat, and $100 \mathrm{~g}$ carbohydrate), they consumed $55 \pm 5 \mathrm{~g}$ protein, $40 \pm 4 \mathrm{~g}$ fat, and $110 \pm 20 \mathrm{~g}$ carbohydrate per day, during week 5-17. During week 18 they consumed $55 \pm 4 \mathrm{~g}$ protein, $45 \pm 5 \mathrm{~g}$ fat, and $176 \pm 24 \mathrm{~g}$ carbohydrate per day. On the days with laboratory lunches, subjects were always told by the dietician how much they had consumed, in $\mathrm{kJ}$, and in grammes carbohydrate, protein and fat, including the preloads, if applicable.

\subsubsection{Meal parameters.}

The meal parameters amount eaten, ealing time, and eating rate, for the four subgroups split according to weight, restraint, and with or without a controlled diet, are given in table 4.

Eating rate was on average constant and the same in all groups throughout the experimental period.

Amount eaten was significantly smaller in the overweight restrained group with the controlled diet than in any of the other groups, and consequently eating time was shorter (chi-square $=1694.07 ; D F=19$; $\mathrm{p}<0.0001$ ) .

Amount eaten did not change after preloads in the normal weight restrained eaters and in the overweight restrained eaters with the controlled diet. The latter compensated, as was concluded from their food intake diaries (on preload days their food intake did not seem to exceed $4200 \mathrm{~kJ}$ too, according to the dietary record).

The normal weight unrestrained eaters compensated during the main course, with $53 \%$; range $48 \%-58 \%$, of the energy content of the preload, irrespective of being a high or low caloric preload.

The overweight restrained eaters without controlled diet showed a slight increase in amount eaten after the preloads. 
Table 9.4 Amount eaten, Eating time, Eating rate, given for the four subgroups split according to weight and restraint** and according to being on a controlled diet or not, for seven times during the experimental period.

\begin{tabular}{|c|c|c|c|c|c|c|c|c|c|}
\hline & & Nom & all weig & (BM) & 25): & Oven & eigh & $\mathrm{MD} 25$ & \\
\hline & & $\begin{array}{l}\mathrm{n}=20 \\
\text { unre }\end{array}$ & rained & $\begin{array}{l}\text { restr } \\
n=20\end{array}$ & ned & $\begin{array}{l}\text { rest } \\
\mathrm{n}=20 \\
\text { cont } \\
\text { diet }\end{array}$ & $\begin{array}{l}\text { ned } \\
\text { Iled }\end{array}$ & $\begin{array}{l}\text { restra } \\
n=20\end{array}$ & ned \\
\hline & week & mear & $\pm \mathrm{sd}$ & mear & $\pm s d$ & men & $1 \mathrm{sd}$ & mean & $\pm s d$ \\
\hline Amount & 0.2 & 692 & 139 & 633 & 133 & 485 & 66 & 689 & 159 \\
\hline eaten $(\mathrm{g})$ & $3-5$ & 698 & 146 & 636 & 134 & 493 & 77 & 688 & 153 \\
\hline & $6-8^{*}$ & 624 & 142 & 631 & 130 & 482 & 84 & 718 & 152 \\
\hline & $9-11$ & 686 & 143 & 636 & 139 & 475 & 76 & 690 & 158 \\
\hline & $12-14 *$ & 637 & 145 & 630 & 131 & 498 & 78 & 723 & 157 \\
\hline & $15-17$ & 685 & 144 & 635 & 137 & 476 & 77 & 686 & 154 \\
\hline & 18 & 688 & 147 & 634 & 132 & 532 & 62 & 686 & 150 \\
\hline Eating & $0-2$ & 979 & 153 & 905 & 157 & 693 & 94 & 984 & 151 \\
\hline time (s) & $3-5$ & 985 & 162 & 909 & 150 & 704 & 87 & 983 & 157 \\
\hline & $6-8 *$ & 892 & 148 & 902 & 158 & 689 & 85 & 1025 & 154 \\
\hline & $9-11$ & 988 & 136 & 908 & 156 & 678 & 78 & 986 & 153 \\
\hline & $12-14^{*}$ & 901 & 141 & 901 & 154 & 711 & 84 & 1032 & 159 \\
\hline & $15-17$ & 987 & 149 & 907 & 153 & 690 & 86 & 980 & 158 \\
\hline & 18 & 989 & 148 & 906 & 152 & 760 & 97 & 980 & 155 \\
\hline $\begin{array}{l}\text { Eating } \\
\text { rate }(\mathrm{g} / \mathrm{s})\end{array}$ & $0-18$ & .7 & 07 & .7 & .08 & .7 & .07 & .7 & .08 \\
\hline
\end{tabular}

* week 6-8 high caloric preload; week 12-14 low caloric preload. The high and low caloric preloads were offered randomly, but the data are presented within these weeks.

** criteria for restraint: $\mathrm{F} 1>9$, or $\mathrm{H}-\mathrm{P}>15$.

\subsubsection{Hunger state and comfort}

Subjects were always hungry when they arrived for the meal tests, and always satiated when they left. Subjects felt they had eaten slightly more (12\%; range $6 \%-18 \%$ ) than in their normal lunch but they felt comfortable (84; range $79-89$ ). Hunger declined gradually after each course, mostly after course 2, the ad libitum main course (see table 9.5). Apart from in the normal weight unrestrained eaters the decline in hunger was the same irrespective of the preloads. In the normal weight unrestrained eaters hunger declined significantly more $(\mathrm{p}<0.05)$ before and after course 1 in the preload situation, but the decline was the same after course 2,3 and 4, compared to the non-preload situation.

Also the hunger ratings in the normal weight unrestrained eating group were higher at the start of the normal lunch meals, and lower at the end of 
these meals, compared to the hunger ratings of the restrained eaters $(\mathrm{p}<0.05)$.

No relationship was found between change in hunger ratings from before to after the meal and amount eaten, total cating time or eating rate.

Table 9.5 Median and range of hunger state $(0-100 \mathrm{~mm}$ scores) before the meal and after each course, for the neals with and without preloads, in the four subject groups.

\begin{tabular}{|c|c|c|c|c|c|}
\hline & $\begin{array}{l}\text { before } \\
\text { the meal }\end{array}$ & $\begin{array}{l}\text { after } \\
\text { course } 1\end{array}$ & $\begin{array}{l}\text { after } \\
\text { course } 2\end{array}$ & $\begin{array}{l}\text { after } \\
\text { course } 3\end{array}$ & $\begin{array}{l}\text { after } \\
\text { course } 4\end{array}$ \\
\hline \multicolumn{6}{|l|}{$\begin{array}{l}\text { normal weight } \\
\text { unrestraint }(20)\end{array}$} \\
\hline without preload & $99 ; 98-100$ & $85 ; 82-88$ & $30 ; 24-36$ & $15 ; 11-19$ & $1 ; 0-2$ \\
\hline with preload & $90 ; 88-92$ & $78 ; 76-80$ & $29 * 26-32$ & $12 ; 10-14$ & $1 ; 0-2$ \\
\hline \multicolumn{6}{|l|}{ normal weight } \\
\hline without preload & $93 ; 91.95$ & $86 ; 82-90$ & $45 ; 38-52$ & $21 ; 16-26$ & $8 ; 6-10$ \\
\hline with preload & $92 ; 89-95$ & $87 ; 84-90$ & $43 ; 3848$ & $23 ; 16-30$ & $9 ; 6-12$ \\
\hline $\begin{array}{l}\text { owerweight } \\
\text { restraint ( } 20 \text { ) } \\
\text { controlled diet }\end{array}$ & & & & & \\
\hline without preload & $93 ; 91-95$ & $76 ; 73-79$ & $36 ; 32-40$ & $17 ; 14-20$ & $7 ; 5 ; 9$ \\
\hline with preload & $92 ; 89.95$ & $78 ; 74-82$ & $39 ; 34-44$ & $18 ; 16-20$ & $7 ; 4-10$ \\
\hline \multicolumn{5}{|l|}{ overweight } & \\
\hline without preload & $91 ; 88-94$ & $81 ; 79-83$ & $40 ; 36-44$ & $19 ; 16-23$ & $6 ; 3-9$ \\
\hline with preload & $96 ; 93-99$ & $85 ; 82-88$ & $42 ; 40-44$ & $18 ; 14-22$ & $6 ; 4-8$ \\
\hline
\end{tabular}

\subsubsection{Relation between subject characteristics and meal parameters}

Body mass index, H-P and F1 scores, were negatively correlated with amount eaten in the entire group (Spearmans'r; $p<0.05$; see table 6). These correlations were not significant in all subgroups.

On closer inspection of the data, the correlation between BMI and amount eaten was only significant in the subgroup normal weight unrestrained combined with overweight restrained on a controlled diet, and was obviously dependent on the artificial combination of being overweight and on a controlled diet, contrarely to being normal weight and unrestrained.

The correlations between restraint and amount eaten appeared only in the subgroups where strictly restraint played a role, namely:

normal weight unrestrained combined with normal weight restrained (eliminating overweight), and normal weight unrestrained combined with overweight restrained on a controlled diet. 
Disinhibition of restraint might have occurred in the overweight restrained group without the controlled diet, after having consumed a preload. Compared to the normal weight restrained eaters they scored slightly higher on $\mathrm{F} 2$, disinhibition, and showed a slight increase in food intake during the lunch after consumption of the preloads. The energy content of this increase in food intake was not related to the energy content of the preload.

No disinhibition after preloads was shown by the overweight restrained eaters on the controlled diet, during the dieting period. Their scores on F2 were decreased during this period. However, in week 18 , when the dieting period finished and the subjects did not have to return to the laboratory anymore, their F2 scores were increased to the original level, and in connection with this, the amount eaten during the last lunch was significantly increased, with $26 \%$; range $18 \%-34 \%$ (chi-square $=129.2$; $\mathrm{DF}=19 ; \mathrm{p}<0.0001)$. Then total intake also exceeded $4200 \mathrm{~kJ}$, with $22 \%$; range $15 \%-29 \%$.

Table 9.6 Correlations between body mass index, H-P score, F1 score, and amount eaten during the lunch meal (Spearman's $r$ ).

Entire group $(\mathrm{n}=80$;

df =79):

Correlations

positive or

$\mathrm{p}<$

negative

BMI- Amount eater

H-P -Amount eaten

negative
negative
negative

0.0001

0.4

F1 - Amount eaten

negative

0.04

0.3

0.3

\subsection{Discussion}

Over a period of 18 weeks body mass index, body fat \%, scores on Herman -Polivy restraint, scores on cognitive restraint, disinhibition and hunger in normal weight restrained and unrestrained eaters, and in overweight restrained eaters remained constant. Also the amount eaten, the eating time and the eating rate during basic lunch meals remained constant in these groups.

This was also the case for most subject characteristics and meal parameters in the overweight restrained group who followed a controlled diet during this period.

The non-constant parameters in this group were body mass index, scores on cognitive restraint and on disinhibition of the TFEQ. BMI decreased significantly, (as was intended), F1 scores increased, and F2 scores decreased with return to the original values in week 18 .

The Herman -Polivy restraint scale is designed to identify dieters and operates successfully in this respect. Irrespective of success among short or long term dieters, it continues to characterize these individuals as 
dieters in a consistent way. The scores on the Herman-Polivy scale, in these (selected) groups are sufficiently related to the scores on the factors of the TFEQ of Stunkard and Messick, so that identifying dieters by H-P scores also means identifying disinhibition. The scores on the TFEQ are rather constant ower a four month period in three subgroups too, which indicates a general reliability of this questionnaire. The sensitivity of the TFEQ to temporal, strict, food concerned dieting was shown by one subgroup, whose members were meant to be dieting. In that case it appeared that there was a discrimination between F1 and F2, but also a correlation. Generally spoken, this correlation was positive, (table 3), but in the dieting group the change in F1 and F2 scores was counterballanced. The relatively low F1 scores in this group at the start of the experimental period, compared to their conspecifics, might indicate a relatively low cognitive personel responsibility because of the forthcoming professionelly counselled dieting period. The following increase in F1 scores might reflect the subjects' growing responsibility, which the type of diet demands. This attitude fades at the end of the dieting period, when the F1 scores return to their original values.

A similar, but reversed pattern, is shown by the F2 scores: an initial decrease, probably due to the comfort of the professionel counselling while dieting, and a final increase to almost their original values, indicating that at the moment when a dieting period finishes, a return to normal daily intake easily overshoots. At this moment being cognitive restraint is given up due to disinhibition. This is effectively shown by the dieting group, when the subjects ate significantly more of the ad libitum lunch course in week 18 , and also exceeded the $4200 \mathrm{~kJ}$ they used to consume per day during the dieting period, according to the dietary records. Although this disinhibition effect was not anticipated by us, -for instance by mentioning that the dieting period soon would be over, -it occurred in all dieters.

If the energy intake measurement in the overweight restraint group with the controlled diet was reliable, and energy expenditure is estimated as 11,12 or $13 \mathrm{MJ}(10)$, weight loss in this group should have been greater. As these calculations imply too many estimates, they are not very reliable as well, but one explanation is that it seems that food intake might have been somewhat higher than reported. However, the idea was to have an overweight group with severe and effective restraint, which was achieved by proposing a more ambitious aim than was acquired. In the entire group, the relations between subject characteristics and amount eaten during lunch were negative, indicating that the higher bodly mass index and restraint, the lower energy intake during lunch.

Concerning the subgroups, the negative relation between BMI and amount eaten during lunch was only significant in the subgroup: normal weight unrestrained with overweight restrained on a controlled diet, indicating that this relation was achieved by the artificial combination of overweight and a strictly limited food intake. 
This relation had been found before, incidentically (19). The negative relation between the subject characteristics F1, H-P, and amount eaten during lunch were only significant in the subgroups: normal weight unrestrained with normal weight restrained; and normal weight unrestrained with overweight restraint on a controlled diet. This indicates that these relations were achieved by means of severe dietary restraint. They support the phenomenon of a slightly higher BMI, related to lower food intake, and, a lower energy expenditure in the normal weight restrained eaters $(14,15)$, compared to normal weight unrestrained eaters. Counterregulation due to disinhibition after the within boundary pre-loads was not shown. The amount eaten during lunch after the preloads changed in two groups. Firstly, normal weight unrestrained eaters compensated partly during the lunch for the ingested pre-load energy. Secondly, overweight restrained eaters consumed slightly more after the preloads.

That the phenomenon of counterregulation did not occur significantly, was probably due to the within boundary preloads. A weak effect, shown by the overweight restrained eaters and by the normal weight unrestrained eaters was unrelated to the energy content itself. These effects have been found before as restraint $x$ preload interactions by Hibscher \& Herman (8), and Ruderman \& Christensen (12). They reported that unrestrained eaters who had a preload ate significantly less than those who did not, whereas restrained eaters who had a preload ate slightly (but not significantly) more than those who did not. They concluded that unrestrained eaters appeared to regulate their eating and restrained eaters appeared to counterregulate.

In our situation, however, the normal weight restrained eaters showed no effect during lunch, and the overweight restrained eaters on the controlled diet showed compensation in their food intake diaries: within the same day food intake never seemed to exceed $4200 \mathrm{~kJ}$. This phenomenon might relate to the boundary model of Herman \& Polivy (4). Although the overweight restrained eaters on the controlled diet got a preload, they were sure that they would be informed about its energy content in order to be able to calculate their daily intake. Perception of having overeaten did not occur, and self-control was not disrupted, which was also shown by the relative decreased $F 2$ (disinhibition) score at that time.

The normal weight restrained eaters, who did not show counterregulation either, probably considered this preload as a modest intake of extra energy, which easily could be kept under control, as they are used to handle similar situations.

In the restrained eaters there was no significant difference in decrease of hunger state during the meal between the preload and non preload situation, but in the unrestrained eaters before and after course 1 hunger was decreased significantly more during the preload situation. This might already be related to the reduced subsequent food intake.

The hunger ratings before and after the courses of the lunch showed a difference between restrained and unrestrained eaters. Unrestrained eaters showed a higher degree of hunger before the meal, in the situations 
without the preloads, and a lower degree of hunger after the meal, compared to the restrained conspecifics. Differences between these groups in hunger ratings have not been found that clear before $(19,21)$, probably due to the homogeneity of the groups in this actual experiment.

The difference found here, is consistent with one of the characteristics of the boundary model, namely the wider zone of biological indifference in dieters, than in non-dieters. As dieters are said to have lower hunger boundaries and higher satiety boundaries than non dieters (12), this means that it takes greater food deprivation for them to report hunger, and greater consumption to report satiety.

Summarizing, the present study has shown the consistency of the scores on the Herman-Polivy restraint scale, irrespective of degree of restraint and of a dieting period, and the sensitivity of the TFEQ by Stunkard and Messick during a dieting period. The relation between both questionnaires was as such, that it allows the conclusion that H-P restraint implies disinhibition of restraint as well.

Considering restraint $x$ preload interactions, the boundary model by Herman \& Polivy was supported by data from this study, in so far that unrestrained eaters regulated food intake to a certain extent, and overweight restrained eaters without a controlled diet seemed to counterregulate. The energy contents of the preloads were as such that the normal weight restrained eaters did not perceive to have overeaten, and the overweight restrained eaters with the controlled diet knew that they were able not to exceed their daily intake. In these groups self-control was not disrupted and disinhibition and subsequently counterregulation did not occur.

For the overweight restrained eating women this non- disrupted selfcontroll was also reflected in the increased cognitive restraint scores and the decreased disinhibition scores during the dieting period.

\subsection{References}

1 Heatherton TF, Herman CP, Polivy J, King GA, McGree ST. The (mis)measurement of restraint an analysis of conceptual and psychometric issues. Journ Abn Psych 1988; 97, 1: 19-28.

2 Herman CP, Mack D. Restrained and unrestrained eating. Journal of personality $1975 ; 43$ : 647-660.

3 Herman CP, Polivy J. Anxiety, restraint and eating behaviour. Journ of Abn Psychol 1975; 84: 666-672.

4 Herman CP, Polivy J. A boundary model for the regulation of eating. In: Stunkard AJ, \& Stellar E, eds. Eating and its disorders. New York: Raven Press, 1984: 141-156.

5 Herman $\mathrm{CP}$, Polivy J. From dietary restraint to binge eating: Attaching causes to effects. Appetite 1990; 14: 123-125.

6 Herman CP, Polivy J. Restrained eating. In: Stunkard AJ ed. Obesity. Philadelphia: Saunders, 1980: 208-225. 
7 Herman CP, Polivy J, Esses V. The illusion of counterregulation. Appetite.

8 Hibscher JA, Herman CP. Obesity, dieting and the expression of 'obese' characteristics. Journ of comparative and physiological psychology 1977; 91: 374-380.

9 Kissileff HR, Klingsberg G, VanItallie TB. Universal eating monitor for continuous recording of solid or liquid consumption in man. Am J Physiol 1980; 238:14-22.

10 Meyer GAL. Physical Activity, implications for human energy metabolism. thesis 1990; Rijks Universiteit Limburg, Maastricht, The Netherlands.

11 Polivy J, Herman CP, Breaking the diet habit. New York: basis books 1983.

12 Ruderman AJ . Dietary restraint: a theoretical and emperical review. Psychol Bull 1986; 99, 2: 247-262.

13 Stunkard AJ, Messick S. The three-factor eating questionnaire to measure dietary restraint and hunger. Journ of Psychosomatic research 1985; 29: 71-83.

14 Tuschl RJ, Laessle RG, Platte P, Dirke KM. Differences in foodchoice frequencies between restrained and unrestrained eaters. Appetite 1990; 14: 9-13.

15 Tuschl RJ. From dietary restraint to binge eating: some theoretical considerations. Appetite 1990; 14: 105-109.

16 Wardle J, Beales S. Restraint and food intake: an experimental study of eating patterns in the laboratory and in normal life. Behav Res Ther $1987 ; 25,3: 179-185$.

17 Westenhoefer J, Pudel V, Maus N. Some restrictions on dietary restraint. Appetite 1990; 14: 137-141.

18 Westerterp KR, Nicolson NA, Boots JMJ, Mordant A, WesterterpPlantenga MS, Obesity, restrained eating and the cumulative food intake curve. Appetite 1988; 11: 119-128.

19 Westerterp-Plantenga MS, van den Heuvel E, Wouters L, ten Hoor F. Restrained eating, obesity and cumulative food intake curves during four-course meals. Appetite 1991; 16: 149-158.

20 Westerterp-Plantenga MS, Westerterp KR, Nicolson NA, Mordant A, Schoffelen PFM, ten Hoor F. The shape of the cumulative food intake curve in humans, during basic and manipulated meals. Physiol and Behav 1990; 47: 569-576.

21 Westerterp- Plantenga MS, van den Heuvel E, Wouters L, ten Hoor F. Deceleration in cumulative food intake curves, changes in body temperature, and post prandial thermogenesis. Physiol and Behav 1990; 48: (6) 831-836.

22 Westerterp-Plantenga MS, van den Heuvel E, Wouters $L$, ten Hoor $\mathbb{F}$. Subjects' estimation of their forthcoming ingestion of familiar and unfamiliar foods as a function of dietary restraint. Int J Obesity 1990; 14, 2: 169. 


\section{Conclusions}

Eating behaviour is partly but representatively described by cumulative food intake curves.

Cumulative food intake curves derived from ad libitum consumed meal courses reflect a subjects' eating style independent of the amount of food consumed.

Most normal weight unrestrained eating women display decelerated cumulative food intake, and a normal diet-induced thermogenesis, during familiar as well as unfamiliar meals.

Most overweight and normal weight restrained eating women display linear cumalative food intake, and a blunted diet induced thermogenesis, during familiar as well as unfamiliar meals.

Diet induced thermogenesis in all groups was relatively increased during the first confrontation with the meal with unfamiliar food.

Normal weight and overweight restrained eating women estimate their forthcoming ingestion of a familiar meal better than unrestrained eating women do.

With an unfamiliar meal this cognitive aspect of eating behaviour is achieved during the second confrontation with the unfamiliar meal.

The subject characteristics relevant to food intake and meal parameters remain constant in normal weight restrained and unrestrained eating women and in overweight restrained eating women without a counselled diet, over a period of four months.

Scores on the Herman-Polivy restraint questionnaire are consistent in the long term ( 4 months), and under changing conditions.

The cognitive restraint factor F1 and the disinhibition factor F2 of the three factor eating questionnaire are sensitive to a strict counselled diet.

Unrestrained eaters regulate to a certain extent, in relation to the consumption of a modest preload. 
Overweight restrained eaters without a counselled diet counterregulate to a certain extent, in relation to the consumption of a modest preload.

Overweight restrained eaters with a counselled diet and normal weight restrained eaters neither regulate nor counterregulate in relation to the consumption of a modest preload. 


\section{Discussion}

Eating behaviour is primarily determined by subject characteristics, and secundarily by the food consumed. In this study, eating behaviour in humans is pretended to be reported on, but in effect it is eating behaviour in women, that has been described and analysed.

Eating behaviour is described party, but representatively by the cumulative food intake curve, which reflects the food-subject interaction with respect to the amount of food eaten, time spent eating, eating rate, and change in eating rate (chapter 4 ). The behaviour during a meal that the cumulative food intake curve only implies indirectly is that of pausing, i.e., the use of a napkin, a sip of water, or attention for the surroundings.

We found an increase in pause duration and drinking in connection with a slowing down of the eating rate, during the fourth temporal quarter of the meal (chapter 4), as did Bellisle et al., (1984).

In social situations, the meal-related behaviour becomes at least as important as the eating behaviour itself, and might even influence the eating behaviour. Stunkard and Kaplan (1977) conclude from a study concerning 'eating in public places' that the circumstances under which food is eaten are of greater importance in determining how it is eaten than other parameters, and postulate that human eating behaviour has an enormous plasticity. In this respect, the affective dimension of a sensation might be an important motivation for physiological behaviour (Pfaffmann, 1960) and vice versa it is modified by changes in the internal state, for instance resulting from ingestion (Fantino, 1984; Cabanac et al., 1968). Social environment (Edelman et al., 1986) and for instance noise are capable of modifying human behaviour with regard to food choice and amount eaten (Levy-Leboyer et al., 1984), and of producing eating disorders (Metz et al., 1978).

Despite this plasticity in human eating behaviour, one can say in general that eating behaviour is conditioned, and possibly some of the influences mentioned are included. Through these learning processes food intake can be tuned to the metabolic needs of the body (Booth, 1985).

Cumulative food intake curves represent in most of the subjects the result of those learning processes. The typical subject-dependent pattern, in successive courses (chapter 5) and under some manipulated circumstances (chapter 4) appeared consistently. Some subjects, however displayed a change in their cumulative food intake pattern under 
manipulated circumstances. Their food intake was apparently more susceptible to their internal feedback, either positive, or negative, or to the environmental influence, simulated by an interrupted meal. Whether feedback represents satiation cannot be distinguished, as there was no difference in the reported satiation after the meal, between the different subjects.

The main relation that has been found throughout this study is the relation between eating behaviour being restrained or unrestrained and the shape of the cumulative food intake curve. One of the food characteristics, palatability, showed a positive correlation with the eating rate (chapter 5), but the eating rate change in the curve was not altered. The cumulative food intake curve can be used as a reliable instrument to describe eating behaviour as a whole, independent of changes in the parameters amount eaten, eating time or eating rate.

A relation between the shape of the cumulative food intake curve and subject characteristics would imply a relation between the parameters that characterize each phenomenon. Such a relation has been found coincidentally between the percentage change in slope of the curve and the diet-induced thermogenesis of the subject. Firstly, diet-induced thermogenesis is a subject characteristic that relates to being normal weight or overweight, and also to being an unrestrained or a restrained eater. In this combination normal weight unrestrained eating subjects displayed a normal diet-induced thermogenesis, and normal weight and overweight restrained eating subjects displayed a blunted diet-induced thermogenesis (chapter 6; 7). The magnitude of the diet-induced thermogenesis was found to be coincidentally positively correlating with the change in slope of the cumulative food intake curve, because both diet-induced thermogenesis and percentage change in slope were correlated negatively with the subjects' restraint scores. In overweight unrestrained eaters the coincidence could be different. They might display decelerated cumulative food intake curves, being unrestrained, but a blunted diet-induced thermogenesis, being overweight. A new phenomenon that was found is represented by normal weight but restrained eaters, displaying a blunted diet-induced thermogenesis (chapter $6 ; 7$ ). Moreover it was found that an increase in body temperature in the proximity of the liver failed to occur in normal and overweight restrained eaters (chapter 6).

An increase in body temperature in the proximity of the liver, which fails to occur in overweight subjects was explained before as being due to increased thermal insulation by subcutaneous abdominal body fat (Brundin et al., 1989). Considering the relatively normal percentage body fat of normal weight restrained eaters (chapter 9), increased thermal insulation cannot be the explanation for normal weight restrained eaters. Here, we must focus on the fact that they have a rather high level of metabolic efficiency. In this respect, Tuschl (1990), has reported a lower food intake, a slightly higher body weight, and a lower energy expenditure in normal weight restrained eaters, compared to their 
unrestrained conspecifics. Plasma levels of triiodothyronine and glucose, which could be taken as indices of long term adaptation to starvation, were not decreased in a restraint group (Laessle et al, 1989). However, the significantly higher levels of triglycerides in restrained eaters, may reflect short term starvation. In relation to their metabolic efficiency they might have elevated levels of free fatty acids. As a consequence of altering eating patterns, psychological and physiological deprivation can be hypothesized in restrained eaters, making them prone to the occurrence of overeating (Laessle, et al., 1989). With respect to this last statement, overweight restrained eaters appear to be more vulnerable than normal weight restrained eaters are. Normal weight restrained eaters who completed the questionnaires on food intake regularly, during a period of four months in our situation, did not show any increase in disinhibition, nor when they returned after longer periods, to participate in a new experiment. In general, normal weight restrained eaters showed the successful type of restrained eating behaviour that overweight restrained eaters aimed for (chapter 9). Overweight restrained eaters appear to be more susceptible to disinhibition than their normal weight conspecifics, and could only cope with a successful restrained eating behaviour that involves a high score on the cognitive component, e.g. when counselled by a dietician.

All in all, restrained eating behaviour may give two possibilities, namely iterative disinhibition promoting susceptibility to eating disorders, and on the other hand successful cognitive restraint that relates well to the consumption of the products of the light-food market of today. The latter effect will enable the cognitive restrained eater to consume a greater variety of 'light' 'fake', but imitating 'normal' food items, without psychological deprivation, or without having the idea to risk disrupted self-control, and consequently disinhibition. Also, the effect of compensation, which is always a pitfall with respect to light-food consumption (chapter 1), will be less severe in restrained eaters, as they behave more cognitively orientated, than physiologically orientated (Westerterp -Plantenga et al., in prep (a)).

The first possibility, susceptibility to eating disorders, may occur in e.g. the subjects who also score significantly higher on the factor disinhibition than our normal weight restrained subjects used to do, and who report several binges a week (with respect to scores on the DSM III-R questionnaire, American Psychiatric Association, they do not necessarily have to be classified as bulimics); Cognitively restrained eating behaviour is only susceptible to eating disorders if the disinhibition (F2) score is sufficiently high (Westerterp-Plantenga et al., in prep (b)).

The last important phenomenon we have to focus our attention on is the problem of being overweight.

Obesity still deserves attention, albeit for medical reasons. Several morbid complications, like hypertension, myocardial infarction, diabetes mellitus and atherosclerosis are related to obesity. In addition to these complications, obesity enhances the risk of other morbidities, like 
galbladder diseases (increased cholesterol production and secretion), abnormal hepatic function (significantly enlarged hepatic triglyceride content), pulmonary problems (hypoventilation), endocrine disorders (reduction in total serum sex hormones, and irregular menstrual cycles in women), increased risk of gout and high hemoglobine levels (Bray, 1985). The part that is due to the genetic background, namely heritability of body weight, can only serve as a consolation to the overweight subjects:

For overweight subjects the two possibilities to loose weight, i.e. restrained eating behaviour and/or increased physical activity, are not easy to fulfill. In the phenotypical margin the opposite effect is often achieved. It appears to be more difficult to be an overweight restrained eater, than being a normal weight restrained eater. Being food-concerned, as normal weight restrained eaters are, guarantees more success than being weight concerned, as overweight restrained eaters are (chapter 5, 9). Owerweight subjects who participated in our first study (chapter 4) were difficult to classify as restrained or unrestrained, because about $60 \%$ of them showed inconsistency in answering the three factor eating questionnaire. Actually, some of them judged themselves being restraint, but during the interview conducted by the dietician, they scored mainly as unrestrained eaters. It appeared that their standards, concerning quality and variety of the menu, were much higher than those of our normal weight subjects, and that they were more knowledgeable about foodrelated items. Therefore, in the three factor eating questionnaire the answers should be checked in the sense whether they relate to quality, quantity, weight concern, health, budget, or certain food-standards. Subjects who answer certain questions with respect to whether and when they eat the food they desire negatively, obviously feel psychologically food-deprived.

The other possibility for overweight subjects to loose weight is increase in energy expenditure through increased physical activity, and consequently increased lipolysis. Here the opposite effect of what is desired, is also often achieved. The opposite effect is probably related to increased insuline release, which disinhibits lipolysis, even although in this situation insulin insensitivity occurs. The opposite effect could also be due to increased metabolic efficiency, possibly after weight cycling, which appears as decreased basal metabolical rate, and as a blunted diet-induced thermogenesis. The latter can be a cause or a consequence of obesity. As we found this blunted diet-induced thermogenesis in normal weight restrained eaters too, we agree to regard this phenomenon as one of the causes of obesity (chapter $6 ; 7$ ).

With respect to lipolysis we have no results to attribute to the discussion, but some remarks could be made. In obesity an excessive accumulation of body fat is seen. In human adipocytes the $\beta$ adrenoceptor is the most important stimulatory receptor involved in lipolysis. Human adipocyte lipolysis appeared to be mediated both by typical $\beta 1, \beta 2$, and atypical $\beta 3$ adrenoceptors In animal obesity it was shown that the $\beta$ adrenoceptor 
mediated lipolysis was dysfunctional, resulting in a decreased lipolytic activity (Hollenga. 1990). This dysfunctional hipolysis was also found, during increased physical activity in obese rats (Balkan, 1991). Westerterp et al., (1990) found a strong negative relation between activity level and fat loss of the subjects in subjects with vertical banded gastroplasty, during observations of $6,12,27$ and 54 weeks after surgery. These results also showed the contrary from what would be expected. They postulated that a lower energy-demand results first in a lower tendency to increase energy intake after surgery and second in a lower gluconeogenesis, thereby saving fat-free mass.

Normal weight, unrestrained eating women apparently have effective food controls. Low scores on questionnaires and little estimate accuracy show that they are not preoccupied with food. Their marked differences in eating rate from the start compared to the end of the meal, in thermogenesis and body temperature in the proximity of the liver from before to during and after the meal, represent physiological responses. By physiological responses unrestrained eaters can be effectively identified, whereas by responses on the questionnaires restrained eaters can be effectively identified.

\section{References}

American Psychiatric Association. Diagnostic and statistical manual of mental disorders. 3rd. ed. American psychiatric Association, 1987, Washington DC.

Balkan, B., Strubbe, J. H., Bruggink, J. E., Steffens, A. B. Altered sympathetic control of nutrient mobilization during physical exercise after lesions in the VMH. Am. J. Physiol., 1991; 260: R368-R372.

Bellisle, F., Lucas, R., Amrami, J, Le Magnen J (1984). Deprivation, pallatability and the micro-structure of meals in human subjects. Appetite, 1984, 5, 85-94.

Booth, D. A. Food-conditioned eating preferences and aversions with interceptive elements: Conditioned appetites and satieties. Ann. N. Y. Acad. Sc. 1985; 443: 22-41.

Bray, G. A. Complications of obesity. Ann. Intren. Med. 1985; 103: $1052-1062$.

Brundin, T., Wahren, J. Thermal insulation of the abdominal wall reduces meal-induced thermogenesis. Int. J. Obes.,1989; 13:2.

Cabanac, M., Minaire, $Y_{.,}$Adairr, E. Influence of internal factors on the pleasantness of a gustative sweet sensation. Comm. Beh. Biol. A., $1968 ; 1: 77-82$.

Edelman, B., Engel, D., Bronstein, P., Hirsch, E. Environmental effects on the intake of overweight and normal weight men. Appetite, 1986; 7: $71-83$.

Fantino, M. Role of sensory input in control of food intake. Journ. Auton. Nerv. Syst. 1984: 10: 347-359. 
Herman, C. P., Polivy, J, Esses, V. M. The illusion of counterregulation. Appetite, 1987; 9: 161-169.

Hollenga, Ch. Beta 3, beta 2, and beta 1 adrenoceptors in human and animall adipocyies. Thesis, 1990; Groningen, The Netherlands.

Laessle, R. G., Tuschl, R. J. Kotthaus, B. C., Pirke, K. M. Behavioural and biological correlates of dietary restraint in normal life. Appetite, $1989 ; 12: 83-94$.

Levy-Leboyer, C., Henrotte, J. L. Birological and behavioral effects of stress induced by noise. In. Rapport sur les recherches effectuees sur le theme bruit, sante. Ministere de l'Environment, Paris, 1984; 161 214.

Metz, B., Brandenberger, G., Follenius, M. Endocrine responses to acoustic stresses. In: I. Assenmacer and D. S. Farner (eds). Environment endocrinology. Berlin, Springer, 1978; 262-269.

Pfaffmann, C. The pleasures of sensation. Psych. Rev. 1960; 67: 253-268.

Stunkard, A., Kaplan, D. Eating in public places: a review of reports of the direct observation of eating behaviour. Int. J. Obes. 1977; 1: 89101.

Tuschl, R.J.; Platte, P.; Laessle, R.G.; Stichler, W.; K.M. Pirke. Energy expenditure and every day eating behavior in healthy young women. Am. J. Clin. Nutr. 52,81-6; 1990.

Westerterp, K. R., Saris, W. H. M., Soeters, P. B., ten Hoor, F. Determinants of weight loss after vertical banded gastroplasty. Int. J. Obesity, 1991; 15: 000-000.

In preparation:

Westerterp-Plantenga, M. S., Duysens, N. A., ten Hoor, F. The effects of caloric perception or caloric belief during and after the consumption of light food lunches, as a function of dietary restraint. (a)

Westerterp-Plantenga, M. S., Duysens, N. A., ten Hoor, F. Food selection patterns during lunch meals in women with mild- binge experiences. (b) 


\section{Summary}

Eating behaviour in humans has physiological as well as psychological aspects. These aspects are clearly shown by the boundary model of Herman \& Polivy, with hunger and satiety being the physiological boundaries, and the zone of biological indifference in between, being the psychological area.

The hypotheses which were tested are: physiological aspects like diet induced thermogenesis contribute to the control of eating behaviour in normal weight unrestrained eating women. Psychological aspects, like cognition and restraint control eating behaviour in normal weight and overweight women, with subjective and possibly objective weight problems. These hypotheses were tested by assessing the relation between relevant subject characteristics and eating behaviour. Subjects were characterized as normal weight or overweight by BMI, and as unrestrained or restrained, by two different psychometric questionnaires. Eating behaviour was characterized by the following meal parameters: meal size, meal duration, eating rate, eating rate change.

Eating rate change turned out to be consistent and representative of a subject's eating style, irrespective of the amount eaten, the eating time, the eating rate. The main relation between subject characteristics and eating behaviour was the relation between dietary restraint and the shape of the cumulative food intake curve. In normal weight women most unrestrained eaters showed decelerated cumulative food intake and most restrained eaters showed linear cumulative food intake over ume, during ad libirum meal courses.

The shape of the cumulative food intake curve during the ad libitum meal course was consistent during the then following courses, irrespective of the amount eaten or the eating rate.

In most cases, under different food conditions, like offering unfamiliar food, neither the shape of the curve, nor the relation with the subject characteristics changed. The positive relation between eating rate and palatability of the food did not affect the shape of the curve nor did it change the relation between shape and subject characteristics. During manipulations i.e. prolonged meals (by intervals) or energy enriched meals, the shape of the curve remained constant in $70 \%$ of the subjects who participated in that part of the study; $30 \%$ showed variability in the shape of the cumulative food intake curve during manipulations. The shift from non-decelerated to decelerated is explained as the onset of negative 
feedback at last; the shift from decelerated to non decelerated as postponed negative feedback by a possible stronger positive feedback.

With regard to physiological aspects of eating behaviour, a relationship between dietary restraint, the shape of the cumulative food intake curve, and the magnitude of diet induced thermogenesis was found in the sense that:

normal weight unrestrained eaters displayed a relatively normal diet induced thermogenesis, measured during $21 / 2$ hours from the start of a meal onwards, and a decelerated cumulative food intake curve."

Normal weight and overweight restrained eaters displayed a blunted diet induced thermogenesis and a linear cumulative food intake. This applied to familiar as well as unfamiliar meals. With respect to unfamiliar meals diet -induced thermogenesis was slightly but significantly elevated during the first confrontation. This may be caused by increased sympathetic nervous system activity, due to a higher alertness when confronted with unfamiliar food. With regard to psychological aspects of eating behaviour, a relation between cognitive dietary restraint, and the accuracy of the subjects' estimate of their forthcoming ingestion was found in the sense that:

- normal weight and overweight restrained eating women estimated their forthcoming ingestion of a familiar meal better than unrestrained eaters did. With an unfamiliar meal, this cognitive aspect of eating behaviour still had to be established. This was accomplished during the second confrontation with the unfamiliar meal.

The consistency of the psychometric scores on the questionnaires was assessed, over a longer period of time, and under changing conditions. The changing conditions implied a four month period of a strict counselled diet. Responses to preload experiments were included in this study. The Herman Polivy restraint questionnaire appeared to characterize dieters in a consistent way, irrespective of changing conditions.

Under changing conditions, the three factor eating questionnaire by Stunkard and Messick showed sensitivity with respect to cognitive restraint and susceptibility to disinhibition.

The boundary model by Herman \& Polivy was supported by the restraint $x$ preload interaction, in so far that with a modest preload, consciously consumed, non-disrupted self control was maintained in counselled restrained eaters, which was reflected in increased cognitive restraint scores and decreased disinhibition scores during the experimental period. In effect, the hypothesis that eating behaviour in normal weight unrestrained eating subjects is controlled by physiological aspects is confirmed as far as diet induced thermogenesis is concerned. As long as an independant physiological measurement of satiation for humans is not available, one cannot state that deceleration in cumulative food intake reflects satiation, and that linearity in these curves reflects lack of satiation. All the subjects were always satiated after a meal, irrespective of the shape of the curve. 
The hypothesis that eating behaviour in restrained eating subjects is to a certain extent controlled by psychological aspects is supported by their estimate accuracy in familiar meals, and their quick achievement of this accuracy after one confrontation with an unfamiliar meal. 


\section{Samenvatting}

Het eetgedrag van mensen wordt beïnvloed door fysiologische zowel als psychologische factoren. Deze factoren beinvloeden het eergedrag gelijktijdig, maar in verschillende mate. Zij bepalen denkbeeldige grenzen, zoals geschetst in het zogeheten 'boundary model' van Herman and Polivy. Alszodanig vormen honger en verzadiging de fysiologische grenzen, terwijl in het gebied tussen honger en verzadiging psychologische factoren overheersen.

De hypotheses die getoetst werden zijn:

-Fysiologische aspecten, zoals dieet-geinduceerde thermogenese beînvloeden overwegend het eetgedrag tijdens een maaltijd van normaal gewichtige, ongeremd etende vrouwen.

-Psychologische aspecten zoals cognitie en geremdheid ten aanzien van eten beïnvloeden overwegend het eetgedrag tijdens een maaltijd van vrouwen die aan subjectieve gewichtsproblemen en eventueel ook aan objectieve gewichtsproblemen lijden.

Deze hypotheses werden getoetst door de relatie tussen rellevante persoonskenmerken en thet eigenlijke eetgedrag tijdens een maaltijd te bepalen. De persoonskenmerken waren: lichaamsgewicht, te weten normaal of overgewichtig, bepaald met behulp van de quetelet index en onderscheiden met behulp van het criterium van Garrow, en mate van geremdheid ten aanzien van voedselopname, bepaald met behulp van psychometrische vragenlijsten.

Het eetgedrag tijdens een maaltijd werd beschreven met behulp van de volgende parameters: maaltijdgrootte, maaltijdduur, eetsnelheid en verandering in eetsnelheid.

De verandering in eetsnelheid bleek consistent en persoonsspecifiek te zijn; dat wil zeggen dat deze herhaaldelijk hetzelfde beeld gaf, ongeacht de hoeveellheid gegeten, de duur van de maaltijd en de eetsnellheid.

De belangrijkste relatie tussen persoonskenmerken en eetgedrag bleek die tussen de mate van geremdheid en de vorm van de cumulatieve voedselopname curve tijdens een ad libitum gang van een maaltijd. Deze relatie manifesteerde zich in die zin dat de meeste als ongeremd etend scorende vrouwen een vertragende cumulatieve voedselopname curve vertoonden, terwijl de meeste als geremd etend scorende vrouwen ongeacht een normaal lichaamsgewicht of overgewicht lineaire cumulatieve voedselopname vertoonden.

De vorm van de cumulatieve opname curve tijdens de tweede gang van een ad libitum maaltijd bleek tevens te gelden voor de derde en vierde gang, ongeacht de hoeveelheid gegeten, eetduur of eetsnelheid. 
Bij variatie in het voedselaanbod, zoals variatie in bekendheid met het voedsel, veranderde noch de vorm van de curve, noch de relatie met persoonskenmerken.

Tijdens manipulaties met het voedselaanbod te weten bij intervalmaaltijden en bij energieverrijkte maaltijden bleef de vorm van de curve stabiel bij $70 \%$ van de proefpersonen en vertoonde deze variatie bij $30 \%$ van de proefpersonen. Deze variatie betrof zowel een verandering van lineair naar vertragend (bij energieverrijkte maaltijden) als andersom (bij intervalmaaltijden en bij energieverrijkte maaltijden). Een verandering van lineair naar vertragend werd verklaard als het optreden van negatieve terugkoppeling in de vorm van het begin van enige verzadiging; een verandering van vertragend naar lineair werd verklaard als het voortduren van een positieve terugkoppeling.

Wat betreft de fysiologische aspecten van het eetgedrag werd de volgende relatie gevonden tussen de mate van geremdheid van voedselopname en de vorm van de cumulatieve opname curve, en tussen de mate van geremdheid van voedselopname en de waarde van de dieetgeinduceerde thermogenese:

-normaalgewichtige ongeremde eters vertoonden een dieetgeinduceerde thermogenese in een relatief normale range, gedurende tweedneenhalf uur na het begin van de maaltijd, en een vertragende cumulatieve voedsel opname curve.

-normaalgewichtige en overgewichtige geremde eters vertoonden een verlaagde dieetgeinduceerde thermogenese en cen lineaire cumulatieve voedselopname.

Dit gold voor situaties met bekende maaltijden. Bij onbekende maallijden was de dieetgeinduceerde thermogenese enigszins, maar significant verhoogd gedurende de eerste confrontatie met het onbekende voedsel. Toename in activiteit van het sympatische zenuwstelsel zou hiervan de oorzaak kunnen zijn vanwege een verhoogde staat van alertheid bij de confrontatie met onbekend voedsel.

Wat betreft de psychologische aspecten van eetgedrag werd de volgende relatie gevonden tussen de mate van cognitief geremde voedselopname, de vorm van de curve, en de nauwkeurigheid waarmee de proefpersonen hun komende voedselopname inschatlen:

-normaalgewichtige en overgewichtige geremde eters schatten hun toekomstige voedselopname nauwkeuriger in dan ongeremde eters. Dit cognitieve aspect van het eetgedrag was nog niet gerealiseerd bij de eerste confrontatie met onbekend voedsel. Eén ervaring bleek voldoende voor een redelijk nauwkeurige inschatting van de toekomstige voedselopname. Consistentie in psychometrische scores op de vragenlijsten betreffende mate van geremdheid van eetgedrag werd getoetst over een langere periode en onder veranderende omstandigheden. Deze omstandigheden betroffen het houden van een streng dieet onder begeleiding van een dietist, gedurende een periode van vier maanden. Preload-experimenten werden tevens tijdens deze periode gedaan. 
De Herman-Polivy restraint questionnaire bleek, ongeacht veranderende omstandigheden, consequent vrowwen die zich beperken in hun voedsel opname te onderscheiden van vrouwen die dat niet doen.

Onder deze veranderende omstandigheden bleek de Three Factor Eating Questionnaire van Stunkard and Messick een gevoeligheid te vertonen voor wat betreft de factoren $F 1$ (cognitief geremd) en F2 (disinhibitie).

Het "boundary" model van Herman and Polivy wordt in zoverre onderstreept door de restraint $x$ preload interactie, dlat in het geval van een bescheiden preload, bewust gegeten door geremdle eters die onder begeleiding van een dietist stonden, de zelfdiscipline gehandhaafd bleef. Dit werd tevens weerspiegeld in de verhoogde scores op de factor cognitief geremd eten en de verlaagde scores op de factor disinhibitie.

De hypothese dat eetgedrag bij normaalgewichtige ongeremde eters voornamelijk wordt bepaald door fysiologische aspecten werd ondersteund voor zover het dieetgeinduceerde thermogenese betrof. Zolang geen onafhankelijke fysiologische maat voor verzadiging bij mensen is gevonden, kan niet worden beweerd dat vertraging in de cumulatieve voedselopname curve verzadiging weerspiegelt, welke zou ontbreken bij een lineaire voedsel opname. De proefpersonen waren altijd verzadigd na de maaltijd, ongeacht de vorm van de curve.

De hypothese dat eetgedrag bij geremde eters voornamelijk psychologisch bepaald is werd ondersteund door de nauwkeurigheid waarmee zij hun toekomstige voedselopname inschatten en door het verschijnsel dat zij maar én ervaring nodig hadden met onbekend voedsel, teneinde deze nauwkeurigheid opnieuw te bereiken. 
1 How often are you dieting? Never, rarely; sometimes; often; always. (scored 0-4).

2 What is the maximum amount of weight (in pounds) that you have ever lost within one month? $0-4 ; 5-9 ; 10-14 ; 15-19 ; 20+$. (scored $0-4$ ).

3 What is your maximum weight gain in a week? $0-1 ; 1.1-2 ; 2.1-3 ; 3.1$ $5 ; 5.1+$. (scored 0-4).

4 In a typical week, how much does your weight fluctuate? 0-1;1.1-2; $2.1-3 ; 3.1-5 ; 5.1+$. (scored $0-4)$.

5 Would a weight fluctuation of $5 \mathrm{Ib}$ affect the way you live your life? Not at all; slightly; moderately; very much. (scored 0-3).

6 Do you eat sensibly in front of others and splurge alone? Never; rarely; often; always. (scored 0-3).

7 Do you give too much time and thought to food? Never; rarely; often; always. (scored 0-3).

8 Do you have feelings of guilt after overeating? Never; rarely: often; always. (scored 0-3).

9 How conscious are you of what you are eating? Not at all; slightly; moderately; extremely. (scored 0-3).

10 How many pounds over your desired weight were you at your maximum weight? $0-1 ; 1-5 ; 6-10 ; 11-20 ; 21+$. (scored $0-4$ ).

From: Herman, C. P. and Polivy, J. Restrained eating. In: A. Stunkard, ed. Obesity. 1980: 208-225. W. B. Saunders; Philadelphia.

2 The Three Factor Eating Questionnaire

True/False $\quad$ Factor number

1 When I smell a sizzling steak or see a juicy piece of meat, I find it very difficult to keep from eating, even if I have just finished a meal.

2 I usually eat too much at social occasions like parties and picnics.

3 I am usually so hungry that I eat more than three times a day.

4 When 1 have eaten my quota of calories, I am usually good about not eating any more.

hungry. of controlling my weight.

7 Sometimes things just taste so good that I keep on eating even when I am no longer hungry. 
8 Since I am often hungry, I sonetimes wish that while I am eating an expert would tell me that I have had enough or that I can have something more to eat.

9. When I feel anxious, I find myself eating.

10 Life is too short to worry about dieting.

11. Since my weight goes up and down, I have gone on reducing diets more than once.

12 I often feel so hungry that I just have to eat something.

13 When I am with someone who is overeating, I usually overeat, too.

14 I have a pretty good idea of the number of calories in common foods.

15 Sometimes when I start eating I just can't seem to stop.

16 Since I know how guilty I will feel afterward, I rarely go on eating binges.

17 It is not difficult for me to leave something on my plate.

18 At certain times of the day I get hungry because I have gotten used to eating then.

19 Sometimes I get so nervous that I just have to eat something.

20 While on a diet, if I eat a food that is not allowed I consciously eat less for a period of time to make up for it.

21 Being with someone who is eating often makes me hungry enough to eat also.

22 When I feel blue, I often overeat.

23 I enjoy eating too much to spoil it by counting callories or watching my weight.

24 When I see a real delicacy, I often get so hungry that I have to eat it right away.

25 I often stop eating when I am not full as a conscious means of limiting the amount that I eat.

26 I get so hungry that my stomach often seems like a bottomless pit.

27 My weight has hardly changed at all in the last ten years.

28 I am always hungry so it is hard for me to stop eating before I finish the food on my plate.

29 When If feel lonely, I console myself by eating.

30 I consciously hold back at meals in order not to gain weight.

31 I sometimes get very hungry late in the evening or at night.

32 I eat anything I want, any time I want. 
33 Without even thinking about it, I take a long time to eat.

34 I count calories as a conscious means of controlling my weight.

35 I do not eat some foods because they make me fat.

36 I am always hungry enough to eat at any time.

37 I pay a great deal of attention to changes in my figure.

38 While on a diet, if I eat a food that is not allowed, I often then splurge and eat other high calorie foods.

39 How often are you dieting in a conscious effort to control your weight?

40 How many pounds over your desired weight were you at your maximum weight?

41 Would a weight fluctuation of $5 \mathrm{lbs}$ affect the way you live your life?

42 How often do you feel hungry?

43 What is your maximum weight loss within one month?

44 Do feelings of guilt about overeating help you to control your food intake?

45 How difficult would it be for you to stop eating halfway through dinner and not eat for the next four hours?

46 How conscious are you of what you are eating?

47 How frequently do you skip a meal as a conscious means of limiting your eating?

48 What is your maximum weight gain within a week?

49 How frequently do you avoid 'stocking up' on tempting foods?

50 In a typical week, how much does your weight fluctuate?

51 How likely are you to shop for low calorie foods?

52 Do you eat sensibly in front of others and splurge alone?

53 How likely are you to consciously eat slowly in order to cut down on how much you eat?

54 How frequently do you skip dessert because you are no longer hungry?

55 How likely are you to consciously eat less than you want?

56 Do you go on eating binges even though you are not hungry? 
57 On a scale of $0-10$, where 0 means no restraint in eating (eat whatever you want, whenever you want it) and 10 means total restraint (constantly limiting food intake and never "giving in'), what number would you give yourself?

'eat whatever you want, whenever you want it'

'usually eat whatever you want, whenever you want it'

'often eat whatever you want, whenever you want it'

'often limit food intake, but often 'give in' "usually limit food intake, rarely 'give in" 'constantly limiting food intake, never "giving in"

58 To what extent does this statement describe your eating behavior?

'I start dieting in the morning, but because of any number of things that happen during the day, by evening I have given up and eat what I want, promising myself to start dieting again tomorrow'. 
This study has been effected through a collaboration between the Open University, Heerlen, $(\mathrm{Ou})$, and the Limburg State University at Maastricht (RL). The Open University provided a guest-researcher for one day a week and financial support, while the Limburg State University provided hospitality, facilities, co-operation and support. Part of the study has been financed by the Dutch Heart Foundation, grant 83055 .

I am grateful to many people who contributed to the work which is reported in this study.

Prof. dr. Henk de Wolf (Open University) encouraged me to organize the research part of my lectureship at the Open University from the beginning onwards.

Prof. dr. Foppe ten Hoor (RL) received me and my ideas with hospitality and encouragement; he allowed me to use the facilities of the Human Biology Department.

Prof. dr. ir. Wim de Jeu (Ou) stimulated the research by providing intellectual and financial management.

The idea behind the topic arose when prof. dr. Foppe ten Hoor visited prof. dr. Viktor Pudel in Göttingen. Actual research started not before dr. Klaas Westerterp (RL) ate from the Universal Eating Monitor on our kitchen table.

Working at the Human Biology Department meant co-operation and support:

I retain good memories of the valuable discussions with dr. Nancy Nicolson, dr. Jan Boots and dr. Klaas Westerterp; of the technical support by ing. Paul Schoffelen, ing. Lock Wouters, Gerri van Wunnik, Eugene Wintjens and Theo Gulikers; of the co-operation with the research dieticians Annemie Mordant, Lillian Hendriks, Ellen van den Heuvel and Nicole Duysens; of support by the dietary cuisine assistants Trudy Mullers and Elly Brouwer; of the secretarial support given by Mary Peters and Truus Dickhaut; of the work on calculating bite sizes cumulatively, done by Arjen and Marit Westerterp; of the company of my roommates prof. dr. ir. Ruud Hermus, drs. Wilhelmine Verboeket and Nicolle Duysens; and of the very co-operative subjects: students, hospital- and university employees, residents of Maastricht and surroundings, and many friends. Without them the study would not have been possible.

I appreciate the interest and stimulation of my colleagues at the Open University.

Dr. Anton Steffens from the Rijks Universiteit Groningen (RUG), introduced me to the international platform of the Physiology of Food and Fluid Intake. He also represents the link with the Biological Centre of the RUG. His work and that of his colleagues at the Institute of Animal Physiology (RUG), aroused my interest in the field of the regulation of food intake.

I enjoyed attending the European and International Congresses on Obesity, as well as the International Congress on the Physiology of Food 
and Fluid Intake. Discussions with prof. dr. John Blundell (Leeds), Britta Barkeling (Stockholm), prof. dr. Harry Kissileff (New York), prof. dr. David Booth (Birmingham), dr. Barbera Rolls (Baltimore), and prof. dr. Albert Stunkard (Philadelphia), have contributed to the quality of this work.

Prof, dr. Foppe ten Hoor, dr. Anton Steffens, prof. dr. John Blundell and dr. Klaas Westerterp critically read all of the manuscript. Their comments and discussions have improved its contents as well as its readability.

Prof. dr. ir. Wim Saris (RL), prof. dr. Marcel van den Hout (RL), dr, Maarten von Meyenfeldt (RL) and dr. ir. Jan Weststrate (Unilever Research Laboratories, Vlaardingen) carefully read the manuscript and gave valuable comments.

Wilma Brüll and drs. Paul Kirschner (Ou) gave assistance with the English text.

Jolanda Willems (Ou) typed out parts of the manuscript, Mark Liedekerken and Evelin Karsten (Ou) designed and realized the lay-out and Harry Vankan (Ou) gave assistance with the design of the cover.

The logistic management in the final stage was provided by Mark Liedekerken. 
Name: $\quad$ Margriet S. Westerterp-Plantenga

1948 Born in Groningen, The Netherlands

Education:

1961-1966 H. B. S. - B at the 1st Chr. H. B. S. in Groningen

1966-1972 Biology study at de State University of

Groningen:

Behavioural Ecology : Institute of Animal

Physiology; prof. dr L. de Ruiter, dr. J. H.

Reddingius, drs. A. I. A. Alingh Prins

Population Genetics : prof. dr. W. van Delden

Education in Biology : prof. dr. A. J. Treffers

1972 Doctorall degree in Biology; State University of Groningen

Professions:

1969-1972 Student-assistant in Zoology : prof, M. Duym

1972-1974 Teacher of Biology at the Willem-Lodewijk Gymnasium in Groningen

1974-1977 Scientific Associate at the department of Animal Ecology; prof. dr. R. H. Drent, State University of Groningen

1974-1977 Scientific Associate at the depariment of Education in Biology, State University of Groningen

1974-1977 Teacher of Biology at the Heymans-college in Groningen

1977-1980 Resident in Stirling, Scotland

1980-1982 Author, Wolters-Noordhoff, Groningen

1983- Lecturer, Open University, Heerlen

1984- Guest researcher, Limburg State University , Maastricht. 
Westerterp, K. R. Nicolson, N. A., Boots, I. M. J., Mordant, A., Westerterp-Plantenga, M. S. Obesity, Restrained Eating and the Cumulative Food Intake Curve.. Appetite "1988; 11, 119-128.

Westerterp-Plantenga, M. S., Wouters, L. ten Hoor, F. Cumulative Food Intake Curves and Changes in Body Temperature. International Joumal of Obesity $1989 ; 13(1), 16$.

Westerterp-Plantenga, M. S. Westerterp, K. R., Wouters, L., ten Hoor, F. Decelerated Food Intake Curves and Changes in Body Temperature. Appetite, 1989; 12, 244-245.

Westerterp-Plantenga, M. S., wan den Heuvel, E., Wouters, L., ten Hoor, F. Diet-Induced Thermogenesis and Cumulative Food Intake Curves during Meals of Familiar and Unfamiliar Food, as a Function of Dietary Restraint. International Journal of Obesity $1990 ; 14(2), 53$.

Westerterp-Plantenga, M. S., van den Heuvel, E., Wouters, L., ten Hoor, F. Subjects' Estimation of Their Forthcoming Ingestion of Familiar and Unfamiliar Food as a Function of Dietary Restraint. International Journal of Obesity $1990 ; 14$ (2), 169.

Westerterp-Plantenga, M. S. , van den Heuvel, E., Wouters, L., ten Hoor, F. Fysiologische en cognitieve aspecten van de voedselopname bij mensen. Voeding, januari, 1990.

Westerterp-Plantenga, M. S., Westerterp, K. R., Nicolson, N. A., Mordant, A., Schoffelen, P. F. M., ten Hoor, F. The Shape of the Cumulative Food Intake Curve in Humans, during Basic and Manipulated Meals. Physiology and Behavior, 1990; 47, 569-576.

Westerterp-Plantenga, M. S., Wouters, L., ten Hoor, F. Deceleration in Cumulative Food Intake Curves, Changes in Body Temperature and Diet- Induced Thermogenesis. Physiology and Behavior, 1990; 48 (6), $831-836$.

Westerterp-Plantenga, M. S., Wouters, L., ten Hoor, F. Restrained Eating, Obesity, and Cumulative Food Intake Curves during Four Course Meals. Appetite, 1991; 16. 149-158.

Westerterp-Plantenga, M. S., van den Heuvel, E., Wouters, L., ten Hoor, F. Dietary Restraint and Preload Effects during a Dieting Period. International Journal of Obesity, 1991; $15(1), 91$. 
Westerterp-Plantenga,,M. S., van den Heuvel, E., Wouters, L., ten Hoor, F. Counterregulation? as a function of cognitive restraint. In: $G$. Ailhaud, B. Guy-Grand, M. Lafontain and D. Ricquier (eds): Obesity in Europe 91. John Libbey \& Co Ltd. London-Paris, 1991.

\section{Courses}

Westerterp-Plantenga, M. S., Brunsting, A. M. H., Blom, S. J. M., Copius Peereboom, J. W., Drupsteen, Th., Ester, P., van der Heyden, H. A., Huisman, W., Kirschner, P. A., de Knegt, C. N., van der Meer, G. J., Olsthoorn, A., van Sandick, O. Z., Slot, W. F., de Smidt, J. T., Verhoeven, W., Terwindt, J. H. J., Zuur, A. P. Algemene Milieukunde, Open universiteit, 1986, 1989; ISBN 9035801830.

Westerterp-Plantenga, M. S., van Bon, J., van Dijk, H., Hols-Elders, W. P. M., Huisman, W., Jonker, A., Kirschner, P. A., van Rhijn, J. G., van Delden, W., Baerends, G. P., de Jeu, W. H. Biologie van Populaties en Gedrag, Open Universiteit, 1987; ISBN 9035803558.

Westerterp-Plantenga, M. S., Hols-Elders, W. P. M., Kirschner, P. A., van Rhijn, J. G., Baerends, G. P., de Jeu, W. H. Biologie van Gedrag, Open Universiteit, 1988; ISBN 9035803604.

Westerterp-Plantenga, M. S., Addink, A. D. F., Beyderwellen, W., van der Boon, J., Drijver -de Haas, J. S., Kuiper, P. J. C., Niesink, R. J. M., Wigman, M., Witteveen, J., de Vries, J. Fysiologie: Adaptatie en Milieu, Open Universiteit, 1989; ISBN 9035806034.

Westerterp-Plantenga, M. S., van Bon, J., Duin, R., Huisman, W., Kirschner, P. A., van de Kamer, J. P. G., Kiekebos, K., Kuiper, C. B. F., van der Meer, J., van Rhijn, J. G., Scholten, H., Sloep, P., van de Vrie, E. M., Glasbergen, P., Daan, N., de Vries, J. Toegepaste Oecologie : Mensen in hun Oecosystemen, Open Universiteit, 1990; ISBN 90358 06573.

Westerterp-Plantenga, M. S., Beer, B. J., van Bladeren, P. J., Dagnelie, P. J., van Dam, M. C. E., Drijver, J. S. Feron, V. J., Fredrix, E. W. H. M., Hermus, R. J. J., Hoefakker, R.E., de Jeu, W. H., van Kasteren, J., Kirschner, P. A., Kuipers, H. A., Meulenberg, M. T. G., van Otterloo, A.H., Rabbinge, R., Ruiter, A., Steffens, A. B., van Trijp, J. C. M., Verhagen, H., de Vries, J. . Westerterp, K. R., Weststrate, J. A. Portretten van Voeding, Open Universiteit, 1991; ISBN 903580928 9, in press. 
Kuiper, P. J., en Westerterp-Plantenga, M. S. Plantenfysiologie: Adaptatie en Milieu, Wolters-Noordhoff, Open Universiteit, ISBN 9001660126 ; 1989.

van Rhijn, J. G. en Westerterp-Plantenga, M. S. Ethologie: Veroorzaking, ontwikkeling, functie en evolutie van gedrag. Wolters-Noordhoff, Open Universiteit, ISBN $9001660029 ; 1989$.

van Rhijn, J. G. en Westerterp-Plantenga, M. S. Mensen in hun Oecosystemen. Wolters-Noordhoff, Open Universiteit, ISBN 9001 $660169 ; 1990$. 